\title{
Glucose transporters in the small intestine in health and disease
}

\author{
Hermann Koepsell ${ }^{1}$ (1)
}

Received: 5 February 2020 / Revised: 11 July 2020 / Accepted: 17 July 2020 / Published online: 23 August 2020

(C) The Author(s) 2020

\begin{abstract}
Absorption of monosaccharides is mainly mediated by $\mathrm{Na}^{+}$-D-glucose cotransporter SGLT1 and the facititative transporters GLUT2 and GLUT5. SGLT1 and GLUT2 are relevant for absorption of D-glucose and D-galactose while GLUT5 is relevant for D-fructose absorption. SGLT1 and GLUT5 are constantly localized in the brush border membrane (BBM) of enterocytes, whereas GLUT2 is localized in the basolateral membrane (BLM) or the BBM plus BLM at low and high luminal D-glucose concentrations, respectively. At high luminal D-glucose, the abundance SGLT1 in the BBM is increased. Hence, D-glucose absorption at low luminal glucose is mediated via SGLT1 in the BBM and GLUT2 in the BLM whereas high-capacity D-glucose absorption at high luminal glucose is mediated by SGLT1 plus GLUT2 in the BBM and GLUT2 in the BLM. The review describes functions and regulations of SGLT1, GLUT2, and GLUT5 in the small intestine including diurnal variations and carbohydrate-dependent regulations. Also, the roles of SGLT1 and GLUT2 for secretion of enterohormones are discussed. Furthermore, diseases are described that are caused by malfunctions of small intestinal monosaccharide transporters, such as glucose-galactose malabsorption, Fanconi syndrome, and fructose intolerance. Moreover, it is reported how diabetes, small intestinal inflammation, parental nutrition, bariatric surgery, and metformin treatment affect expression of monosaccharide transporters in the small intestine. Finally, food components that decrease D-glucose absorption and drugs in development that inhibit or downregulate SGLT1 in the small intestine are compiled. Models for regulations and combined functions of glucose transporters, and for interplay between D-fructose transport and metabolism, are discussed.
\end{abstract}

Keywords Glucose transporter · Small intestine · Regulation · SGLT1 · GLUT2 · GLUT5 · Glucose-galactose malabsorption · Fructose intolerance $\cdot$ Diabetes $\cdot$ Bariatric surgery

$\begin{array}{ll}\text { Abbreviations } \\ \text { Akt2 } & \text { RAC-beta serine/threonine-protein } \\ \text { ALDOB } & \text { Aldolase B } \\ \text { AMG } & \alpha \text {-Methyl-D-glucoside } \\ \text { AMPK } & \text { AMP-stimulated protein kinase } \\ \text { BBB } & \text { Brush border membrane } \\ \text { BLM } & \text { Basolateral membrane } \\ \text { BMAL } & \text { Brain and muscle arnt-like protein } \\ \text { CBP } & \text { cAMP response element protein- } \\ & \text { binding protein } \\ \text { CCK } & \text { Cholecystokinin }\end{array}$

This article is part of the special issue on Glucose Transporters in Health and Disease in Pflügers Archiv-European Journal of Physiology

Hermann Koepsell

hermann@koepsell.de

1 Institute for Anatomy and Cell Biology, University of Würzburg, Koellikerstr 6, 97070 Würzburg, Germany

\begin{tabular}{|c|c|}
\hline ChREBP & $\begin{array}{l}\text { Carbohydrate-responsive element- } \\
\text { binding protein }\end{array}$ \\
\hline CRE & cAMP response element \\
\hline CREB & cAMP response element-binding protein \\
\hline DJB & Duodeno-jejunal bypass \\
\hline DNJ & 1-Deoxynojirimycin \\
\hline 2-DOG & 2-Deoxy-D-glucose \\
\hline DXR & Doxorubicin \\
\hline EEC & Enteroendocine cell \\
\hline EGF & Epithelial growth factor \\
\hline EGFR & Epithelial growth factor receptor \\
\hline ER & Endoplasmic reticulum \\
\hline FBS & Fanconi-Bickel syndrome \\
\hline $2-\left[{ }^{18} \mathrm{~F}\right] \mathrm{DG}$ & 2-Deoxy-2-[ $\left.{ }^{18} \mathrm{~F}\right]$-D-glucose \\
\hline FGID & Functional gastrointestinal disorder \\
\hline $5-\mathrm{FU}$ & 5-Fluorouracil \\
\hline GIP & Glucose-dependent insulinotropic hormone \\
\hline GLP-1 & Glucagon-like peptide 1 \\
\hline GLP-2 & Glucagon-like peptide 2 \\
\hline GGM & Glucose-galactose malabsorption \\
\hline
\end{tabular}




\begin{tabular}{|c|c|}
\hline GNG & Gluconeogenesis \\
\hline HFI & Hereditary fructose intolerance \\
\hline $\mathrm{HNF}$ & Hepatic nuclear factor \\
\hline HSP & Heat shock protein \\
\hline HuR & Human antigen $\mathrm{R}$ \\
\hline IEC & Intestinal epithelial cell \\
\hline IFM & Isolated fructose malabsorption \\
\hline IIP & Ileal interposition \\
\hline KHK & Ketohexokinase \\
\hline LXR & Liver $\mathrm{X}$ receptor \\
\hline LPS & Lipopolysaccharide \\
\hline MAP & Mitogen-activated protein \\
\hline NAFLD & Nonalcoholic fatty liver disease \\
\hline NHE & $\mathrm{Na}+\mathrm{H}+$ exchanger \\
\hline ODC & Ornithine decarboxylase \\
\hline OGTT & Oral glucose tolerance test \\
\hline ORT & Oral rehydration therapy \\
\hline 3-OMG & 3-O-Methyl D-glucoside \\
\hline PET & Positon emission tomography \\
\hline PPAR & Peroxisome proliferator-activated receptor \\
\hline PYY & Peptide YY \\
\hline RELM- $\beta$ & Resistin-like molecule beta \\
\hline RYGB & Roux-en-Y gastric bypass \\
\hline SNV & Single nucleotide variation \\
\hline STZ & Streptozotocin \\
\hline TGF $\beta 1$ & Tissue growth factor beta 1 \\
\hline SGK & Serum- and glucocorticoid-inducible kinase \\
\hline T1DM & Type 1 diabetes mellitus \\
\hline $\mathrm{T} 2 \mathrm{DM}$ & Type 2 diabetes mellitus \\
\hline TGN & Trans-Golgi network \\
\hline TLR & Toll-like receptor \\
\hline TRIOK & Triosekinase \\
\hline URE & Uridine-rich element \\
\hline YFP & Yellow fluorescent protein \\
\hline VSG & Vertical sleeve gastrectomy \\
\hline
\end{tabular}

\section{Introduction}

Absorption of monosaccharides in the small intestine is pivotal for caloric intake of mammalians and adjusted in accordance with food supply, food composition, and energy demand in diverse physiological and pathophysiological situations. In respect to caloric intake, D-glucose, D-galactose, and D-fructose are the most relevant monosaccharides. For absorption, monosaccharides must cross a layer of epithelial cells that are connected by tight junctions which do not allow permeation of monosaccharides [189, 192]. Because monosaccharides are hydrophilic, they cannot permeate cell membranes passively. Hence, for absorption of D-glucose, D-galactose, and D-fructose, transporters in the luminal brush border membrane (BBM) and basolateral membrane (BLM) of small intestinal epithelial cells
(IECs) are required. In addition, the carbohydrate metabolism in small IECs has been adjusted to allow an adequate transcellular movement of nonphosphorylated monosaccharides.

In this review, the functions and membrane locations of transporters for D-glucose, D-galactose, and/or D-fructose expressed in the small intestine are described. They belong to the $S L C 2$ family with facilitative diffusion transporters (GLUTs) and the SLC5 family with $\mathrm{Na}^{+}$-D-glucose cotransporters (SGLTs). D-Glucose and D-galactose are transported across the brush border membrane of small intestinal enterocytes via the $\mathrm{Na}^{+}$-D-glucose cotransporter SGLT1 and leave the enterocytes across the basolateral membrane via GLUT2 (Fig. 1). The driving force of SGLT1-mediated monosaccharide transport is provided by the transmembrane $\mathrm{Na}^{+}$gradient and membrane potential that are generated by the $\mathrm{Na}^{+}-\mathrm{K}^{+}$-ATPase. GLUT5 in the BBM and BLM is responsible for transport of D-fructose across the BBM and BLM (Fig. 1). At high D-glucose concentration in the small intestine, GLUT2 is also incorporated into the BBM and supports uptake of D-glucose and D-galactose across the BBM. In the next part of the review, the regulation of the most relevant small intestinal monosaccharide transporters, namely the $\mathrm{Na}^{+}$-D-glucose cotransporter SGLT1 and the facilitative diffusion systems for D-glucose, D-galactose, and/or D-fructose GLUT2 and GLUT5, is depicted. Therefore, the general knowledge about regulation of these transporters as well as their specific regulations in the small intestine is compiled. In addition, the combined action of the transporters for adaptation of monosaccharide absorption to different physiological conditions is discussed. Because monosaccharide transporters are also expressed in enteroendocrine cells and contribute to stimulation for enterohormone secretion, also the expression and physiological functions of monosaccharide transporters in enteroendocrine cells are reviewed.

Small intestinal monosaccharide transporters play important roles during emergence, progression, and treatment of various diseases. Covering these issues, diseases are reviewed that are caused by or associated with malfunctions of small intestinal glucose transporters. Also, current knowledge about effects of diabetes on glucose transporters in the small intestine and about the impact of small intestinal inflammations of different genesis on glucose transporters is compiled. In addition, therapeutic measures are discussed that are based on the function or change of function of small intestinal glucose transporters such as oral hydration therapy, parental nutrition, and bariatric surgery. Finally, antidiabetic food components, antidiabetic drugs, and lead compounds of antidiabetic therapy are discussed that inhibit or downregulate SGLT1 or GLUT2 in the small intestine. 
Fig. 1 Location of monosaccharide transporters in enterocytes that are involved in small intestinal absorption of Dglucose, D-galactose, and Dfructose. The locations were determined in different species including humans. Highly expressed transporters are outlined bold. Locations of monosaccharide transporters observed under various physiological and pathophysiological conditions are indicated in green. GLUT2 that was only observed in the BBM at high small intestinal D-glucose concentrations or in some pathological conditions is indicated in yellow. The $\mathrm{Na}^{+}+\mathrm{K}^{+}$ ATPase in the BLM generating the inwardly directed $\mathrm{Na}^{+}$ gradient is also depicted

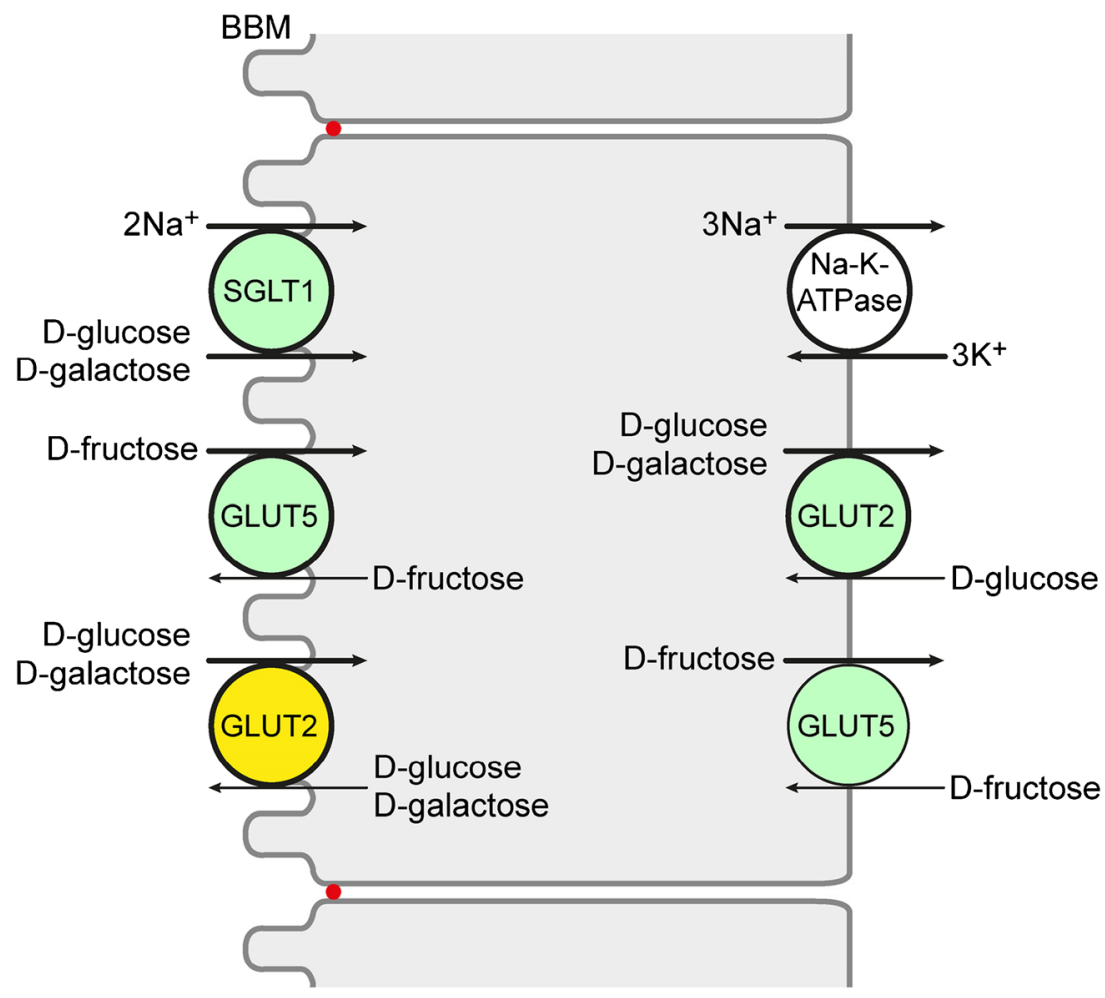

Transport mode, selectivity, and location of glucose transporters expressed in the small intestine

\section{$\mathrm{Na}^{+}$-D-glucose cotransporter SGLT1}

In the small intestine of mammals, high expression of the $\mathrm{Na}^{+}-$ D-glucose cotransporter SGLT1 (SLC5A1) was observed on the mRNA and protein level [424]. In the duodenum of human, rat, and mice, different relative levels of SGLT1/Sglt1 mRNA were determined following the order human $>$ mouse $>$ rat [195]. Proteomic analysis revealed that Sglt1 is the most abundantly expressed plasma membrane protein in mouse small intestine [422]. In mouse and human, minor expression of SGLT1/Sglt1 mRNA expression was also observed in the colon $[65,253,431]$.

SGLT1/Sglt1 is a secondary active transporter that translocates one D-glucose molecule together with two sodium ions into cells employing the inwardly directed sodium gradient that is generated by the $\left(\mathrm{Na}^{+} / \mathrm{K}^{+}\right)$-ATPase as driving force [231]. Human SGLT1 transports D-glucose and D-galactose with respective apparent $K_{\mathrm{m}}$ values of $0.5 \mathrm{mM}$ and $1 \mathrm{mM}$ at physiological membrane potential and inward-directed $\mathrm{Na}^{+}$ gradient, whereas it does not interact with $\mathrm{D}$-fructose (Table 1) [424]. SGLT1/Sglt1-mediated uptake is inhibited by phlorizin but not by phloretin and cytochalasin B [424].

SGLT1/Sglt1-related immunoreactivity was detected in BBMs of IECs and in enteroendocrine cells $[25,132,142$, $155,253,387,410]$. Apart from some differences in segment distribution, similar membrane location of SGLT1/Sglt1 was observed in different species. In human IECs, SGLT1 protein was observed not only in the BBM but also in subapical vesicles [410]. Similarly, in differentiated $\mathrm{CaCo}-2$ cells, a model of human enterocytes, SGLT1, was localized to the BBM and intracellular vesicles [198]. The intracellular location of SGLT1/Sglt1 in enterocytes is consistent with data revealing a D-glucose-dependent regulation of the exocytotic pathway of SGLT1/Sglt1 in the small intestine of mouse and humans [66, 341, 408]. In rats, the BBM abundance and transport capacity of Sglt1 per unit length in the jejunum was higher compared to that in the duodenum and ileum $[25,83,142$, 203]. These differences are mainly due to the different length of the villi and microvilli. Whereas in BBMs along the small intestinal villi very strong SGLT1/Sglt1-related immunoreactivity was observed, only weak or no staining was detected in

Table 1 Characteristics of uptake of D-glucose, D-galactose, and/or Dfructose by human SGLT1, GLUT2, GLUT 5, and GLUT7

\begin{tabular}{lllll}
\hline Transporter & \multicolumn{2}{l}{ Approximate $K_{\mathrm{m}}$ value $(\mathrm{mM})$} & \multirow{2}{*}{ Reference } \\
\cline { 2 - 4 } & D-Glucose & D-Galactose & D-Fructose & \\
\hline SGLT1 & 0.5 & 1 & n.i. & {$[424]$} \\
GLUT2 & 17 & 92 & 76 & {$[182]$} \\
GLUT5 & n.d. & n.i. & 6 & {$[46]$} \\
GLUT7 & 0.3 & n.i. & 0.06 & {$[236]$} \\
\hline
\end{tabular}

n.i., no interaction; $n . d$., not determined 
BBMs of enterocytes in the crypts [25, 30, 83, 142, 168, 231]. This is consistent with the observation that enterocytes are dividing within the crypts and differentiate during migration along the villi $[109,112]$. In human and rat, similar abundance of SGLT1/Sglt1-related immunoreactivity was observed in BBMs of jejunal enterocytes of female and male [25, 410].

In mouse and human small intestine, SGLT1/Sglt1-related immunoreactivity was also detected in enteroendocrine $\mathrm{K}$ cells secreting glucose-dependent insulinotropic hormone (GIP) and in L cells secreting glucose-dependent secretion of glucagon-like peptide 1 (GLP-1) [132, 410].

\section{Glucose facilitator GLUT2}

In the small intestine of mammals and rodents, also high expression of GLUT2/Glut2 (SLC2A2) was observed in most species [123, 394, 431]. The abundance of GLUT2/Glut2 mRNA in the duodenum of human, mouse, and rat follows the order rat $>$ mouse $>>$ human [195]. In mice, a similar abundance of Glut2 mRNA was observed in the jejunum, ileum, and colon [345].

GLUT2/Glut2 is a facilitated diffusion system that transports D-glucose, D-galactose, and fructose in human with apparent $K_{\mathrm{m}}$ values of $\sim 17 \mathrm{mM}, \sim 92 \mathrm{mM}$, and $\sim 76 \mathrm{mM}$, respectively (Table 1) [133, 182]. GLUT2/Glut2-mediated transport is inhibited by phloretin and cytochalasin B but not by phlorizin. Of note, human GLUT2 transports D-glucosamine with an apparent $K_{\mathrm{m}}$ of $\sim 0.8 \mathrm{mM}$ [403].

Between meals when the glucose concentration in the small intestinal lumen is low or in human mucosa biopsies that were taken after food traces had been removed by bowl rinsing, GLUT2/Glut2-related immunoreactivity was observed at the BLM of small intestinal enterocytes [70, 98, 345, 395]. In membrane vesicles derived from BLMs of rat small intestine, glucose transport with properties similar to Glut2 was observed [63]. In the presence of high glucose concentrations, in various species, GLUT2/Glut2-related immunoreactivity was also detected in the BBM and phloretin- or gluosamineinhibited glucose uptake was detected in BBM vesicles $[5,73$, 132, 134, 189-191]. In addition, phloretin- or gluosamineinhibited glucose uptake was detected in BBM vesicles $[132,189]$.

\section{Fructose facilitator GLUT5}

In the small intestine of mammals and rodents, also GLUT5/ Glut5 (SLC2A5) is expressed abundantly [46, 92, 188, 195]. Similar for SGLT1/Sglt1 and GLUT2/Glut2, species differences were observed for the abundance of GLUT5/Glut5 mRNA in the duodenum following the order rat $>$ human $>$ mouse. In human, mRNA abundance of GLUT5 is higher in the jejunum compared to that in the ileum [46].
In human and rodents, GLUT5/Glut5 is an efficient facilitative diffusion system which is specific for D-fructose [46, 266, 311]. Fructose uptake by GLUT5/Glut5 is not inhibited by phlorizin, phloretin, and cytochalasin B. Human GLUT5 transports D-fructose with an apparent $K_{\mathrm{m}}$ of $6 \mathrm{mM}$ (Table 1) [46].

In human and rodents, GLUT5/Glut5 was localized to the BBM of small intestinal enterocytes [28, 46, 70, 81, 254, 358]. Of note, in one study, GLUT5-related immunoreactivity was also detected in the basolateral membrane of human enterocytes [36].

\section{Glucose facilitators with nonresolved functional significance}

\section{GLUT1}

In the small intestine of human, mice, and rat, mRNA of the erythroid glucose facilitator GLUT1/Glut1 (SLC2A1) was detected $[59,122,195,334,402,431]$. In rat with streptozotocin (STZ)-induced diabetes, Glut1-related immunoreactivity was observed in the BLM and the BBM of small intestinal enterocytes [39]. After duodeno-jejunal bypass (DJB) in rats, Glut1 in the BLM and basolateral uptake of 2-deoxy$2\left[{ }^{18} \mathrm{~F}\right]$ fluoro-D-glucose $\left(2-\left[{ }^{18} \mathrm{~F}\right] \mathrm{DG}\right)$ in the alimentary jejunal limb were higher compared to the respective jejunal segment of sham-operated animals [59, 334]. Because Glut1 was not detected in the small intestine of nondiabetic rats [39], it is not supposed to contribute significantly to D-glucose absorption in healthy individuals.

\section{GLUT7}

In human small intestine and colon, mRNA of GLUT7 (SLC2A7) was detected [236]. Human GLUT7 transports Dglucose and D-fructose with apparent $K_{\mathrm{m}}$-values of $0.3 \mathrm{mM}$ and $0.06 \mathrm{mM}$, respectively, but does not accept D-galactose as substrate (Table 1) [236]. Because Glut7 related immunoreactivity was located to the BBM of rat small intestinal enterocytes [236] it could be relevant for fructose absorption at low fructose concentrations.

\section{GLUT8}

In the small intestine and colon of mice and in CaCo-2 cells, expression of Glut8 (SLC2A8) was observed [89, 169, 326, 327, 381]. In IECs and after expression of GLUT8/Glut8 in different cell types, GLUT8/Glut8 was located to intracellular vesicles [169, 243, 327]. Different to the small intestine, plasma membrane location of Glut8 in blastocytes was promoted by insulin [19, 169, 243, 307, 344]. After expressing a GLUT8 mutant with an inactivated N-terminal dileucine motif in oocytes, uptake of 2-deoxy-D-glucose (2-DOG) with an 
apparent $K_{\mathrm{m}}$ of $2.3 \mathrm{mM}$ was measured [169]. Different to wild-type mice, the abundance of Glut12 in enterocytes of Glut8-knockout mice was increased in response to a highfructose diet [84]. Based on these observations, the hypothesis was raised that GLUT8/Glut8 interacts with GLUT12/Glut12. The functional role of GLUT8/Glut8 in the small intestine is enigmatic.

\section{GLUT12}

In human small intestine, GLUT12 (SLC12)-related immunoreactivity was observed in a Western blot [323]. After expression in Xenopus oocytes, GLUT12-mediated uptake of 2DOG was demonstrated that was inhibited by D-fructose and D-galactose [324]. In mice in which Glut2 was overexpressed, the absorption of D-fructose in the small intestine was increased 2.5-fold [84]. After expression of GLUT12 in Chinese hamster ovary cells, the transporter was localized to the Golgi and the plasma membrane [117]. In human skeletal muscle cells, a N-terminal dileucine motif corresponding to the abovementioned dileucine motif in GLUT8 was required for insulin-dependent changes of GLUT12 abundance in the plasma membrane $[4,117,377]$. Further studies are required to elucidate the functional role of GLUT12/Glut12 in the small intestine.

\section{SGLT4}

SGLT4 (SLC5A9) has been cloned from human [391]. Expressing human SGLT4 in COS-7 cells the authors observed $\mathrm{Na}^{+}$-dependent AMG uptake with an apparent $K_{\mathrm{m}}$ value of $2.6 \mathrm{mM}$ that could be inhibited by high concentrations of D-glucose, D-fructose, and D-galactose. It was observed that human SGLT4 is highly expressed in the small intestine and to lower degrees in pancreas, skeletal muscle, lung, kidney, caecum, colon, and testis [65]. Expression of Sglt4 was also observed in mouse small intestine [31]. So far, plasma membrane location of SGLT4/Sglt4 in IECs has not been determined. Also, transport of D-glucose, D-fructose, and D-galactose by SGLT4/Sglt4 has not been demonstrated and characterized. Hence, the relevance of SGLT4/Sglt4 for absorption of D-glucose, D-fructose, and D-galactose has not been resolved.

\section{Regulation of monosaccharide transport in the small intestine}

\section{Nonspecific and specific regulations}

In the small intestine, nonspecific and specific adaptations are developed to cover different energetic demands for monosaccharide absorption [112]. In nonspecific adaptations, small intestinal capacity for uptake of different monosaccharides and nutrients is changed in parallel, whereas specific adaptations affect uptake of individual or few monosaccharides. In nonspecific adaptations, the overall absorptive capacity of the small intestine is changed. This includes changes of the absorptive surface, the number of the enterocytes (hyperplasia), their size (hypertrophy), and the degree of their differentiation. The absorptive surface is determined by small intestinal length, height of villi, and length of microvilli. Enterocyte stem cells located within the crypts divide and migrate onto the villi. They differentiate during migration and are exfoliated at the top of the villi exhibiting life spans between days and weeks [112]. Nonspecific adaptations of the small intestine are slow and require few days at minimum. They have been observed in response to changed nutrition [361], during diabetes $[246,343]$, and after surgical interventions [40, 136].

Specific adaptations of monosaccharide absorption include changes in the amount of transporter molecules in the BBM and/or BLM of IECs. They may be due to transcriptional and/ or posttranscriptional regulations of individual transporters and may occur within minutes, hours, or days. Specific regulations of monosaccharide transporters have been observed following a diurnal rhythm, directly after uptake of carbohydrate-rich meals, in response to carbohydrate content of diets, in response to hormones and neuronal activation, accompanied with diseases, and after surgical interventions. Since regulatory signals such as carbohydrates and hormones may regulate different glucose transporters, coordinated regulations of transporters in the BBM and BLM are possible. Current knowledge about regulations of small intestinal transporters for D-glucose, D-galactose, and D-fructose in humans is fragmentary for several reasons. Thus, only some of the potentially involved regulatory mechanisms have been investigated and only very few investigations have been performed with human small intestine. All in vivo measurements were carried out in rodents. Additional investigations were performed in cultivated cells derived from porcine kidney (LLC-PK1 cells) or from human intestinal tumors (Caco2 cells) or after expression of transporters in cultivated epithelial cells or oocytes. In Table 2, a survey about the investigated regulatory mechanisms, species, and employed methods are presented.

\section{Regulation of SGLT1}

\section{Basic knowledge about transcriptional regulation in human}

Several factors that regulate the transcription of human SGLT1 at the promotor region have been identified (Fig. 2). For example, binding of hepatic nuclear factor (HNF) 1, transcription factor SP1, and cAMP response element-binding protein (CREB) to the $5^{\prime}$ region of the human SGLT1 gene and their effects on transcription have been demonstrated 
Table 2 Description of the studies reported in this review in which regulations of monosaccharide transporters were investigated that are supposed to be relevant for absorption of D-glucose, D-galactose, and Dfructose in human small intestine

\begin{tabular}{|c|c|c|c|}
\hline $\begin{array}{l}\text { Level of } \\
\text { regulation }\end{array}$ & $\begin{array}{l}\text { GLUT2/ } \\
\text { Glut2 }\end{array}$ & $\begin{array}{l}\text { GLUT5/ } \\
\text { Glut5 }\end{array}$ & SGLT1/Sglt1 \\
\hline Transcription & $\begin{array}{l}\text { Human: } \\
\text { e.c.c.; } \\
\text { rodents: } \\
\text { in vivo }\end{array}$ & $\begin{array}{l}\text { Human: } \\
\text { e.c.c., C; } \\
\text { rodents: } \\
\text { in vivo }\end{array}$ & $\begin{array}{l}\text { Human: e.c.c., C; pig: L; } \\
\text { sheep: in vivo; rabbit: } \\
\text { e.c.c.; rodents: in vivo }\end{array}$ \\
\hline $\begin{array}{l}\text { mRNA } \\
\text { stability }\end{array}$ & & Human: C & Pig: L \\
\hline $\begin{array}{c}\text { Translation } \\
\text { or protein } \\
\text { stability }\end{array}$ & $\begin{array}{l}\text { Rodents: } \\
\text { in vivo } \\
\text { (n.d.) }\end{array}$ & $\begin{array}{l}\text { Rodents: } \\
\text { in vivo } \\
\text { (n.d.) }\end{array}$ & $\begin{array}{l}\text { Sheep: in vivo (n.d.); rabbit: } \\
\text { e.o. (p.s.) }\end{array}$ \\
\hline $\begin{array}{l}\text { Protein } \\
\quad \text { trafficking }\end{array}$ & $\begin{array}{l}\text { Rodents: } \\
\text { in vivo }\end{array}$ & & $\begin{array}{l}\text { Human: e.o.; rabbit: e.o.; } \\
\text { rodents: in vivo }\end{array}$ \\
\hline
\end{tabular}

Different levels of regulation were investigated in different species in vivo and in vitro. For in vitro studies, two cell models and different expression systems were employed

$C$, measurements in Caco 2 cells derived from human; $L$, measurements in LLCP-K1 cells derived from pig; e.o., transporter expression in oocytes of Xenopus laevis; e.c.c., transporter expression in cultivated cells; $n$.d., no differentiation between translation and protein stability was performed; p.s., protein stability was investigated

[259, 417]. Employing murine STC-1 cells derived from intestinal endocrine cells, data were obtained which suggest that glucose-induced upregulation of transcription of ovine SGLT1 is dependent on the integrity of the HNF-1 consensus

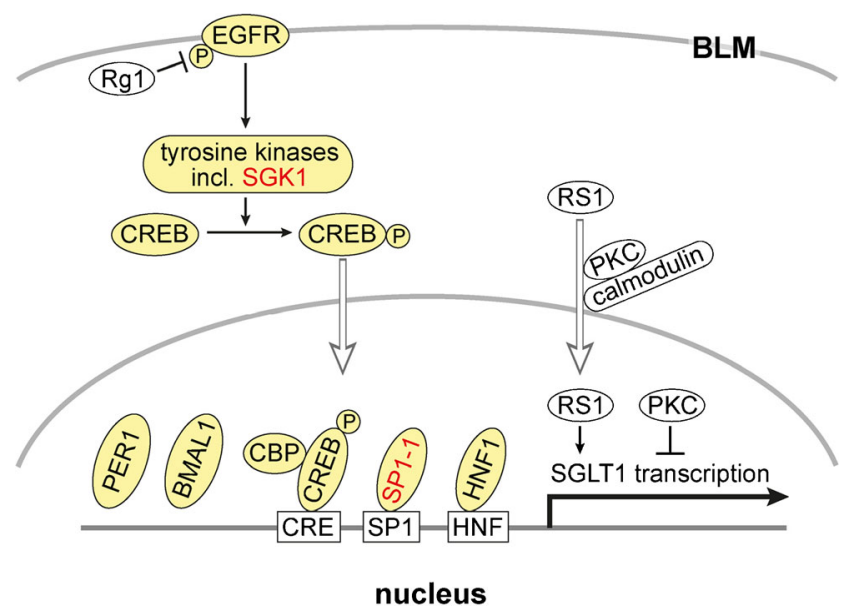

Fig. 2 Transcriptional regulation of SGLT1/Sglt1. Response elements in the promotor of human SGLT1 and components that were shown to be involved in transcriptional regulation of SGLT1/Sglt1 are indicated. Components that participate in transcriptional regulation in the small intestine are marked with yellow. If they participate in D-glucose-dependent regulation, they are indicated in red. EGFR, epithelial growth factor receptor; Rg1, ginsenoside component Rg1; SGK, serum- and corticoidstimulated kinase; CREB, cAMP response element- binding protein- ; CBP, cAMP response element protein-binding protein; PER1, period circadian regulator 1; BMAL1, brain and muscle ANRT-like 1; SP1-1, specificity protein 1 subtype $1 ; \mathrm{HNF} 1$, hepatic nuclear factor 1 sequence in the promotor [404]. Binding of transcription factor HNF-1 $\beta$ to the promotor of rat SGLT1 has been demonstrated [319]. In Chinese hamster ovary cells transfected with rabbit Sglt1, transcription was stimulated after inhibition of protein kinase C [57].

\section{Basic knowledge about transcriptional and posttranscriptional regulation derived from studies with LLC-PK1 cells}

In LLC-PK1 cells that are derived from porcine kidney, expression and function of endogeneous SGLT1 is upregulated during confluence [12, 267]. This may be considered a model for upregulation of SGLT1 in the small intestine during differentiation of enterocytes. In subconfluent LLC-PK1 cells, SGLT1 mRNA abundance, glucose uptake, and PKC activity are low whereas in confluent LLC-PK1 cells, SGLT1 mRNA abundance, glucose uptake, and PKC activity are high [12, 205, 267, 353]. When PKC is blocked in confluent cells, dedifferentiation is induced and expression SGLT1 mRNA and SGLT1 protein is decreased. Dedifferentiation and decreased SGLT1 expression is also induced when confluent LLC-PK1 cells are incubated with polyamines, whereas differentiation combined with an increase of SGLT1 abundance is promoted when synthesis of putrescine is blocked by inhibition of ornithine decarboxylase (ODC) [302]. Regulatory protein RS1 (RSC1A1) [222, 406] is involved in confluence-dependent regulation of SGLT1 transcription [205] (Fig. 2). RS1 has been shown to affect expression of human SGLT1 in bacteria (R. Poppe and H. Koepsell, unpublished data). Porcine SGLT1 exhibited a 5-fold higher nuclear abundance in subconfluent compared to confluent LLC-PK1 cells [115, 205]. Nuclear abundance of RS1 is regulated via a nuclear shuttling domain that contains a $\mathrm{Ca}^{2+}$-dependent calmodulin binding site and is associated with a PKC-dependent phosphorylation site, and nuclear abundance of RS1 is modulated by PKC [115] (Fig. 2).

The higher overall abundance of SGLT1 mRNA in confluent versus subconfluent LLC-PK1 cells associated with decreased PKC activity and increased PKA activity is partially due to effects of PKC and PKA on the stability of SGLT1 mRNA [303, 353]. In LLCP-K1 cells, two transcripts of SGLT1 mRNA with 2.2 and 3.9 kilobases $(\mathrm{Kb})$ were observed which differ in length of the 3' untranslated region. Whereas PKC decreases the stability of both transcripts [353], cAMP and PKA stimulate the stability of the 3.9-kb transcript [232, 303]. The cAMP-induced increase of mRNA stability is due to binding of human antigen $\mathrm{R}(\mathrm{HuR})$, an RNA-binding protein of the embryonic lethal abnormal vision family, to 47 nucleotides in a 120 nucleotide long uridine-rich element (URE) in the 3' untranslated region of the 3.9-kb SGLT1 transcript [244]. Expression of HuR was increased by cAMP and binding of HuR was increased by cAMP-dependent 
phosphorylation of non-identified cellular proteins. Of note, cytoplasmic HuR levels are regulated by AMP-stimulated protein kinase (AMPK), which is stimulated by metformin [413, 440].

When confluent LLC-PK1 cells were cultivated with $25 \mathrm{mM}$ versus $5 \mathrm{mM}$ D-glucose in the medium, the transcription of SGLT1 was decreased after 2 days [205, 284]. The glucose-dependent regulation of SGLT1 in LLC-PK1 cells differs from the glucose-dependent regulation of SGLT1 in the small intestine because it goes into the opposite direction and appears to be independent of RS1 [205].

After a $2 \mathrm{~h}$ incubation of confluent LLC-PK 1 cell at $42^{\circ} \mathrm{C}$, cytosolic heat shock protein (HSP) 70 and SGLT1-mediated glucose uptake were increased. The upregulation of SGLT1 activity was mediated by tissue growth factor beta 1 (TGF $\beta 1$ ) and associated with translocation of SGLT1 and HSP70 to the apical cell side $[171,383]$. The data suggest that the exocytotic pathway of SGLT1 is influenced by TGF $\beta 1$ and may be activated by HSP70 (Fig. 3).

\section{Basic knowledge about posttranscriptional regulation derived from studies with oocytes of Xenopus laevis}

Studies in which human SGLT1 or human SGLT1 fused to yellow fluorescent protein (YFP-SGLT1) was expressed in

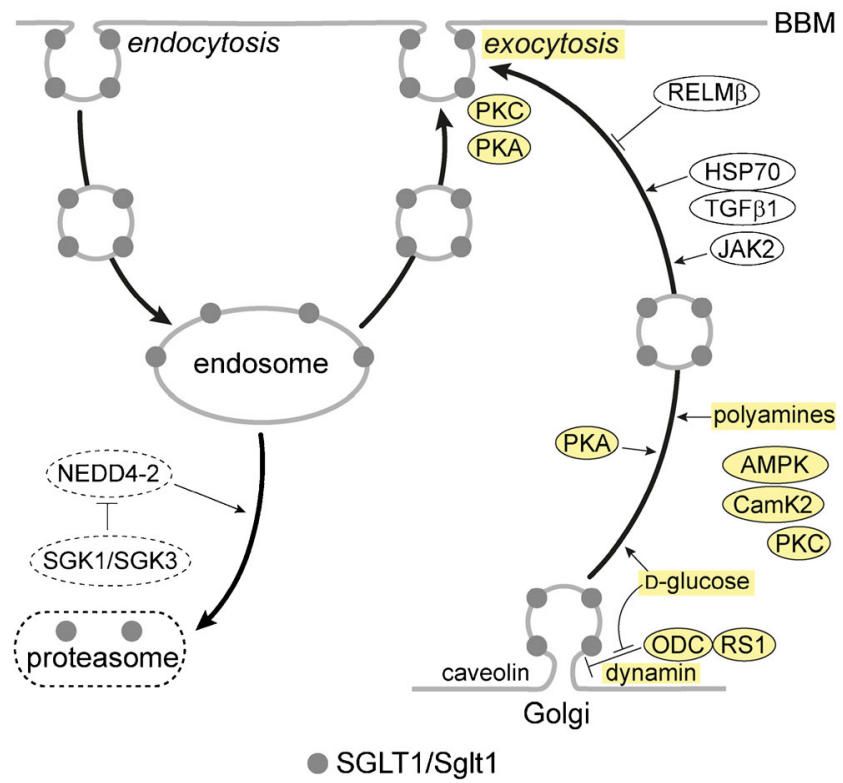

Fig. 3 Membrane trafficking of SGLT1/Sglt1. The scheme is based on experiments in which SGLT1 from human or rabbit was expressed in oocytes, and on experiments with mouse small intestine. Components which have been shown to be involved in short-term regulation of SGLT1/Sglt1 in the small intestine are indicated in yellow. The proteasomal degradation pathway is not well explored. RELM, resistinlike molecule; HSP, heat shock protein; TGF, tissue growth factor; JAK, Janus-activated kinase; AMPK, AMP-activated protein kinase; CamK, calmodulin-stimulated kinase; ODC, ornithine decarboxylase; NEDD, neural precursor cell expressed developmentally downregulated; SGK, serum- and glucocorticoid-stimulated kinase
Xenopus laevis oocytes were employed to characterize shortterm regulations of SGLT1 abundance in the plasma membrane. Oocytes expressing SGLT1 were incubated for short time periods with membrane permeant modifiers and/or injected with various compounds, and effects on transport or plasma membrane abundance of the transporter were analyzed. The oocytes were incubated with PKA or PKC $[156,407]$ and/or injected with inhibitors of endocytosis or exocytosis [407], with brefeldin A that destroys the Golgi, with protein RS1 (RSC1A1), or with peptides derived from RS1 [341, 405, 408]. After time periods up to $60 \mathrm{~min}$, SGLT1-mediated uptake of $\alpha$-methyl-D-glucoside (AMG) or AMG-induced currents, membrane capacitance reflecting the plasma membrane surface area, or plasma membrane abundance of YFP-SGLT1 was measured. Upregulation of AMG-mediated inward currents and increase of plasma membrane capacitance were observed several minutes after stimulation of SGLT1 expressing oocytes with PKA or PKC $[156,407]$. Because no short-term changes in SGLT1 activity were detected when endocytosis was inhibited by imipramine or chlorpromazine whereas short-term downregulation was observed after inhibition of exocytosis by botulinum toxin B or after destroying the Golgi with brefeldin A [104, 407], the exocytotic pathway is supposed to be mainly involved in short-term regulation of SGLT1 (Fig. 3). The exocytotic pathway of SGLT1 was accelerated by Janus-activated kinase (JAK) [166] and shown to be dependent on dynamin and caveolin 1 [104, 407]. Evidence was provided that protein RS1 is critically involved in regulation of the dynamin-dependent exocytotic pathway of SGLT1 by decelerating the release of SGLT1 containing vesicles from the Golgi [407] (Fig. 3). Thus, downregulation of human SGLT1 by injection of RS1 or the RS1-domain RS1-Reg was abolished when the Golgi was destroyed with brefeldin A [407, 408], and RS1 and porcine SGLT1 were colocated at the trans-Golgi network (TGN) in LLC-PK1 cells [212]. RS1-Reg contains multiple consensus sequences for protein kinases, and the affinity for downregulation of human SGLT1 by RS1-Reg was increased after activation of PKC or calmodulin-stimulated kinase 2 (CamK2). This suggests that kinases modulate RS1-Reg-mediated shortterm regulation of SGLT1 [408]. Short-term regulation of SGLT1 abundance by RS1-Reg is D-glucose-dependent and involves the interaction of RS1 with ODC. Since D-glucose-dependent regulation has been shown to be relevant for the small intestine, it is described in the next chapter.

Proteasomal degradation of rabbit SGLT1 after ubiquitination by the ubiquitin ligase Nedd4-2 has been shown to be blunted by the serum- and glucocorticoidinducible kinases SGK1 and SGK3 (Fig. 3) [87].

\section{Transcriptional regulation in the small intestine by epithelial growth factor}

Epithelial growth factor (EGF) activates transcription of SGLT1/Sglt1 in the small intestine [417] (Fig. 2). EGF binds 
to the EGF receptor (EGFR) that is supposed to be localized in the BLM of enterocytes [308]. Binding of EGF to EGFR stimulates phosphorylation of cAMP response elementbinding protein (CREB) by tyrosine kinases including serum- and corticoid-stimulated kinase (SGK) 1 (Fig. 2). After phosphorylation, CREB migrates into the nucleus and activates SGLT1/Sglt1 transcription by binding to cAMP response element (CRE) in the promotor. This activation of transcription is modulated by cAMP response element protein-binding protein (CBP). In the small intestine of diabetic $d b / d b$ mice, stimulation of Sglt1 expression by SGK1 was demonstrated [240].

\section{Diurnal regulation in the small intestine}

Rats kept with free access to food and 12-h lightening ingest and absorb $\sim 90 \%$ of their daily food and have a higher capacity for glucose absorption during night time [116, 125, 374]. The capacity for glucose absorption peaks in the late light/ early dark phase. During night time, also an increase of sucrase activity was observed [148]. The higher glucose uptake and sucrase activity during night time were independent from lightening schedule [280, 373] and persisted in starved animals [124, 375].

Consistent with the notion that SGLT1/Sglt1 is rate limiting for glucose absorption [132], circadian rhythmicity peaking in the late light/early dark phase was also observed in rodents for abundance and transcription of Sglt1 mRNA, for abundance of Sglt1 protein, and for Sglt1-mediated glucose transport [69, 177, 319, 389, 390]. Since in the small intestine of monkeys different SGLT1 mRNA abundance was observed at 9 a.m. versus 10 p.m. [319], also humans are supposed to exhibit a circadian periodicity of small intestinal SGLT1 expression.

Limited information about the potential molecular mechanism for rhythmic regulation of SGLT1/Sglt1 transcription is available. Transcription factors $\mathrm{HNF}-1 \alpha, \mathrm{HNF}-1 \beta$, histone acetylation, an mRNA elongation factor, and clock genes appear to be involved. In rats fed at libitum, binding of transcription factors HNF-1 $\alpha$ and HNF-1 $\beta$ to the promotor of Sglt1 was different at 10 a.m. versus 4 p.m. [319]. In mice, it was observed that the circadian expression of Sglt1 mRNA was associated with histone acetylation and mRNA abundance of elongation factor BRD4-P-TEFb [428]. Evidence was provided that the clock gene products, brain and muscle arnt-like protein (BMAL) 1), and period 1 protein (PER1), are involved in the diurnal regulation of Sglt1 transcription [23, 177] (Fig. 2).

Like small intestinal glucose absorption, circadian periodicity of Sglt1 transcription occurs independently of food intake. Since the diurnal changes of Sglt1 mRNA abundance and Sglt1-mediated glucose uptake precede food uptake, they may be considered anticipatory to food ingestion [389]. The food-independent periodicity of glucose absorption and Sglt1 expression is accompanied and probably controlled by neuroendocrine regulation involving insulin. Thus, diurnal changes of blood insulin concentration and of insulin sensitivity independently of feeding were abolished after truncation of the vagus nerve [34, 147, 248]. The diurnal food-independent periodicity of Sglt1 mRNA abundance is supposed to be mainly due to changes of Sglt1 transcription; however, regulation of mRNA degradation may be also involved. Noteworthy, the diurnal changes of Sglt1 mRNA were observed in enterocytes at the upper villi [389]. Since enterocytes need 1 to 2 days to migrate from crypts where they divide to villi, the diurnal changes of Sglt1 mRNA must occur in differentiated enterocytes on the villi.

\section{Short-term post-translational regulation in the small intestine by glucose}

Glucose-dependent, short-term upregulation of SGLT1/Sglt1 in the small intestinal BBM has been observed in rodents and humans. In rat, the $V_{\max }$ of phlorizin-inhibited glucose uptake across the small intestinal BBM was increased when the intestine had been perfused for 30 min with buffer containing $25 \mathrm{mM}$ of D-glucose [351]. In mouse small intestine, $V_{\max }$ of phlorizin inhibited AMG uptake into BBM vesicles and Sglt1 protein in the BBM were increased 30 min after the animals had been gavaged with D-glucose [132].

Effects of glucose on posttranscriptional and posttranslational regulation of human SGLT1 expressed in oocytes were studied in detail [65, 341, 405, 407, 408]. On the basis of these data, hypotheses on glucose-dependent short-term regulation of human SGLT1 were raised (Fig. 3). Accordingly, D-glucose-dependent upregulation of SGLT1 in the plasma membrane is due to a glucose-induced acceleration of the exocytotic pathway of SGLT1 from the Golgi that is modulated by protein RS1 (RSC1A1) [66, 407, 408]. Human SGLT1 or YFP-SGLT1 was expressed in oocytes, and the post-translational active domain of RS1 (RS1-Reg) or peptide motifs of RS1-Reg were injected into the oocytes. The injections were performed without or with coinjection of non-metabolizable AMG, and effects on SGLT1 in the plasma membrane were analyzed [66, 341, 405, 407, 408]. In the experiments, either AMG uptake, AMG-induced inward currents, or fluorescence of YFP-SGLT1 in the plasma membrane was determined. Since RS1-Reg contains multiple consensus sequences for phosphorylation including the functional active motif Gln-Ser-Pro (QSP) [405, 408], experiments were also performed with QSP, Gln-Glu-Pro (QEP), and with RS1-Reg mutants in which serine residues in potential phosphorylation sites were mutated. Additional investigations that were performed with mouse small intestine, human small intestinal mucosa, and differentiated Caco 2 cells, a model for human small intestinal enterocytes, revealed that RS1- 
Reg-mediated glucose-dependent regulation of SGLT1/Sglt1 occurs in the small intestine [66, 408] (C.Otto et al. 2020, unpublished data). Recently, further details about the mechanism of the RS1-Reg-mediated regulation of human SGLT1 at the TGN were enlightened [66]. Thus, evidence was obtained that RS1-Reg binds to the ODC which has been assigned to several intracellular locations but appears to be also located at the Golgi [185]. It was detected that RS1-Reg inhibits the enzymatic activity of ODC, i.e., the formation of putrescine by decarboxylation of ornithine, in a glucosedependent manner, and that ODC contains a glucosebinding site. In addition, evidence was presented that downregulation of human SGLT1 abundance in the plasma membrane can also be induced by inhibiting ODC activity, and that this effect is counteracted by putrescine. Based on these data, hypotheses have been raised and included in a model (Fig. 4(A, B)) [200]. At low intracellular D-glucose concentration, the RS1-Reg domain of RS1 binds to ODC and inhibits ODC activity reducing the local concentration of putrescine at the TGN. Under this condition, dynamindependent budding of SGLT1 containing vesicles from the TGN mediated by non-identified budding proteins that interact with putrescine is slow. At high intracellular D-glucose concentration, D-glucose binds to ODC and induces a conformational change that leads to a dissociation of bound RS1 and results in activation of ODC activity. As a result, the local concentration of putrescine at the TGN is increased and putrescine binds to the budding protein complex and activates budding activity of the complex.

\section{Short-term post-translational regulation in the small intestine by hormones}

In rat small intestine, also short-term regulation of Sglt1 by glucagon 37, glucagon-like peptide 2 (GLP-2), cholecystokinin $(\mathrm{CCK})$, prostaglandin E2, EGF, leptin, insulin, and resistin-like molecule beta (RELM- $\beta$ ) was observed [64, 67, 149, 158, 211, 261, 305, 347, 378-380]. Glucagon 37 and GLP-2 are secreted by L cells whereas CCK is secreted by small intestinal I cells. It was observed that Sglt1-mediated Dglucose uptake in the small intestine was rapidly upregulated by vascular infusion with glucagon 37 or GLP-2 whereas it was rapidly downregulated by serosal application of CCK. Receptors for glucagon 37 and CCK are located in the BLM of enterocytes whereas enterocytes do not contain a receptor for GLP-2 [35, 268, 301, 435]. GLP-2 rather binds to receptors in enteric neurons $[35,140]$ and stimulates neuronal activation of enterocytes. This leads to an increase of intracellular cAMP that activates AMPK, a signal for short-term upregulation of the exocytotic pathway of SGLT1/Sglt1 (Fig. 3). RS1 is probably involved in the GLP-2-mediated short-term regulation of SGLT1 because the effect of GLP-2 infusion was blunted when the Golgi was dissociated by brefeldin A [64]. $L$ cells in the small intestine express the sweet taste receptor T1R1/T1R3 and secrete GLP-2 directly after application of a high concentration of D-glucose or the artificial sweetener sucralose to the mucosal side [268]. In mice in which the sweet taste receptor or the GLP-2 receptor was removed, long-term upregulation of Sglt1 on the mRNA and protein levels in
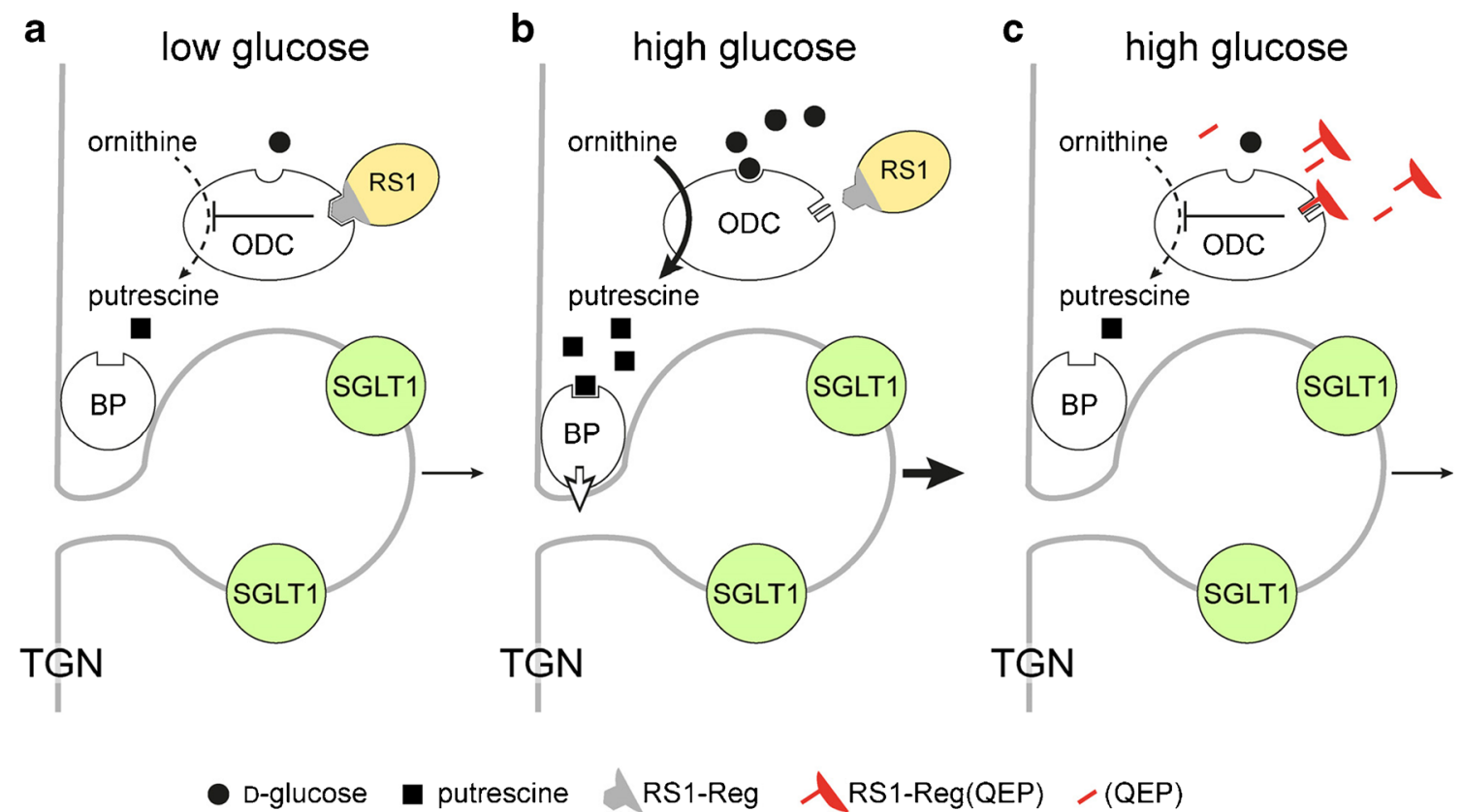

putrescine

RS1-Reg

Fig. 4 Model depicting the presumed role of RS1 in D-glucose-dependent release of vesicles containing human SGLT1 from the Golgi $(a, b)$ and the action of modified peptides derived from RS1-Reg (c) that downregulate SGLT1 in the BBM. RS1-Reg in RS1 is indicated in gray. TGN, trans-

Golgi network; ODC, ornithine decarboxylase; BP, putrescine-binding protein of a budding protein complex that induces the release of vesicles containing human SGLT1 from the TGN 
response to carbohydrate-rich diet was blunted [257, 268]. It has been suggested that the sweet taste receptor is also involved in glucose-dependent short-term upregulation of Sglt1; however, no experimental evidence has been provided.

After 20-min arterial perfusion of rat jejunum with $10 \mathrm{nM}$ insulin, phlorizin-inhibited glucose absorption was decreased suggesting downregulation of Sglt1 in the BBM after binding of insulin to the insulin receptor isoform B (IR-B) located in the BLM [14, 32, 305]. Employing an isolated, jointly perfused rat preparation of the small intestine and liver, it was observed that insulin in the portal vein promoted a rapid increase of phlorizin-inhibited D-glucose absorption [380]. This stimulation was supposed to be mediated via insulin binding to a portal insulin receptor that activates parasympathetic hepatoenteral nerves which upregulate Sglt1 in the BBM [380].

Short-term upregulation of SGLT1/Sglt1 was also observed after interaction of EGF and prostaglandin E2 [67, 149, 261, 347]. Activation of the prostaglandin $E_{2}$ receptor in the BBM of rodents promoted the increase of cytosolic cAMP that stimulated the exocytotic Sglt1 pathway [85, 347, 350, 421].

In addition, short-term downregulation of SGLT1/Sglt1 abundance in small intestinal BBM can be induced by leptin $[95,247]$. Leptin is secreted by salivary glands and chief cells in gastric mucosa $[20,49,139]$. By binding to a protein with structural similarity to the soluble leptin receptor, leptin becomes resistant to the acidic $\mathrm{pH}$ in stomach [50]. In the small intestine, leptin binds to the leptin receptor in the BBM and mediates PKC-dependent downregulation of SGLT1/Sglt1 [29].

Moreover, RELM- $\beta$ appears to be involved in short-term upregulation of SGLT1/Sglt1 [211]. RELM- $\beta$ is expressed in the digestive tract where it plays a role in host defense but it is also observed in the blood and can act as hormone [16, 278, $357,372]$. After application of $1 \mathrm{nM}$ RELM- $\beta$ to the mucosal side of rat small intestine, RELM- $\beta$ decreased glucoseinduced short-circuit currents and Sglt1 abundance in the BBM within 2 min [211].

\section{Long-term regulation in the small intestine in response to carbohydrate-rich diet}

Enhancement of Sglt1 expression and capacity for glucose absorption in response to increased dietary carbohydrates was observed in herbivores and omnivores but not in carnivores [37, 43, 86, 100, 257, 354, 362]. In rodents, D-glucose, D-fructose, D-galactose, AMG, 3-O-methyl D-glucoside (3OMG), D-mannose, D-xylose, and/or different artificial sweeteners were shown to increase Sglt1 expression on mRNA and/ or protein level; however, I has not been clarified whether the different compounds address the same regulatory mechanism $[28,199,233,257,265,362]$. After 5-day application of diets containing high amounts of D-glucose, AMG, D-galactose, Dfructose, D-mannose, or D-xylose to rats, Sglt1 mRNA in the small intestine was increased [265]. Monosaccharidedependent upregulation of Sglt1 mRNA may occur relatively rapidly. Thus, an increase of Sglt 1 mRNA was also observed in the small intestine of rats that had been fed for $12 \mathrm{~h}$ with diets containing high amounts of D-glucose, D-fructose, or sucrose $[199,430]$. The data indicate that upregulation of SGLT1 in response to dietary monosaccharides occurs on the level of mRNA; however, additional mechanisms including changes in metabolism are involved (see below).

Measuring phlorizin binding to mouse enterocytes from different regions of villi and crypts at different time intervals after switching to carbohydrate-rich diet, it was observed that carbohydrate-mediated induction of Sglt1 expression occurred within the crypts $[110,111,113]$. Whereas phlorizin binding in the crypts was increased $12 \mathrm{~h}$ after exposure to carbohydrates, 3 days were required until phlorizin binding on the tips of the villi was maximally increased. This time lag is supposed to be due to the time required for crypt enterocytes to migrate onto villi. Experiments with mice in which the taste receptor T1R3 or the $\mathrm{G}$ protein $\alpha$-gustin that are expressed in G cells, were removed revealed that long-term upregulation of Sglt1 mRNA and Sglt1 protein in mice by glucose and artificial sweeteners was dependent on taste reception $[257,268]$. Because mucosal application of D-glucose or sucralose leads to an acute secretion of GLP-2 and enteric nerves contain GLP-2 receptors (see below), taste receptor-mediated GLP-2 release from G cells and neuronal stimulation of Sglt1 transcription are supposed to be critically involved in diet-dependent upregulation of Sglt1 expression in rodents.

RELM- $\beta$ which is present in the blood is involved in longterm regulation of Sglt1 and Glut2 in response to saturated free fatty acids and glucose $[120,129,372]$. In response to high glucose, the concentration of RELM- $\beta$ in rat small intestinal enterocytes was decreased which resulted in a long-term decrease and increase of Sglt1 and Glut2 in the BBM, respectively $[120,211]$. These inverse changes may represent a mechanism for energy conservation during chronic high glucose load (see below).

Ruminant sheep exhibit an extensive, carbohydratedependent regulation of SGLT1. In the small intestine of lambs, SGLT1 is highly expressed during breastfeeding when D-glucose and D-galactose enter the small intestine whereas SGLT1 expression is largely reduced after weaning when the rumen where carbohydrates are fermented has maturated and no hexoses enter the small intestine. In adult sheep, SGLT1 protein in the BBM and SGLT1-mediated glucose uptake in BBM vesicles was decreased $>200$-fold whereas SGLT1 mRNA was only decreased about 4-fold [233, 355]. When the small intestine of adult lambs was perfused with $10 \mathrm{mM}$ D-glucose, SGLT1 protein in the BBM and SGLT1mediated glucose transport into BBM vesicles were increased 
$>40$-fold and SGLT1 mRNA was increased about 2-fold. After perfusion with $10 \mathrm{mM}$ mannitol, small intestinal expression of SGLT1 was not changed. Some upregulation of SGLT1 was also observed after perfusion with the membrane impermeable D-glucose analogue, di(glucos-6yl)poly(ethylene glycol) 600 that does not interact with SGLT1 [99]. The data indicate a dramatic upregulation of SGLT1 in the presence of D-glucose in the diet that occurs partially on the level of mRNA but mainly on the translational or post-translational level. The upregulation appears to be partially independent of glucose uptake and to be partially mediated via sweet taste receptors.

\section{Regulation of GLUT2}

\section{Basic knowledge about transcriptional regulation in human}

Various transcription factors that interact with consensus sequences in the promotor region of human GLUT2 and influence transcription in hepatocytes have been identified (Fig. 5) [7]. CCAAT/enhancer-binding proteins (C/EBP) $\alpha$ and $\beta$ form dimers which upregulate GLUT2 transcription [194]. Peroxisome proliferator-activated receptor (PPAR) $\gamma$ that dimerizes with the retinoid $X$ receptor (RXR) $\alpha$ is involved in the antidiabetic action of thiazolidinedione that binds to $\operatorname{PPAR} \gamma$ [281]. In hepatocytes, also transcriptional upregulation of GLUT2 by hepatic nuclear factors has been observed and interaction of HNF $1 \alpha$ and forkhead box (FOX) A2 with HNF consensus sequences in the GLUT2 promoter has been demonstrated [7, 60]. HNF1 $\alpha$ is most abundantly expressed in the liver but has been also detected in the intestine, kidney, and spleen [26]. Importantly, glucose uptake and transcription of GLUT2 in hepatocytes are stimulated by glucose, fructose, and sorbitol but not by non-metabolized 2-DOG or 3-OMG $[17,318]$. Data have been presented showing that the transcription factor sterol regulatory element-binding protein (SREBP) 1c that is also expressed in the intestine, is involved in this regulation $[38,114,173,397]$.

\section{Diurnal regulation in the small intestine}

Expression of Glut2 mRNA in the small intestine undergoes diurnal circuity that is coordinated with Sglt1 and Glut5. In rodents that were fed ad libitum and kept with a 12-h light/ dark cycle, expression of Glut2 in the small intestine peaked at the end of the light phase and was lowest at the end of the dark phase [69, 108, 177, 390]. Vagal innervation was shown to be critically involved [390] and evidence was presented that the transcription factor BMAL1 that regulates central clock genes is required [177].

\section{Short-term post-translational regulation in the small intestine by glucose}

In response to small intestinal glucose concentrations of $30 \mathrm{mM}$ or above, Glut 2 is rapidly inserted into the BBM of the enterocytes [132, 134, 152, 189, 192]. This enables an effective, energy-saving D-glucose uptake at glucose concentrations far above the $K_{\mathrm{m}}$ of SGLT1. In parallel, the capacity for D-fructose uptake into the enterocytes is increased. When high luminal glucose dissipates, Glut2 abundance in the BBM decreases with a delay of minutes [189, 396]. Evidence has been presented that the glucose-dependent increase of Glut2 in the BBM is due to upregulation of exocytosis of Glut2containing vesicles; however, it has not been elucidated whether the vesicles originate from the BLM, an intracellular vesicle pool or the Golgi.

The mechanism of glucose-dependent incorporation of Glut2 into the BBM has been investigated in some detail. PKC may be involved because the BBM abundance of Glut2 was also increased rapidly when the small intestine was incubated with PMA [5, 152]. Maximal electrogenic glucose transport by Sglt1 at high intestinal glucose when Sglt1 in the BBM is upregulated and the transporter operates at $V_{\max }$ is supposed to trigger Glut2 incorporation into the BBM (Fig. 6). Sglt1-mediated $\mathrm{Na}^{+}-\mathrm{D}-$ cotransport causes a depolarization of the BBM that activates $\mathrm{Ca}^{2+}$ uptake via $\mathrm{Ca}^{2+}$ channel $\mathrm{Ca}_{\mathrm{v}}$ 1.3. [269, 270]. The increased intracellular $\mathrm{Ca}^{2+}$ stimulates phosphorylation of myosin II by protein kinase C $\beta$ II (PKC $\beta$ II) that is activated upon recruitment to the plasma membrane $[192,250,251,401]$. Recruitment of PKC $\beta$ II to the plasma membrane is also promoted by RELM- $\beta$ that has been also shown to increase Glut2 in the BBM [211]. Phosphorylation of myosin II leads to a rearrangement of the subapical terminal web that is supposed to facilitate BBM insertion of Glut2. Because $\mathrm{Ca}^{2+}$ uptake into enterocytes

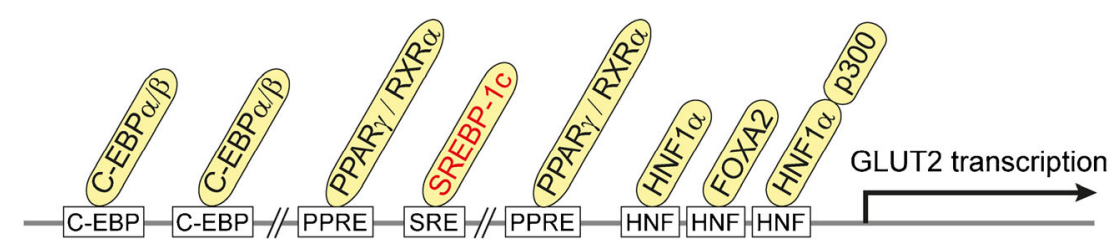

Fig. 5 Transcriptional regulation of GLUT2. Response elements in the promotor of human GLUT2 and transcription factors that are supposed to be involved in the regulation of GLUT2/Glut2 in the small intestine are indicated. SREBP-1c participates in D-glucose-dependent regulation of

Glut2. C-EBP, CCAAT enhancer-binding protein; PPAR, peroxisome proliferator-activated receptor; RXR, retinoid X receptor; SREBP, sterol receptor element-binding protein; HNF, hepatic nuclear factor; FOX, forkhead box; p300, histone acetyltransferase p300 


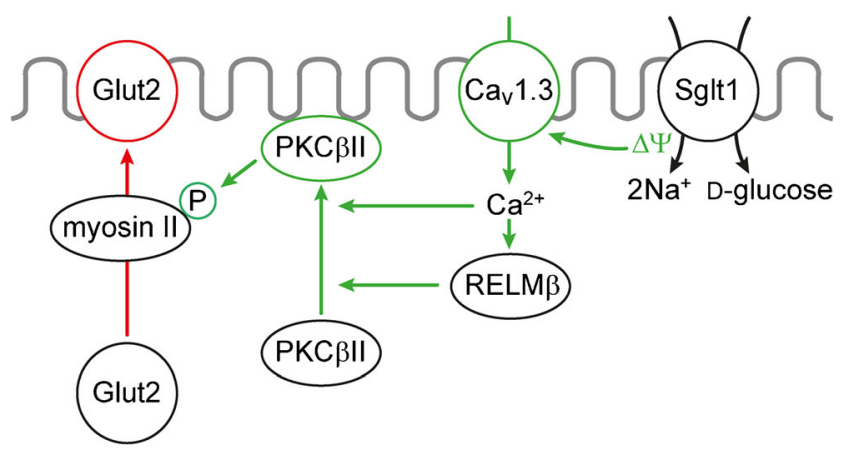

Fig. 6 Model depicting components that are involved in targeting of Glut2 to the BBM at high luminal glucose concentrations. The underlying experiments were performed in rats. $\Delta \Psi$, membrane depolarization due to $\mathrm{Na}^{+}$-D-glucose cotransport; $\mathrm{Ca}_{\mathrm{v}}$, voltagedependent $\mathrm{Ca}^{2+}$ channel; RELM, resistin-like molecule

was stimulated maximally at $20 \mathrm{mM}$ D-glucose but higher glucose concentrations were required for insertion of Glut2 into the BBM, an additional glucose-dependent process has been postulated [192]. This process could be related to glucose-dependent phosphorylation of AMPK or to paracrine effects of taste receptor activation in enteroendocrine cells $[192,211,412]$.

\section{Short-term regulation in the small intestine by insulin and GLP-2}

Short-term effects of insulin on plasma membrane abundance of Glut2 were investigated in the small intestine of mice that had been kept for 5, 15, or 30 days on fructose-rich diet [396]. After 15 and 30 days on fructose-rich diet, the abundance of Glut2 in the BBM was increased due to long-term upregulation (see below), and the animals became resistant to insulin after 30 days on fructose-rich diet. When the insulin-sensitive animals kept for 15 days on fructose-rich diet were infused with insulin under hyperinsulinemic-euglycemic clamp conditions, the increased BBM abundance of Glut2 due to the fructoserich diet was decreased whereas this effect was not observed in the insulin-resistant animals. The effect of insulin on shortterm, glucose-induced trafficking of Glut2 to the BBM was investigated in the mice that had been fed for 5 days with fructose-rich diet. Thirty minutes after glucose gavage of these mice, Glut2 in the BBM was largely increased; however, this increase was blunted when insulin had been injected prior to glucose gavage. The data indicate that insulin induces shortterm removal of Glut2 from the BBM and prevents short-term glucose-dependent trafficking of Glut2 to the BBM.

Trafficking of Glut2 to the BBM combined with an increase of glucose absorption in rat small intestine was observed after 1-h vascular perfusion with GLP-2 [18]. Evidence was presented that the GLP-2-induced upregulation of Glut2 in the BBM involves activation of enteric neurons [268].
Long-term carbohydrate-dependent regulation in the small intestine

After 5-day application of diets containing high amounts of Dglucose, D-galactose, or D-fructose, the abundance of Glut2 mRNA in rat enterocytes was increased whereas high amounts of AMG, D-mannose, or D-xylose were not effective [265]. Noteworthy, post-translational upregulation of Glut2 and Glut5 was observed in mice after 25-week application of high-fructose diet [91]. This fructose-dependent upregulation was associated with mRNA upregulation of thioredoxininteracting protein (TXNIP) that is involved in regulation of various metabolic pathways [300]. TXNIP was shown to bind to human GLUT2 and GLUT5 and increased the abundance of these transporters after coexpression in Caco-2 cells [91]. In nondiabetic rodents on standard chow, Glut2 was almost exclusively located in the BLM of enterocytes between meals. At variance, in animals receiving a glucose-rich and/or fructose-rich diet, Glut2 was located in both the BLM and the BBM, between meals $[28,134,396]$.

\section{Regulation of GLUT5}

\section{Knowledge about transcriptional and epigenetic regulation}

The promoter regions of human, rat, and/or mouse GLUT5/ Glut5 contain response elements for cAMP (CRE), glucocorticoid receptor (GR), liver X receptor (LXR), carbohydrateresponsive element-binding protein (ChREBP), and thyroid hormone receptor/retinoid X receptor heteromer [255, 260, $283,385,441]$.

In Caco-2 cells transfected with reporter gene constructs containing the human GLUT5, promoter expression was stimulated by adenylate cyclase [255]. Using the same experimental setup, transcriptional regulation by thyroid hormone was observed [260]. It was shown that binding of thyroid hormone receptor/retinoid X receptor heteromers to the promotor was blunted by thyroid hormone.

In rat small intestine, Glut5 mRNA was upregulated after weaning provided that systemic glucocorticoids were present and fructose had been ingested [385]. Epigenetic regulation is probably involved because the glucocorticoid-promoted upregulation of Glut 5 transcription after weaning was associated with histone $\mathrm{H} 3$ acetylation of the promotor [385]. At variance, sucrose-dependent upregulation of Glut5 mRNA observed after feeding of starved rats with sucrose-rich food was associated with histone $\mathrm{H} 3$ acetylation of the encoding DNA sequence [162]. Functionality of liver X receptor $\alpha$ response element (LXRE) in the murine Glut5 promoter was suggested by the observation that Glut 5 mRNA was increased by a LXR agonist [441]. ChREBP and thyroid hormone are probably involved in upregulation of Glut5 transcription by Dfructose. Whereas in wild-type mice on high-fructose diet the 
abundance of Glut5 mRNA in the small intestine was eight times higher compared to standard diet, fructose in the diet had no effect on small intestinal abundance of Glut5 mRNA in ChREBP knockout mice [283].

The abundance of GLUT5 mRNA is also regulated on the level of mRNA stability. Thus, the degradation of GLUT5 mRNA in Caco-2 cells was slowed down by cAMP and fructose $[135,255]$. This increase of message stability was due to cAMP-dependent binding of cytosolic proteins to untranslated regions of GLUT5 mRNA [135].

\section{Diurnal regulation in the small intestine}

In rats kept with a 12-h light/dark cycle and free access to food, Glut5 mRNA in the jejunum was increased in the late light/early dark phase similar to the mRNAs of Glut2 and Sglt1 [58, 69, 108, 177, 390].

\section{Fructose-dependent upregulation in the small intestine}

So far, no short-term post-translational upregulation of GLUT5/Glut5 by monosaccharides has been described. However, Glut5 in the BBM of rat small intestine was increased within minutes after application of inhibitors of signal pathways involving epithelial receptor kinase (ERK)/mitogen-activated protein (MAP) kinase or phosphoinositol-3 kinase [151].

In rodents, upregulation of Glut5 on the level of mRNA was observed in response to dietary D-fructose whereas other monosaccharides were not effective. For example, an increase of small intestinal Glut5 mRNA was observed when rats were fed for 5-7 days with a D-fructose-rich diet whereas diets enriched with D-glucose, D-galactose, AMG, D-mannose, or D-xylose were not effective $[45,265]$. When mice on a carbohydrate-poor diet were switched to a D-fructose-rich diet, transcription of Glut5 was enhanced $12 \mathrm{~h}$ later $[135,199]$. The onset of dietary upregulation of Glut5 mRNA only requires several hours. In mice, 4-h perfusion of small intestine with buffer containing $100 \mathrm{mM}$ fructose provoked a significant increase of Glut5 mRNA whereas perfusion with $100 \mathrm{mM}$ glucose was not effective [77, 385]. In addition to mRNA, also Glut5 protein abundance in cytosol and BBM were increased.

\section{Carbohydrate-dependent regulation of monosaccharide absorption}

In the following, it will be discussed how the above-described monosaccharide-dependent regulations of Sglt1, Glut2, and Glut5 affect small intestinal absorption of D-glucose and Dfructose. Three regulatory states that are fundamentally different from each other will be considered: first, the situation in individuals on carbohydrate-poor (low-carb) diets after low- carb meals (Fig. 7a); second, the situation in individuals on low-carb diets after carbohydrate-rich (high-carb) meals containing large amounts of sucrose that is rapidly split into D-

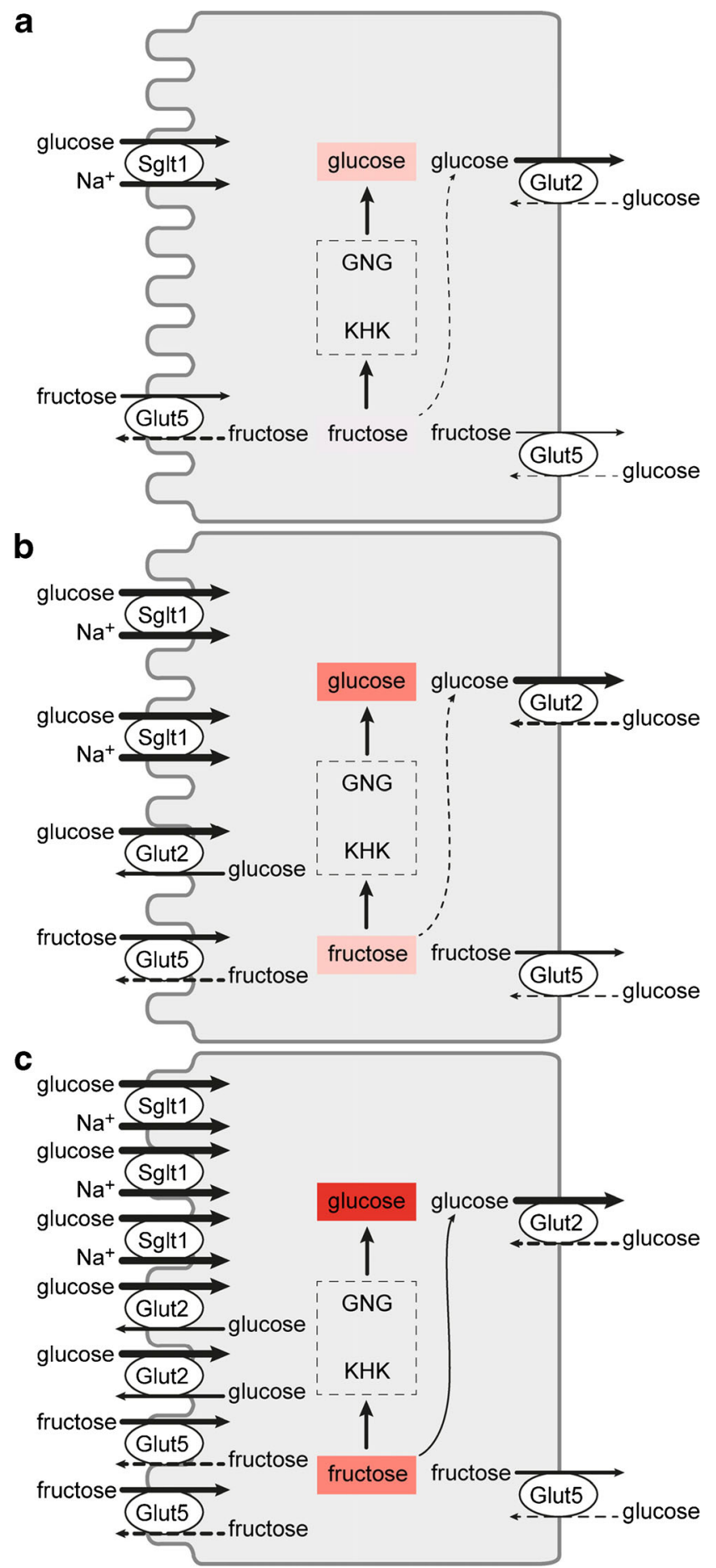

Fig. 7 Plasma membrane localization and abundance of Sglt1, Glut2, and Glut3 in response to carbohydrates in the diet after ingestion of a carbohydrate-poor or a carbohydrate- and sucrose-rich meal. The underlying experiments were performed in rats. a Carbohydrate-poor diet after a carbohydrate-poor meal. b Carbohydrate-poor diet after a sucrose-rich meal. c Carbohydrate-rich diet after a sucrose-rich meal. KHK, ketohexokinase; GNG, gluconeogenesis 
glucose and D-fructose by sucrase-isomaltase (Fig. 7b); and third, the situation in individuals on a high-carb diets after meals containing large amounts of sucrose (Fig. 7c).

In the small intestine of rats on low-carb diet after ingestion of low-carb food, when the concentrations of D-glucose and Dgalactose are below the respective $K_{\mathrm{m}}$ values of SGLT1/Sglt1mediated uptake (Table 1), the abundance of Sglt1 and Glut5 in the BBM of the enterocytes and of Glut2 in the BLM is low and Glut2 is not present in the BBM (Fig. 7a). Under this condition, small concentrations of D-glucose and D-galactose after low-carb meals are effectively absorbed by secondary active transport by Sglt1 across the BBM followed by passive diffusion of intracellularly enriched monosaccharides across the BLM via Glut2. D-Fructose enters the enterocytes via Glut5 in the BBM. In a recent study performed in mice, evidence has been provided that about $90 \%$ of $\mathrm{D}$-fructose entering the enterocytes is metabolized and increases the intracellular pool of D-glucose due to gluconeogenesis [179]. Hence, the intracellular D-fructose concentration is low and only small amounts of D-fructose leave the cells via Glut2 and Glut5 (Fig. 7). In the small intestine, ketohexokinase (KHK) phosphorylates D-fructose in position 1 and provides the starting compound for fructolysis (Fig. 8). After removal of KHK in mice, D-fructose in the serum after high-fructose feeding was largely increased whereas fructose-induced hyperglycemia was blunted [296]. Catalyzed by aldolase B (ALDOB), D-

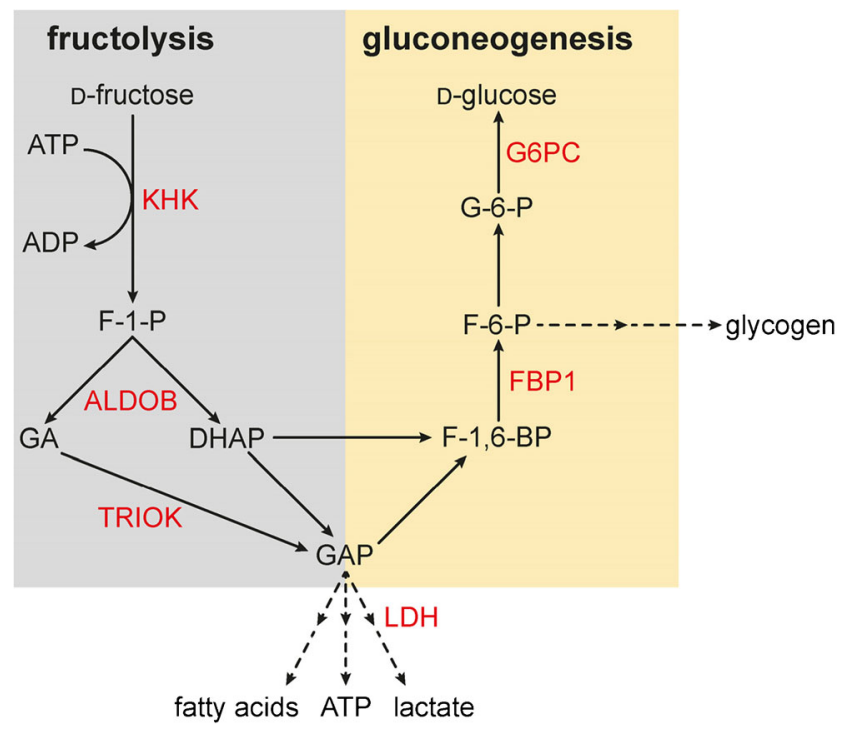

Fig. 8 Fructolysis and gluconeogenesis, and effects of removal of carbohydrate-responsive element (ChoRE)-binding protein in mice on fructose-dependent expression of the involved enzymes. Enzymes that are upregulated by high-fructose diet in the presence but not in the absence of ChoRE are indicated in red. Of note, also Glut5 in the luminal membrane of enterocytes mediating D-fructose uptake is only upregulated by high-fructose diet if ChoRE-binding protein is expressed in the enterocytes. Ketohexokinase (KHK), aldolase B (ALDOB), triosekinase (TRIOK), glucose-6-phosphatase (G6PC), fructose-1,6-biphosphatase (FBP1), and lactate dehydrogenase (LDH) are upregulated fructose-1-phosphate is split into glyceraldehyde (GA) and dihydroxyacetone phosphate (DHAP). DHAP and glyceraldehydephosphate (GAP) formed by triosekinase (TRIOK)-mediated phosphorylation of GA enter gluconeogenesis (GNG) (Fig. 8). GAP enters other metabolic pathways including fatty acid synthesis.

Glut2 located in the BLM that transports D-glucose, D-galactose, and D-fructose, is probably not the only transporter for D-glucose export across the BLM because glucose absorption was not significantly decreased in Glut2 knockout mice [381]. Because it was observed that D-glucose absorption in Glut2 knockout mice was blocked when glucose-6-phosphate (G-6P) translocase in the endoplasmic reticulum (ER) was inhibited, the hypothesis was raised that uptake of glucose6-phosohate into the ER and exocytosis is involved in glucose transport across the BLM [381]. So far, unequivocal experimental evidence for the existence of this translocation pathway is missing. Measurement of glucose absorption in the absence and presence of inhibitors of exocytosis and uptake measurements in vesicles from small intestinal BLMs of Glut2 knockout mice are recommended. It is possible that Glut1, Glut7, Glut8, or Glut12 is targeted to the BLM when Glut2 is removed and provides a compensatory path for efflux of $\mathrm{D}$ glucose.

When rats on low-carb high diet had ingested high-carb meals containing large amounts of sucrose, it was observed that the amount of Sglt1 in the BBM was increased and that Glut2 was present not only in the BLM but also in the BBM (Fig. 7b). After meals containing large amounts of sucrose, the concentrations of D-glucose and D-fructose in the small intestinal lumen close to the BBM are $>100 \mathrm{mM}$ because sucroseisomaltase degrades sucrose effectively. Under these conditions, Sglt1 and Glut2 transport D-glucose and Glut5 transports D-fructose at $V_{\max }$ across the BBM whereas Glut2 transports D-fructose with about half maximal efficacy (Table 1). D-Glucose uptake across the BBM is mediated about one-third by Sglt1 and two-thirds by glut2 [192], whereas D-fructose uptake across the BBM is mediated to similar proportions by Glut5 and Glut2 [134]. Computer simulation studies on measurements performed in Caco-2 cells support the concept that facilitative diffusion of D-glucose across the BBM contributes to D-glucose uptake into enterocytes at high glucose concentrations [6]. The bulk of intracellular D-fructose at high-carb diet is phosphorylated, split, and transformed to D-glucose by GNG. Transport of the relatively high amounts of intracellular D-glucose across the BLM is supposed to be mediated by GLUT2/Glut2, whereas transport of the relatively small amounts of intracellular D-fructose is supposed to be mediated by GLUT5/Glut5 and GLUT2/Glut2.

It has been observed that small intestinal absorption of Dfructose was stimulated by high concentrations of luminal Dglucose [159, 330-332]. In humans, a similar effect of D-glucose was observed on the absorption of sorbitol that is not 
transported by GLUT5 [331], and D-fructose absorption was also stimulated by amino acids which are translocated by sodium-amino acid cotransporters across the BBM [159]. The stimulation of D-fructose by luminal D-glucose or amino acids is probably due to water removal from the intestinal lumen that leads to an increase of the luminal fructose concentration and enhances transport efficacy of GLUT5/Glut5. Cotransport of D-glucose and amino acids with sodium leads to an increase of sodium in the intercellular spaces and promotes permeation water across the tight junctions.

In response to high-carb diet containing large amounts of sucrose, the overall expression of Sglt1, Glut2, and Glut5 in the enterocytes is increased (Fig. 7c). Between meals and after uptake of low-carb meals, Sglt1 and Glut5 are located in the BBM whereas Glut 2 and probably also Glut5 are located in the BLM as depicted in Fig. 7 b. After ingestion of high-carb food with high amounts of sucrose, the same short-term regulation takes place as in individuals on low-carb diet. Thus, additional molecules of Sglt1 are incorporated into the BBM and additional amounts of Glut 2 and Glut5 are targeted to the BBM (Fig. 7c). In consequence, the capacity for absorption of D-glucose and D-galactose is maximized leading to maximal increases of plasma glucose after sucrose ingestion. Also, the capacity of D-fructose uptake into the enterocytes is maximized leading to maximal D-glucose generation by GNG. Under these conditions, there is a maximal risk for fructose intolerance (see below).

\section{Expression and function of SGLT1 and GLUTs in enteroendocrine cells}

\section{Secretion and functions of enterohormones}

Secretion of the enterohormones GLP-1, glucagon-like peptide 2 (GLP-2), and peptide YY (PYY) by L cells, GIP by K cells, CCK by I cells, neurotensin by $\mathrm{N}$ cells, and serotonin by EC cells is involved in the regulation of appetite, gastric emptying, small intestinal motions, D-glucose absorption, and Dglucose metabolism [21, 62, 137, 314, 317, 320]. The effects of GLP-2, ghrelin, CCK, neurotensin, and serotonin on appetite and functions of the alimentary tract are mediated by stimulation of neuronal receptors in peripheral neurons and/or central neurons [24, 314, 369]. At variance, effects of GLP1 and GIP on D-glucose metabolism are mainly mediated via stimulation of insulin secretion by $\beta$ cells in pancreatic islets and of insulin-independent D-glucose disposal [21, 78, 210]. In addition to amino acids, peptides, and fatty acids, secretion of GLP-1 by L cells and of GIP by K cells is stimulated by Dglucose and D-fructose [72, 193, 215, 251]. In rodents and humans, L cells are mainly expressed in the ileum and colon whereas $\mathrm{K}$ cells are mainly expressed in the jejunum [317,
320]. Some L cells are also expressed in the duodenum [143, 382, 393].

\section{Roles of glucose transporters for secretion of GLP-1 and GIP}

Discussing the role of glucose transporters in D-glucose sensing by small intestinal $\mathrm{L}$ and $\mathrm{K}$ cells, the limitations of the available data must be considered. First, our knowledge about the mechanisms involved in D-glucose-dependent stimulation of GLP-1 and GIP secretion is derived from studies in different species and in cultured cells. Second, different populations of the enteroendocrine cells (EECs) may have been investigated because $\mathrm{L}$ and $\mathrm{K}$ cells consist of different cell populations that secrete partially different enterohormones $[101,143$, $384,386]$. Third, the functional properties of EECs may have been changed in response to nutrient exposition and during diabetes [15, 52, 345, 382, 393].

The available data indicate that SGLT1/Sglt1 and GLUT2/ Glut2 are critically involved in glucose-dependent stimulation of GLP-1 and GIP secretion in the small intestine at high luminal D-glucose concentrations [132, 271, 322, 382], and that activation of the sweet taste receptor T1R2/T1R3 heterodimer may participate [121, 178]. Additional proteins have been associated with D-glucose-dependent secretion of GLP1 and GIP. These are (a) voltage-dependent $\mathrm{Ca}^{2+}$ channel(s) $\left(\mathrm{Ca}_{\mathrm{v}}\right)$ and the ATP-regulated $\mathrm{K}^{+}$channel Kir6.2/Sur1 $\left(\mathrm{K}_{\mathrm{ATP}}\right)$ [251, 279, 282, 315, 325, 382, 393]. Sglt1-mediated D-glucose uptake triggers glucose-dependent secretion of GLP-1 and GIP at low and high luminal D-glucose concentrations. Cotransport of sodium and D-glucose by Sglt1 leads to depolarization of the luminal plasma membrane and induces $\mathrm{Ca}^{2+}$ uptake via (a) voltage-dependent $\mathrm{Ca}^{2+}$ channel(s) [295, 316]. $\mathrm{Ca}^{2+}$ uptake may stimulate insertion of Glut2 into the luminal membrane in enterocytes (Fig. 6). At luminal D-glucose concentrations far above the $K_{\mathrm{m}}$ for SGLT1/Sglt1, GLUT2/Glut2 in the luminal membrane is supposed to mediate a considerable fraction of D-glucose uptake in addition to Sglt1. High intracellular D-glucose increases carbohydrate metabolism [294, 316, 393]. The increased metabolism results in an increase of intracellular ATP that may lead to closure of $\mathrm{K}_{\text {ATP }}$ channels and promote depolarization of the plasma membrane. This may result in the opening of $\mathrm{Ca}_{\mathrm{v}}$ channels located in the basolateral membrane [316]. The increase of intracellular $\mathrm{Ca}^{2+}$ may be further enhanced by $\mathrm{Ca}^{2+}$-promoted $\mathrm{Ca}^{2+}$ release from the endoplasmic reticulum. The increase of intracellular $\mathrm{Ca}^{2+}$ causes the exocytosis of vesicles containing GIP and GLP-1.

Experimental evidence for a pivotal role of Sglt1 in glucose-induced secretion of GLP-1 and GIP was provided as follows. In mice, the early secretion of GLP-1 after gavage with D-glucose was blunted and the secretion of GIP was abolished when SGLT1 was removed [132, 295, 322]. 
Perfusing rat small intestine in vivo, it was observed that the secretion of GIP and/or GLP-1 was stimulated when the luminal D-glucose concentration was increased from 5 to $100 \mathrm{mM}$ D-glucose and that this increase was blunted by $45 \%$ when Sglt1 was inhibited with phlorizin [251]. In humans, the secretion of GIP and/or GLP-1 during oral glucose tolerance tests (OGTTs) was decreased when SGLT1 was inhibited by oral application of an SGLT1/Sglt1 inhibitor $[88,176]$. It was observed in rodents and humans that secretion of GLP-1 and GIP was also stimulated by nonmetabolizable sugars such as AMG and 3-OMG [251, 271, $321,382,425]$. This indicates that metabolism and ATPmediated closure of the $\mathrm{K}_{\mathrm{ATP}}$ channel were not critical under the employed conditions. However, in one study performed in humans, the stimulation of GLP-1 secretion by $300 \mathrm{mM}$ Dglucose was more pronounced than the stimulation by $300 \mathrm{mM}$ AMG [382].

Relevance of GLUT2/Glut2 for stimulation of GLP-1 and/ or GIP by very high glucose concentrations in the intestinal lumen was indicated by the following data. In experiments in which rat small intestine was perfused, secretion of GLP-1 and GIP was stimulated by $100 \mathrm{mM}$ D-glucose in the presence of phlorizin, and this Sglt1-independent stimulation was blocked when Glut2 was inhibited with phloretin or cytochalasin B [251]. In the same study, it was observed that the secretion of GLP-1 and GIP in the presence of $100 \mathrm{mM}$ D-glucose was decreased when $\mathrm{K}_{\text {ATP }}$ channels were blocked by tolbutamide. In another study in rat, no stimulation of GLP-1 secretion by 1.1 M luminal D-glucose was observed when the $\mathrm{K}_{\mathrm{ATP}}$ channels were opened by diazoxide or when the $\mathrm{Ca}_{\mathrm{v}}$ channels were blocked by veratridine [215]. After removal of Glut 2 in mice, the increase of GLP-1 in the blood during the OGTT was blunted whereas the increase of GIP was not changed [51]. The relevance of GLUT2/Glut2-mediated glucose uptake for GLP-1 secretion was approved for humans. D-Glucose-dependent GLP-1 secretion by isolated mucosa of healthy individuals was affected by phloretin, the ATP synthesis inhibitor 2,4 dinitrophenol, the $\mathrm{K}_{\mathrm{ATP}}$ channel blocker tolbutamide, and the L-type $\mathrm{Ca}^{2+}$ channel blocker nifedipine [382]. At variance, in patients with type 2 diabetes, no effects of the $\mathrm{K}_{\text {ATP }}$ channel inhibitors glibenclamide and repaglinide on secretion of GLP1 and GIP during OGTTs were observed [371].

In rats and humans, secretion of GLP-1 was also observed after luminal application of D-fructose [321, 370]. Because fructose is transported by the facilitated diffusion transporters GLUT5/Glut5 and GLUT2/Glut2 but not by SGLT1/Sglt1, GLP-1 secretion is most probably not triggered by transportrelated depolarization of the luminal membrane. D-Fructoseinduced secretion is probably mediated by effects of intracellular D-fructose on metabolism leading to increased intracellular ATP.

The sweet taste receptor T1R2/T1R3 is supposed to be involved in secretion of GLP-1 by high D-glucose concentrations. It may also mediate secretion of GIP and GLP-1 by artificial sweeteners; however, conflicting data concerning this function have been reported. In humans, GLP-1 secretion after gastrical or duodenal application of a D-glucose bolus was impaired by sweet taste receptor inhibitor lactisole [128]. In mice, the stimulation of GLP-1 secretion after gavage with D-glucose was blunted when the sweet taste receptor component T1R3 or the G protein subunit $\alpha$ transducin had been removed [178]. In perfused rat small intestine, the secretion of GIP and/or GLP-1 was(were) increased by luminal application of artificial sweeteners [215, 251]. In contrast, no stimulation of GLP-1 secretion by artificial sweeteners was observed in Zucker diabetic fatty rats and in healthy humans $[121,249,370,425]$. Also, in mice, no increase of plasma GIP was observed 15 min after gavage with the artificial sweetener saccharin [282].

\section{Roles of glucose transporters for secretion of neurotensin}

Neurotensin is produced by endocrine cells in intestine with low expression in the duodenum, caecum, and colon; intermediate expression in the jejunum; and high expression in the ileum $[55,214,320]$. EECs expressing neurotensin have been designated as $\mathrm{N}$ cells [320]; however, since coexpression of GLP-1, GIP, or CCK with neurotensin has been observed $[101,143,386], \mathrm{N}$ cells can be considered subpopulations of $\mathrm{L}, \mathrm{K}$, or I cells. Neurotensin induces small intestinal muscle contractions, promotes arterial hypotension, and increases plasma D-glucose by affecting hepatic carbohydrate metabolism [56, 119]. Stimulation of small intestinal secretion of neurotensin by luminal D-glucose was demonstrated in rat and human [79, 213, 214]. In rat, evidence was provided that Sglt1 and Glut2 are involved in glucose sensing and that Dglucose metabolism, $\mathrm{K}_{\mathrm{ATP}}$ channels, and $\mathrm{Ca}_{\mathrm{v}}$ channels may participate. It was observed that perfusion of rat small intestine with $5 \mathrm{mM}$ and $250 \mathrm{mM}$ D-glucose resulted in 4.4- and 12fold stimulation of neurotensin secretion [79]. The stimulation at both glucose concentrations was prevented by luminal application of phlorizin whereas it was not changed when phloretin was applied from the basal cell side. These observations suggested a pivotal role of SGLT1/Sglt1 for neurotensin secretion at low and high luminal D-glucose concentrations. Similar to D-glucose-induced stimulation of GLP-1 secretion by $L$ cells, D-glucose-induced stimulation of neurotensin secretion is supposed to be due to Sglt1-mediated D-glucose transport plus Sglt1 promoted incorporation of Glut2 into the luminal membrane that becomes relevant at high glucose concentrations. An increase of plasma neurotensin after gavage with D-glucose was also observed in humans [213]. Using perfused rat small intestine, the mechanism how high luminal D-glucose concentrations stimulate the secretion of neurotensin was investigated [214]. By luminal application 
of 1.1 M D-glucose neurotensin secretion was stimulated whereas vascular application of D-glucose was not effective. D-Glucose-mediated stimulation of neurotensin secretion was totally abolished in the presence of luminal phlorizin and was decreased by about $90 \%$ in the presence of luminal phloretin. Stimulation of neurotensin secretion by luminal D-glucose was also abolished when ATP synthesis had been blocked with 2-4-dinitrophenol, when $\mathrm{K}_{\mathrm{ATP}}$ channels had been opened by diazoxide, or when $\mathrm{Ca}_{\mathrm{v}}$ channels had been blocked with veratridine. Luminal application of artificial sweeteners did not induce neurotensin secretion. The data indicate that D-glucose-mediated stimulation of neurotensin secretion by EEC cells is similar to GLP-1 secretion by L cells.

\section{Diseases caused by or associated with malfunctions of glucose transporters in the small intestine}

\section{Glucose-galactose malabsorption}

Glucose-galactose malabsorption (GGM) is a rare congenital autosomal recessive disease with severe neonatal diarrhea and water loss due to the inability of intestinal D-glucose and Dgalactose absorption. Without therapy, the outcome is fatal. All symptoms and pathophysiological consequences of GGM can be avoided by D-glucose and D-galactose-free diets that may contain D-fructose, allowing a normal life without GGMrelated health problems. GGM has been first described in 1962 [225, 242]. About one decade later, the underlying defect in GGM was attributed to defective $\mathrm{Na}^{+}$-D-glucose cotransport in the small intestinal $\mathrm{BBM}$ and recessive inheritance was detected [103, 262, 376]. In 1991, Wright and coworkers provided evidence that genetic loss-of-function single nucleotide variations (SNVs) in both DNA strands of the SLC5A1 cause GGM whereas heterozygous carriers have no clinical symptoms [400]. Meanwhile, the SLC5A1 genes of more than hundred GGM patients have been sequenced [187, 258, 423, 424]. With few exceptions, SNVs have been observed in SLC5A1. They cause missense, nonsense, frame shift and splice site mutations, and mutations in the promotor. Most missense mutations result in defects of SGLT1 trafficking to the plasma membrane whereas some cause loss of transport function [187, 258, 424]. The nonsense, frame shift, and splice site mutations lead to truncated protein whereas the mutations in the promoter induce decreased transcription.

The few cases in which GGM patients did not contain SNVs in SLC5A1 could be due to genetic defects in proteins that are selectively involved in targeting of SGLT1 to the plasma membrane. Malabsorption of D-glucose and D-galactose may also be associated with more general defects in transporter expression that are associated with malabsorption of additional monosaccharides. For example, mutations in the gene encoding neurogen-3 that lead to depletion of enteroendocrine cells cause monosaccharide malabsorption [414]. The severe diarrhea observed in humans with neogenin-3 mutants could be prevented by diets that do not contain D-glucose, D-galactose, and D-fructose. The sensitivity of diarrhea to $\mathrm{D}$-fructose indicates that the defect is not limited to SGLT1. A decrease of SGLT1 abundance in the BBM can be also induced by defects of proteins that are involved in sorting or trafficking. Such defect could be relatively specific for SGLT1 because sorting in the Golgi, and trafficking of plasma membrane transporters in enterocytes shows some specificity for individual transporters. For example, protein RS1 (RSC1A1) is critically involved in the D-glucose-dependent short-term regulation of SGLT1 in the small intestinal BBM and D-glucose absorption was increased in RS1 knockout mice [286].

The concept that loss-of-function SNVs in SLC5A1 are the main cause for GGM was verified by removal of Sglt1 in mice [132]. In Sglt1 knockout mice, small intestinal glucose absorption was reduced by more than $95 \%$. After birth and in the preweaning period, SGLT1 knockout mice appeared to be healthy at variance to newborn humans; however, they developed severe diarrhea and died within 2 weeks when they were kept on standard diet after weaning. As observed in humans with GGM, diarrhea disappeared and the Sglt1 knockout mice developed well when they were fed with a D-glucose- and Dgalactose-free diet. The difference concerning neonatal diarrhea in humans with GGM compared to Sglt1 knockout mice is supposed to be due the expression of Sglt3b in mice. This rodent-specific Sglt subtype is located in the small intestinal $\mathrm{BBM}$ and is able to mediate phlorizin-inhibitable D-glucose uptake [10, 132].

In several newborn humans with GGM, nephrocalcinosis and nephrolithiasis were the diagnosis $[1,2,102,288,365$, 388]. Future studies are necessary to clarify whether nephrocalcinosis associated with GGM is due to metabolic acidosis during the diarrhea and/or to comorbidity factors that promote hypercalcemia [102, 288] and/or tubular acidification [102].

\section{Fanconi-Bickel syndrome}

Fanconi-Bickel syndrome (FBS) is a rare congenital disease with the key symptoms hepatomegaly, nephropathy, postprandial hyperglycemia, fasting hypoglycemia, and growth retardation [106, 337]. FBS is occasionally linked with intolerance to D-glucose and D-galactose caused by impaired small intestinal carbohydrate absorption that may lead to diarrhea after ingestion of carbohydrate-rich food [337]. Sequencing the SLC2A2 gene encoding GLUT2 in 49 patients, SNVs causing inactive or truncated transporters were detected which were homozygous in $74 \%$ of the patients $[336,338,339]$. This 
indicates that a defective function of GLUT2 is the predominant cause for FBS.

The impaired small intestinal absorption of D-glucose and D-galactose with unchanged absorption of D-fructose observed in some patients with FBS suffering from diarrhea is consistent with the presumed function of GLUT2 for basolateral release of monosaccharides from enterocytes and/or for GLUT2-mediated monosaccharide uptake across the BBM at very high glucose concentrations. However, in most patients, the function of GLUT2 in the small intestine is probably partially compensated by upregulation of other glucose transporters in IECs like in mice in which Glut2 was selectively removed in the small intestine [345].

\section{Fructose intolerance and fructose malabsorption}

\section{General considerations}

Fructose malabsorption is one type of fructose intolerance. The umbrella term "fructose intolerance" comprises situations in which D-fructose becomes available for bacterial fermentation leading to diarrhea, flatulence, pain, and intestinal cramps $[13,27,130,313]$ and in which high D-fructose concentrations are observed in the portal vein that exhibit pathogenetic effects in the liver. D-Fructose malabsorption can be due to insufficient D-fructose uptake into enterocytes relative to the amount of D-fructose in the intestinal lumen. In addition, it can be caused by insufficient intracellular fructolysis resulting in high intracellular D-fructose concentrations that also decrease Dfructose uptake (see Fig. 7). In this case, the concentration of D-fructose in the portal vein is increased and large amounts of D-fructose may enter hepatocytes. This may lead to hepatic steatosis, nonalcoholic steatohepatitis, nonalcoholic fatty liver disease (NAFLD), and/or metabolic syndrome [241]. The incidence of fructose intolerance is correlated with the amount of sucrose and free D-fructose supplied with the food. DFructose in the food has been increased dramatically since the nutrients and beverages were enriched with sucrose. In 2004, male human Americans ingested on average more than $70 \mathrm{~g}$ of D-fructose per day in the age of 15-25 years and more than $30 \mathrm{~g}$ per day in the age of 1-3 years [93]. In humans, the capacity for small intestinal absorption of D-fructose is much smaller than the capacity for D-glucose absorption; it is very small after birth and increases later on in response to D-fructose in the diet [93]. In a population of healthy adults, an intestinal load of $25 \mathrm{~g}$ D-fructose was only absorbed completely by about one-half of the individuals [360]. However, in combination with D-glucose, the capacity for D-fructose absorption is increased due to additional fructose uptake in response to luminal water reabsorption associated with $\mathrm{Na}^{+}$-Dglucose cotransport $[159,399]$. SNVs with impact on GLUT5 or on enzymes that are critical for fructolysis promote fructose intolerance.

\section{Isolated fructose malabsorption}

Individual pediatric cases of abdominal pain, colicky cramps, and diarrhea after ingestion of low amounts of D-fructose that resolve upon fructose-free diet have been assigned as isolated fructose malabsorption (IFM) [27, 411, 418]. The absence of hepatic symptoms and the occurrence of intestinal symptoms after ingestion of low amounts of D-fructose in toddlers supported the hypothesis that the observed symptoms were due to an isolated defect in absorption. Studies with mice in which Glut5 was removed indicated that GLUT5/Glut5 is pivotal for D-fructose absorption and that malfunction of GLUT5/Glut5 can induce intestinal symptoms observed in IFM [28]. In the presence of high dietary D-fructose, small intestinal fructose absorption was $\sim 75 \%$ lower in adult Glut5 knockout mice compared to adult wild-type mice whereas the fructose concentration in the serum was $\sim 90 \%$ lower. Seven days after receiving the high-fructose diet, the Glut5 knockout mice developed a greatly enlarged and dilated colon in contrast to the wild-type mice.

Attempts were made to determine whether mutations in GLUT5 are the main cause for fructose malabsorption observed in IFM. In one study, employing 8 patients with IFM no SNVs were detected in the coding region of SLC2A5 [418]. In another study performed on 11 patients with diagnosed functional gastrointestinal disorder (FGID) showing fructose malabsorption and 15 healthy individuals, similar amounts of GLUT5 mRNA were observed in small intestinal biopsies [420]. The data suggest that functional defects in GLUT5 or decreased transcription of GLUT5 is not the predominant cause for fructose malabsorption in IFM and/or FGID. To exclude that posttranscriptional defects in GLUT5 expression such as impaired translation and/or trafficking cause IFM, measurements of GLUT5 protein in the BBM of small intestinal biopsies of patients with IFM must be performed. Of note, the intestinal expression of GLUT5 is very low in human newborns and increases slowly after birth in response to Dfructose in the food. Hence, a delayed upregulation of GLUT5 after birth could be one reason for IFM in toddlers [93].

\section{Fructose intolerance due to genetic defects in aldolase B}

Hereditary fructose intolerance (HFI) due to dysfunction of aldolase B (ALDOB) is a long known and well investigated disease $[9,61,74,75,153]$. ALDOB is expressed in the small intestine, liver, and kidney and catalyzes the cleavage of $\mathrm{D}$ fructose-1-phosphate formed from D-fructose into D-glyceraldehyde (GA) and dihydroxyacetone phosphate (DHAP) that enters gluconeogenesis (GNG) (Fig. 8). ALDOB is regulated in a tissue-specific manner by dietary carbohydrates including D-fructose and by hormones [276]. Failure of ALDOB in enterocytes results in fructose malabsorption due to a disturbed metabolism of $\mathrm{D}$-fructose leading to severe abdominal 
symptoms after ingestion of high amounts of D-fructose. Disturbed hepatic GNG due to ALDOB failure may cause hypoglycemia in patients with HFI. If newborns and toddlers with HFI are not put on a fructose-free diet, they develop severe hepatic and renal injury, remain retarded in growth, and may die.

\section{Fructose intolerance including fructose malabsorption due to malfunction of ChREBP}

When ChREBP knockout mice or mice with isolated removal of ChREBP in the small intestine were kept on high-fructose diet, they showed a decreased small intestinal expression of Glut5 compared to wild-type mice and exhibited intestinal symptoms of fructose malabsorption such as dilatation of the intestine, diarrhea, and loss of weight [197, 230, 283]. The data suggest that ChREBP is critically involved in the D-fructose-dependent upregulation of GLUT5/Glut5. ChREBP is a transcription factor that is essential for adaption of metabolic programs in response to availability of carbohydrates, in particular to availability of D-fructose. ChREBP is upregulated by high-fructose diet [196]. It is critically involved in fructosedependent stimulation of enzymes like ketohexose kinase (KHK), aldolase B (ALDOB), TRIOK, fructose-1,6biphosphatase, glucose-6-phoshatase (G6PC), and lactate dehydrogenase (LDH) that are pivotal for fructolysis, gluconeogenesis, and/or lipogenesis (Fig. 8) [76, 170, 196, 197]. In the liver ChREBP, is supposed to be involved in emergence of dyslipidemia, metabolic syndrome, and NAFLD during high fructose consumption [3, 229, 241]. In genome-wide association studies, SNVs in ChREBP have been linked to hypertriglyceridemia, increased liver enzymes in the blood, and NAFLD [3]. Considering the role of ChREBP in D-fructosedependent upregulation of GLUT5/Glut5 and of enzymes involved in fructolysis and GNG, it is expected that SNVs in ChREBP are associated with fructose malabsorption after fructose-rich meals.

\section{Effects of diabetes on glucose transporters in the small intestine}

\section{General considerations}

Considering the above-described effects of dietary D-glucose and of plasma insulin on expression and/or distribution of glucose transporters in the small intestine, it is expected that the expression and/or distribution of glucose transporters in the small intestine is changed during diabetes. This issue has been investigated in several animal models of diabetes and in humans.

\section{Effects of diabetes observed in animal models}

\section{Streptozotocin- or alloxan-induced type 1 diabetes mellitus in rodents}

In the 1970s, it was reported that 4-140 days after treatment with alloxan or STZ that induce type 1 diabetes mellitus (T1DM) by destroying pancreatic $\beta$ cells, the absorption of D-glucose or 3-ODG was increased [163, 246, 343]. Twenty to 140 days after alloxan or STZ treatment, small intestinal mass and villous surface area were increased [246, 343].

More than one decade later, the effects of STZ-induced T1DM on small intestinal glucose transporters were investigated in rats. In one study in which mRNA abundance of Sglt1 was determined 2-60 days after application of STZ, Sglt1 mRNA was increased after 30 days [264]. In another study, functional Sglt1 protein in rat small intestine was determined 14-60 days after application of STZ by measuring $\left[{ }^{3} \mathrm{H}\right]$ phlorizin binding [109]. In the jejunum, no effect on phlorizin binding was observed after 14 days; however, phlorizin binding was increased about 10 -fold after 60 days. Additional studies on the effects of STZ on Sglt1-related immunoreactivity and on transport in rat small intestine were performed employing intact tissue and isolated BBMs [47, 83, 97, 218]. Whereas no upregulation of Sglt1 was detected 7 days after STZ application, upregulation of Sglt1-related immunoreactivity and Sglt1-mediated D-glucose transport was observed 2-6 weeks after STZ treatment.

Measuring mRNA of Glut2 and Glut5 in rat small intestine 2-60 days after STZ treatment, Glut2 mRNA abundance was increased after 2 days and reached a maximal level after 10 days whereas Glut5 mRNA was decreased after 10 days [264]. In contrast it was observed by another group that Glut5 mRNA in rat small intestinal mucosa was upregulated 7 days after STZ treatment [58]. Upregulation of Glut2 mRNA and Glut 5 mRNA in rat small intestine was also observed 6 weeks after STZ application [47].

Corpe and coworkers investigated the effects of STZ on plasma membrane abundance and function of Glut2 and Glut5 in rat small intestine [70]. They measured transporterrelated immunoreactivity in isolated BBMs and BLMs and determined D-fructose absorption employing small intestinal perfusion in vivo and in vitro. Five and 10 days after application of STZ, Glut2 was upregulated in the BLM and showed up in the BBM. In addition, Glut5 in the BBM was upregulated. The changes were associated with increased and decreased Glut5-mediated D-fructose absorption in vitro and in vivo, respectively. Whereas the increased absorption observed in vitro is consistent with the changed transporter concentrations in the BBMs and BLMs, the decreased D-fructose absorption observed in vivo may be due to changes of the intracellular carbohydrate metabolism. For example, it has been described that small intestinal expression of G-6-P was 
increased in STZ-induced diabetes [309]. Of note, STZinduced upregulation of Sglt1, Glut2, Glut5, and G-6-P in the small intestine could be reversed by insulin $[47,218,252]$.

\section{Rodent models of type 2 diabetes}

$O b / o b$ mice that do not express leptin, leptin receptor-deficient $d b / d b$ mice, and Zucker diabetic fatty rats with a nonfunctional $d b$ receptor and a mutation affecting transcription in pancreatic $\beta$ cells are frequently employed rodent models of type 2 diabetes mellitus (T2DM). In these diabetic models obesity, hyperglycemia, hyperlipidemia, hyperinsulinemia, and insulin resistance were observed [416].

Five to 10-week-old $o b / o b$ mice are hyperphagic, obese, and hyperinsulinemic and exhibit hypertrophy and length increase of small intestine which persist in 20-week-old mice [90, 146, 272]. Absorption of $10 \mathrm{mM}$ and $28 \mathrm{mM}$ D-glucose per unit small intestinal length in 10 and 20-week-old ob/ob mice was higher compared to lean wild-type mice, whereas Dglucose absorption related to small intestinal weight was not different [272]. The data suggest that the involved transporters Sglt1 and Glut2 in the enterocytes are not upregulated. Consistently, a similar Sglt1-related immunoreactivity was observed in the BBM of 3-6-month-old ob/ob mice compared to heterozygous controls [90].

$D b / d b$ mice have a defective leptin receptor and increased plasma concentrations of leptin. Similar to $o b / o b$ mice, $d b / d b$ mice are hyperphagic, obese, hyperglycemic, and hyperinsulinemic $[240,416]$. In 3-6-month-old $d b / d b$ mice, small intestinal length and mucosal mass were increased due to cellular proliferation [90]. In small intestinal enterocytes of $d b / d b$ mice at similar age, Sglt1 mRNA and total Sglt1 protein were increased [90, 240].

In 3-4-month-old obese Zucker diabetic fatty rats with large increased plasma glucose levels compared to lean wild-type mice, no differences in small intestinal mRNA and protein levels of Sglt1, Glut2, and Glut5 were detected [71].

\section{Effects of type 2 diabetes in humans}

Expression and distribution of SGLT1, GLUT2, and GLUT5 in duodenal mucosal biopsies performed in the morning after overnight fasting were compared between patients with T2DM and healthy individuals at the same age [98]. The T2DM patients had a mean age of 58 years and most of them were on antidiabetic diets and underwent treatment with sulfonylurea drugs or metformin, whereas the control group received standard diet. In the duodenal mucosa of the T2DM patients, about 3-fold upregulation of SGLT1, GLUT2, and GLUT5 was observed on the mRNA level. In the BBM, only SGLT1- and GLUT5-related immunoreactivity was detected which was approximately 4-fold higher in the T2DM patients compared to the control group. The data suggest an upregulation of SGLT1, GLUT2, and GLUT5 and no BBM location of GLUT2 in treated T2DM patients between meals. The upregulation may be due to increased transcription.

In duodenal mucosal biopsies of newly diagnosed, so far untreated T2DM patients with a mean age of 71, a significant increase of L and K cells expressing SGLT1 was observed [393].

\section{Role of SGLT1 in enteric inflammation}

\section{General considerations}

\section{Signaling in enterocytes during inflammation}

The gastrointestinal tract contains a network of surveillance systems for host defense that include enterocytes, EECs, and immune cells with receptors recognizing pathogens [161, 291]. Signaling in IECs is mediated by nutrient components, commensal microflora, and pathogens that may induce intestinal inflammation. The pathogens include bacterial lipopolysaccharide (LPS), components of fungi, and protozoic parasites. Pathogenic signature structures are recognized by receptors including Toll-like receptors (TLRs) in IECs, EECs, and immune cells $[8,54,291]$. TLRs in IECs activate kinases including interleukin-1 receptor-associated kinases, MAP kinases, and PKC [235]. MAP kinases promote migration of $\mathrm{NF} \kappa \mathrm{B}$ into the nucleus where NFKB stimulates the expression of inflammatory cytokines [235, 275, 427]. Excreted cytokines activate and/or recruit immune cells like Th2 lymphocytes. Activated Th2 lymphocytes secrete interleukins that modulate immune response and downregulate the expression of TLRs in a feedback loop [273]. This may cause a permeability increase of the small intestinal epithelial cell layer. In addition, a decreased proliferation and increased apoptosis of IECs is observed during inflammation.

\section{SGLT1-mediated signaling in enterocytes}

Reflecting upon the role of SGLT1/Sglt1 in enteric inflammation, SGLT1/Sglt1-mediated signaling in the small intestine must be understood because cross-talk with inflammatory signaling is expected. Above, it has been described how membrane polarization by SGLT1/Sglt1 is supposed to induce trafficking of GLUT2/Glut2 to the BBM of IECs (Fig. 6). This includes activation of a voltage-dependent $\mathrm{Ca}^{2+}$ channel, activation of PKC $\beta I I$, and phosphorylation of myosin II. It has been reported that SGLT1/Sglt1-mediated membrane depolarization also promotes recruitment of the $\mathrm{Na}^{+}-\mathrm{H}^{+}$-exchanger (NHE) 3 into the BBM; however, different intracellular signaling has been described. In this case, signaling involves phosphorylation of MAP kinase kinase 2 by p38 MAP kinase, downstream phosphorylation of RAC-beta serine/threonine- 
protein (Akt2) kinase, and phosphorylation of cytoskeletal linker protein ezrin by Akt2 [167, 292, 356]. Phosphorylated ezrin binds to both actin and the C-terminus of NHE3 which is supposed to promote the incorporation of NHE3 into the BBM [439].

\section{Effects of SGLT1 on enteric inflammation by bacterial lipopolysaccharide}

\section{Experiments with intestinal human cell lines}

When monolayers of SGLT1-transfected Caco-2 cells were incubated with LPS in the presence of $5 \mathrm{mM}$ D-glucose, DNA fragmentation, and caspase-3 cleavage indicating apoptosis and paracellular permeability were increased [432]. These effects were attenuated and the anti-apoptotic proteins $\mathrm{B}$ cell lymphoma (Bcl)-2 and $\mathrm{Bcl}-\mathrm{X}(\mathrm{L})$ were increased when the treatment with LPS was performed in the presence of $25 \mathrm{mM}$ D-glucose. The D-glucose-dependent cytoprotection was blunted in the presence phlorizin. Hence, it was concluded that an increased SGLT1-mediated glucose transport at high glucose concentrations represents a protective mechanism for LPS-induced apoptosis. Noteworthy, it was also observed that LPS promoted recruitment of SGLT1 to the plasma membrane at $25 \mathrm{mM}$ D-glucose [433].

A protective SGLT1-dependent effect of glucose on LPS cytotoxicity was also observed in human colon carcinoma HT29 cells that express SGLT1 endogenously [292]. When HT29 cells that had been cultivated in the presence of $5 \mathrm{mM}$ D-glucose were treated with LPS, a smaller release of IL-8/ keratinocyte-derived chemokine and a blunted increase of nuclear migration of NFkB were observed compared to HT29 cells that had been cultivated with $1 \mathrm{mM}$ D-glucose. The glucose effect on NFKB activation promoting apoptosis was dependent on phosphorylation of Akt2. The protective effects of D-glucose on apoptosis were abolished by phlorizin and reduced when the expression of SGLT1 was decreased by siRNA technology. Noteworthy, the protective effect of D-glucose was independent from metabolism because it was also observed when the cultivation and LPS treatment was performed in the presence of $5 \mathrm{mM} 3-\mathrm{OMG}$ [292]. The data suggest that SGLT1-mediated glucose uptake affects LPSinduced intracellular signaling promoting apoptosis.

\section{Experiments with mice}

Protective effects of Sglt1-mediated D-glucose uptake into IECs on intestinal inflammation induced by oral application of LPS and on endotoxic shock by i.p. injection of LPS were demonstrated in mice [292]. After 5-day treatment with LPS by daily gavage, extensive damage of ICEs was observed that was due to apoptosis. The damage of the ICEs was prevented when a bolus of D-glucose or 3-OMG was applied together with LPS but not when the animals had been orally treated with phlorizin prior to gavage with LPS and D-glucose. To investigate the impact of Sglt1-mediated glucose uptake into ICEs on endotoxic shock, an animal model was employed in which a high dose of LPS was i.p. injected together with Dgalactosamine [127]. When mice received $0.25 \mathrm{mg} / \mathrm{kg}$ LPS together with $1 \mathrm{~g} / \mathrm{kg}$ D-galactosamine, a dramatic serum increase of tissue necrosis factor (TNF)- $\alpha$ and chemokine (C-X$\mathrm{C}$ motif) ligand $1(\mathrm{KC})$ was observed within $4 \mathrm{~h}$ and all animals died within $36 \mathrm{~h}$ [292]. However, when the animals were pretreated by gavaging with D-glucose or 3-OMG $1 \mathrm{~h}$ prior to the LPS/D-galactosamine injection, the increase of TNF- $\alpha$ and $\mathrm{KC}$ was largely reduced and the animals survived. The protective effects of D-glucose and 3-OMG were abolished when the animals had been pretreated with phlorizin. Noteworthy, no protective glucose effect on the LPS/D-galactosamine-induced endocytotic shock was observed after i.p. injection of Dglucose. The protection by glucose gavage was correlated with a 18-fold serum increase of the anti-inflammatory cytokine IL-10 $4 \mathrm{~h}$ after the LPS/D-galactosamine treatment. The data indicate that the LPS/D-galactosamine-induced endotoxic shock initiated by small intestinal damage can be prevented by Sglt1-mediated D-glucose uptake independently of metabolism.

A dansyl C-glucoside (see called compound 5 in [220]) later on called BLF501 [53] was synthesized that is predicted to interact with Sglt1. BLF501 abolished the LPS-induced production of interleukin 8 (IL-8) in the human cell line HT29 similar to high D-glucose concentrations but was not effective when the expression of Sglt1 had been decreased by siRNA [220,292]. These observations suggest that binding of BLF501 to SGLT1/Sglt1 triggers SGLT1/Sglt1-mediated intracellular signaling similar to SGLT1/Sglt1-mediated Dglucose cotransport. Noteworthy, the endocytotic shock after i.p. application of LPS and D-galactosamine was bunted when the animals had been gavaged with BLF501. Whereas all animals died within $24 \mathrm{~h}$ without pretreatment, all animals survived after BLF501 gavage [220].

\section{Effects of SGLT1 during infection with giardia duodenalis}

Giardia duodenalis is a waterborne protozoan pathogen of humans and domestic animals that causes diarrhea worldwide [340]. Exposition with giardia duodenalis trophozoites induces structural and permeability changes in the small intestine due to increased apoptosis and caspase activity [293, 348, $392,398]$. Confluent cell layers of Caco- 2 cells that had been transfected with rabbit Sglt1 were employed to investigate whether Sglt1-mediated D-glucose uptake has an impact on apoptosis after incubation with giardia duodenalis trophozoites or sonicates of the trophozoites [434]. After cultivation of the Caco 2 cells with $5 \mathrm{mM}$ D-glucose, a higher degree of 
caspase-3-dependent apoptosis was induced by giardia duodenalis-derived components compared to cultivation with $25 \mathrm{mM}$ D-glucose. The protective effect of high D-glucose was dependent on Sglt1-mediated $\mathrm{Na}^{+}-\mathrm{D}$-glucose cotransport during incubation with the giardia duodenalis sonicates since it was blunted when the incubation was performed in the presence of phlorizin. Of note, Sglt1-mediated AMG uptake into Caco2 cells and Sglt1 abundance in the plasma membrane were upregulated by giardia duodenalis sonicates. The data suggest that SGLT1/Sglt1-mediated membrane depolarization during D-glucose transport triggers signaling events that interact with the signaling cascade involved in giardia duodenalismediated apoptosis.

\section{Implication of SGLT1 on gastrointestinal mucositis during chemotherapy}

Oral and gastrointestinal mucositis are serious side effects of many forms of radiotherapy and chemotherapy. Complex pathophysiologic processes are involved that include damaging of epithelial and immune cells and affect their complex interactions [364]. Changes in proliferation, apoptosis, and/or necrosis of IECs and changes in their cytoskeleton architecture were associated with drug-induced mucositis in the small intestine [53, 364]. Data obtained by two experimental setups suggest that SGLT1/Sglt1-mediated signaling influences effects of cytostatic drugs in the small intestine. Using confluent SGLT1 expressing LLC-PK 1 cells grown in the presence of $5.6 \mathrm{mM}$ D-glucose as model, it was observed that the electrical resistance of the cell layer was decreased and the percentage of necrotic cells was increased after 1-h incubation with cisplatin [172]. These effects were largely attenuated when the incubation with cisplatin was performed in the presence of phlorizin. Rumio and coworkers employed a mouse model in which intestinal mucositis was induced by i.p. injection of doxorubicin (DXR) or of DXR plus 5-fluorouracil (5-FU) and studied effects of oral application of the dansyl C-glucoside BLF501 on small intestinal morphology, on proliferation of IECs, and/or on a marker for apoptosis [53]. BL1501 is supposed to interact with SGLT1/Sglt1 and was shown to have a similar protective effect on LPS-induced endotoxic shock in mice as Sglt1-mediated glucose transport (see above). Seventy-two hours after a single i.p. injection of DXR, the number of proliferating IECs was reduced by $65 \%$ whereas the number of proliferating IECs was not altered when the animals were gavaged at the same time with BLF501 [53]. A three-times weekly i.p. application of DXR plus 5-FU resulted in dramatic morphological changes in the small intestine such as villus atrophy, reduction of villus length and loss of the BBM, and increase of caspase- 3 expression. All these effects were not observed when the animals were gavaged with BLF501 during the DXR/5-FU injections. The experiments suggest that BLF501 activates SGLT1/Sglt1-mediated intracellular signaling which leads to protection of the IECs from DXR/5-FU injury.

\section{Small intestinal glucose transporters and therapeutic measures}

\section{Oral rehydration therapy}

Diarrheal diseases represent a global health threat in different societies. In developing countries, infection by bacteria, such as enterotoxigenic and enteropathogenic E. coli, Salmonella, Shigella, and Vibrio cholerae, and infection by various parasites cause millions of deaths. In industrial societies, infection by resistant bacteria and ingestion of food that is contaminated with bacterial toxins cause major problems. In 1968, it was discovered that oral ingestion of D-glucose-rich solutions could effectively replace intravenous infusion of large amounts of fluids to prevent life-threatening dehydration during cholera infection $[157,306]$. After introducing and establishing the oral rehydration therapy (ORT) in developing countries for treatment of severe diarrhea caused by infections with V. cholera, rotavirus, E. coli, and Yersinia, countless lives were saved $[312,409]$. The original oral rehydration solution contained $75 \mathrm{mM} \mathrm{NaCl}, 75 \mathrm{mM}$ D-glucose, $20 \mathrm{mM}$ $\mathrm{KCl}$, and $10 \mathrm{mM}$ sodium.

For diarrhea caused by various infections, effectiveness of ORT is mainly due to water absorption associated with SGLT1-mediated cotransport of sodium and D-glucose. Whereas SGLT1-mediated water uptake across the BBM has been studied in some detail, it is not understood how water reaches the intercellular space. In a first step, SGLT1mediated $\mathrm{Na}^{+}-\mathrm{D}$-glucose cotransport across the BBM promotes water uptake into the enterocytes. Expressing human SGLT1 in oocytes Loo and coworkers observed that SGLT1mediated uptake of one molecule D-glucose was associated with uptake of 260 molecules of water [245]. They hypothesized that human SGLT1 translocates water together with $\mathrm{Na}^{+}$ and D-glucose. However, Lapointe and coworkers observed that SGLT1-mediated D-glucose uptake into oocytes expressing human SGLT1 precedes water uptake and showed that AMG uptake by SGLT1 generated a local osmotic gradient that is sufficient to drive passive water influx across the BBM $[96,126,226]$. Measuring the water permeability of confluent monolayers of MDCK cells transfected with human SGLT1, it was observed that passive water permeability was orders of magnitude larger than water permeability associated with SGLT1-mediated glucose uptake [105]. Under the restriction that MDCK cell monolayers may not represent IEC layers sufficiently well, this observation suggests that transcellular water movement is small and cannot explain the effect of ORT. Most probably, SGLT1-mediated increase of sodium and D-glucose in IECs stimulates efflux of sodium and D- 
glucose across the lateral membranes via the Na, K-ATPase, and GLUT2, respectively. The high osmolarity in the intracellular spaces is supposed to promote water flux across the tight junctions [228, 367].

The oral rehydration solution proposed by the WHO has been modified by recommending a reduced osmolarity and a smaller concentration of D-glucose [360]. In addition, it has been proposed to include starch and $\mathrm{Zn}^{2+}[33,164,359]$. Discussing the role of SGLT1 for oral rehydration during diarrhea caused by infections, it should be considered that sodium uptake into enterocytes is also mediated by the $\mathrm{Na}^{+}$$\mathrm{H}^{+}$-exchanger NHE3 and that infections by enteropathogenic E. coli and rotavirus are associated with a decreased expression of SGLT1 in enterocytes [80, 82, 144].

\section{Parenteral nutrition}

Parenteral nutrition is a life-saving medical measure that is employed in premature babies with incompletely developed intestinal functions and in adults during medical treatments of prolonged coma, sepsis, pancreatitis, intestinal malabsorption, short bowel syndrome, and severe burns. Considering the various regulations of small intestinal functions in response to luminal nutrients, effects of parenteral nutrition on small intestinal glucose absorption are expected. Consistently, it was observed in rats, piglets, and/or humans that intestinal mass, intestinal surface area, and villi length were decreased during parenteral nutrition $[41,48,73,138,181,234]$. Evidence was provided that also small intestinal absorption of amino acids and D-glucose were decreased [73, 174, 207]. The effects on transport are mainly due to the changes in intestinal morphology and intestinal mass. For example, after parenteral nutrition, absorption of 3-OMG per centimeter of the small intestine was smaller compared to enteral nutrition whereas 3OMG absorption per gram of the small intestine was larger [207]. After parenteral nutrition, the blood concentration of enterohormones such as GLP-2, GIP, and PYY were lower compared to enteral nutrition [48]. Consistent with established trophic effects of GLP-2 on the small intestine [94], evidence has been presented that application of GLP-2 or a GLP-2 agonist during parenteral nutrition reduces atrophy in the small intestine $[73,180,346]$.

\section{Treatment of type 2 diabetes with metformin}

Oral application of metformin influences D-glucose metabolism in the small intestine and changes D-glucose absorption and basolateral D-glucose uptake into intestinal tissue. After oral application of metformin to rats, an increased small intestinal glucose utilization was observed $[22,304]$. In mice, absorption of 2-deoxy-2-[ $\left[{ }^{18} \mathrm{~F}\right]$-D-glucose $\left(2-\left[{ }^{18} \mathrm{~F}\right] \mathrm{DG}\right)$ was decreased after a single oral application of metformin [165]. Consistently, positon emission tomography (PET) in mice gavaged with $2-\left[{ }^{18} \mathrm{~F}\right] \mathrm{DG}$ revealed that the absorption of $2-\left[{ }^{18} \mathrm{~F}\right] \mathrm{DG}$ was decreased after oral application of metformin [165] (L. Zubiaga and F. Francois, unpublished data). After short- and/or long-term oral application of metformin to rats and mice, uptake of i.v. applicated 2-deoxy-D- $\left[{ }^{3} \mathrm{H}\right]$-glucose or $2-\left[{ }^{18} \mathrm{~F}\right] \mathrm{DG}$ into small intestinal tissue was increased $[22,165$, 201]. In metformin-treated T2DM patients undergoing PET with i.v. injected 2-[ $\left.{ }^{18} \mathrm{~F}\right] \mathrm{DG}$, a higher intensity of PET signal in the small intestine was observed compared to T2DM patients that were not under metformin treatment [201, 287].

Some data from rodents concerning effects of metformin on abundance of Sglt1 and Glut2 in the small intestinal BBM have been reported. In the absence of luminal D-glucose, metformin decreased the BBM abundance of Sglt1 in rat small intestine whereas it increased the BBM abundance of Glut2 [335]. After luminal application of $10 \mathrm{mM}$ D-glucose in the absence of metformin, the abundance of both Sglt1 and Glut2 in the BBM was increased. Metformin decreased the elevated BBM abundance of Sglt1 in the presence of D-glucose, whereas it further increased the elevated BBM abundance of Glut2 in the presence of D-glucose. Consistently, Sglt1-mediated short-circuit current induced by $10 \mathrm{mM}$ luminal D-glucose was decreased after a 3-min preincubation with metformin [335]. The data indicate a differential interference of metformin with glucose-dependent intracellular trafficking of Sglt1 and Glut2 to the BBM that may lead to a decrease or increase of D-glucose uptake at different glucose concentrations.

Whereas the metformin-induced upregulation of basolateral uptake of 2-DOG and 2-deoxy-2-F-D-glucose (2FDG) into IECs may be due to an increase of Glut2 abundance in BLM, it is not understood why metformin decreases the absorption of 2-DOG and 2-FDG. This effect is probably independent of Sglt1 and Glut5 because these transporters do not accept 2-DOG and 2-FDG as substrates. It suggests downregulation of an additional transporter in the BBM that is critical for absorption of DOG and 2-FDG.

Recently, it was observed in mice that oral application of metformin blunted the increase of plasma D-glucose during OGTTs and that this effect was abolished in Sglt1 knockout mice but persisted in Glut2 knockout mice [165] (L. Zubiaga and F. Francois, unpublished data). These data may be explained by the requirement of Sglt1-mediated depolarization of the BBM for upregulation of Glut2 and/or a unidentified glucose transporter in the BBM and/or BLM.

\section{Bariatric surgery}

\section{Surgery procedures}

Bariatric surgery procedures have been approved as most effective medical measures to reduce body weight of morbidly obese individuals improving follow-up diseases such as heart attack, stroke, and cancer [42, 310, 342]. Bariatric surgery 
procedures turned out to improve T2DM independently of body weight reduction [263, 298, 329, 342]. Different surgery procedures are employed; however, vertical sleeve gastrectomy (VSG) and Roux-en-Y gastric bypass (RYGB) are predominantly applied (Fig. 9) [342, 366]. In VSG, most of the stomach is removed leaving a vertical tube. Hence, ingested food is not acidified and partially degraded in the stomach and rapidly delivered to duodenum. In addition, gastric regulation of bile secretion, pancreatic secretion, and appetite are abolished. In RYGB, the stomach is dissected in the very upper part. The lower part of the stomach is closed whereas the upper part is connected to the lower end of the jejunum that is dissected in its top third. The upper part of the dissected jejunum that contains the junction of the pancreatic/bile duct, is connected end to side to the distal end of the jejunum. Hence, proximal and distal alimentary limbs and a bile limb of the jejunum can be distinguished (see p.a.l., d.a.l., b.l. in Fig. 9c). Investigating the underlying mechanisms of bariatric surgery in animal models, two additional surgery procedures, duodeno-jejunal bypass (DJB) (Fig. 9d) and ileal interposition (IIP), have been studied. DJB can be considered modification of RYGB in which the removal of the stomach is omitted. It is probably less effective concerning body weight reduction and antidiabetic effect compared to RYGB [438]. In IIP, a segment of the distal ileum is interposed into the proximal jejunum exposing jejunal $\mathrm{L}$ cells to high nutrient concentrations $[20,184,297]$.

\section{Proposed functional mechanisms}

Various functional mechanisms are supposed to contribute to weight reduction and/or weight-independent antidiabetic effects of bariatric surgical procedures [160, $221,349]$. The complete panel of proposed effective mechanisms comprising five main groups are expected in RYGB. First, appetite regulation and/or energy expenditure may be changed due to omission of gastric neuronal and ghrelin-mediated signals to the brain in response to stomach removal (VSG) or to separation of the stomach from alimentary passage (RYGB). Second, small intestinal absorption of nutrients including monosaccharides that may influence energy balance, carbohydrate metabolism, and/or composition of the microbiome may be decreased or slowed down. This may be due to shortening of the alimentary path, to morphological changes in the small intestine, to decreased expression and functional activity of small intestinal nutrient transporters and/or digestive enzymes, and to the absence of bile acids and pancreatic enzymes in parts of the alimentary path. Third, the stimulation of enterohormone secretion by L cells (GLP-1, GLP-2, and PYY) and K cells (GIP) may be changed [206, 289, 298, 310, 415]. Whereas K cells are mainly located in the jejunum, $\mathrm{L}$ cells are mainly located in the ileum and colon [317, 320]. Because SGLT1/Sglt1 expressed in L and K cells is critically involved in D-glucose-dependent stimulation of enterohormone secretion by these cells, the concentration of D-glucose in the jejunum and ileum has a critical impact on enterohormone secretion. In particular, evidence has been provided that the secretion of GLP-1 during OGTTs is increased when the D-glucose concentration in the ileum is increased by reducing absorption of D-glucose in the jejunum during RYGB or DJB [183] or by an increased D-glucose concentration in the ileum by IIP [184]. Fourth, the concentrations of bile acids in part of the alimentary tract is decreased changing lipid absorption and metabolism [118, 299, 333]. Fifth, the composition of the gut microbiome is changed with impact on metabolic functions in the small intestine and the entire organism [349].
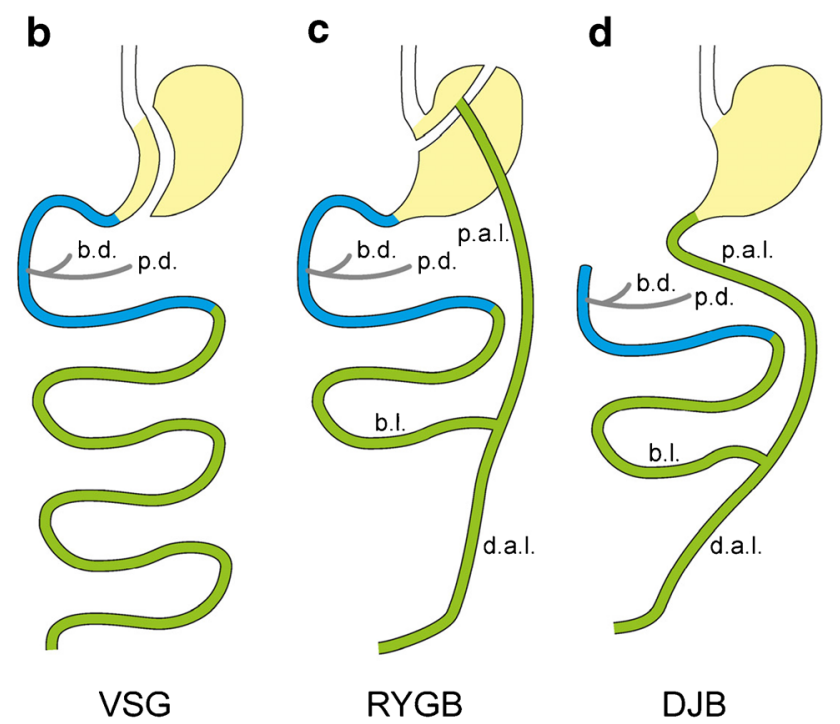

RYGB
DJB
Fig. 9 Schematic representation of the most common bariatric surgery procedures. a Normal situation. b VSG, vertical sleeve gastrectomy. c RYGB, Roux-enY gastric bypass. d DJB, duodeno-jejunal bypass. Stomach yellow, duodenum blue, jejunum green. b.d, bile duct; p.d., pancreatic duct; p.a.1., proximal alimentary limb; d.a.l., distal alimentary limb; b.1., bile limb a

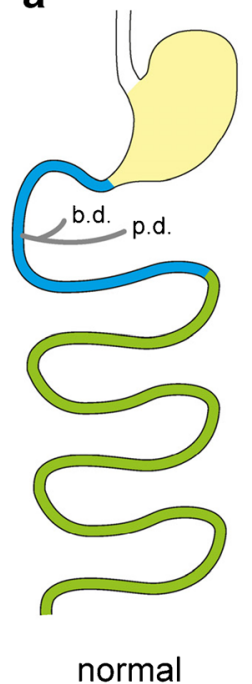




\section{Effects on intestinal structure and glucose transporters}

Alimentary-mediated stimulators trigger enterohormonemediated and/or nervous signals that promote proliferation and differentiation of small intestinal mucosa [352]. Hence, small intestinal segments that are excluded from contact with nutrients such as the bile limbs in RYGB and DJB or from contact with enzymatically digested nutrients such as the proximal alimentary limbs in RYGB and DLB undergo morphological changes $[209,426]$. These changes may be atrophic or hyperplastic including a decrease or increase of the mucosal surface, respectively. In addition, the expression and plasma membrane location of glucose transporters may be changed.

After RYGB and/or DJB in healthy and diabetic rodents, mucosal surface area and villi length in the bypassed foregut were decreased which was combined with a reduction of Sglt1-mediated AMG uptake per intestinal length [183, 209, 290, 426]. In the proximal alimentary limbs after RYGB and GJB receiving bile-less undigested food, mucosal hypertrophy with increased mucosal surface area, villi length, and increased number of L cells was observed [44, 59, 145, 274, $334,368,429]$. In rodents, also the glycolytic metabolism was increased [334]. Noteworthy, these changes were associated with downregulation of Sglt1 in the BBM and with upregulation of Glut1 in the BLM. The abundance Sglt1 mRNA and of Sglt1-mediated AMG uptake per intestinal length were decreased [183, 429]. After RYGB in rats, uptake of i.v. applied $2-\left[{ }^{18} \mathrm{~F}\right] \mathrm{DG}$ into the proximal alimentary limb was increased and the expression of Glut1 was increased whereas the expression of Glut2 was not changed [59, 334].

One month after VSG in mice, the body weight of the animals was reduced and the increase of blood glucose after OGTT was blunted [426]. In the jejunum, Sglt1 mRNA and abundance of Sglt1 protein in the BBM were decreased [426].

The duodenum and jejunum have a larger mucosal surface with longer villi compared to the ileum. When in IIP in normal and diabetic rats, the distal ileum was transposed into the proximal jejunum, hypertrophy of the transposed segment was observed [184, 202, 204]. Thereby, ileal mass including protein and DNA, mucosal surface, and villi length were increased. Sglt1 protein in the BBM and phlorizin-inhibited AMG uptake per unit length were increased so that the capacity of Sglt1-mediated glucose uptake was similar to the surrounding jejunum [184].

The data suggest that differential impacts of bariatric surgery procedures on expression of SGLT1/Sglt1 and/or GLUT1/Glut1 contribute to antidiabetic and/or antiobese effects. However, since bariatric surgery acts via various mechanisms that appear to be effective in different combinations, effects of bariatric surgery procedures on small intestinal glucose transporters may be supportive rather than critical for the achieved therapeutic effects.

\section{Glucose transporters in the small intestine as drug targets}

\section{Food compounds}

\section{Special foods and food extracts}

Antidiabetic properties have been associated with foods containing flavonoids and other phenolic compounds such as strawberries and blueberries, yerba maté, and germinated waxy black rice [68, 141, 186, 285, 328, 419]. Evidence has been presented that such foods or extracts thereof inhibit and/ or downregulate small intestinal glucose transporters. Thus, anthocyanin-rich berry extracts acutely inhibited SGLT1and GLUT2-mediated glucose transport [11, 107, 256]. In addition, berry extracts downregulated SGLT1 mRNA, GLUT2 mRNA, and GLUT2 protein within 12-16 h [11]. When normal rats or rats with alloxan-induced T1DM were gavaged during 4 weeks with extract of Yerba maté (Ilex paraguariensis), the expression of Sglt1 mRNA in the small intestine related to mRNA of $\beta$-actin was decreased [285]. Furthermore, the expression of Sglt1 and Glut2 in rats with STZ-induced T1DM was decreased on mRNA and protein levels when the food was supplemented for 8 weeks with germinated waxy black rice [186]. Although specific foods or food extracts may have beneficial effects, usage of the effective food components is preferred for practical and security reasons.

\section{Isolated food compounds}

Interactions of individual flavonoids and the glucose analogue 1-deoxynojirimycin (DNJ) present in mulberry leaves with SGLT1/Sglt1, GLUT2/Glut2, and/or GLUT5/Glut2 were tested. The measurements were performed using Xenopus laevis oocytes in which the respective transporters were expressed and in preparations of rat intestinal mucosa.

The flavonol quercetin is present in various foods such as red wine, onions, and green tee [328]. In foods, quercetin mostly occurs in glycosylated forms; however, it is deglycosylated in the small intestine [219]. In the small intestine, quercetin concentrations of up to $100 \mu \mathrm{M}$ were determined; however, since absorption of quercetin is poor, the plasma concentration does not exceed $2 \mu \mathrm{M}$ [219]. Measuring substrate-induced inward currents in voltage-clamped oocytes expressing human SGLT1, no SGLT1-mediated transport of unglycosylated or glycosylated quercetin was detected [208]. When quercetin was glycosylated at C3 or C4, SGLT1mediated uptake of AMG was inhibited with apparent $K_{\mathrm{i}}$ values of $640 \mu \mathrm{M}$ and $40 \mu \mathrm{M}$, respectively, whereas incomplete low affinity inhibition of human SGLT1 was observed with nonglycosylated quercetin [208]. Hence, inhibition of SGLT1 in the small intestine by quercetin does not appear to 
be of biomedical relevance. However, uptake of 2-DOG and D-fructose by human GLUT2 expressed in oocytes was inhibited by quercetin with $I C_{50}$ values of $13 \mu \mathrm{M}$ and $16 \mu \mathrm{M}$, respectively [219]. A similar inhibition was observed with the quercetin analog myricetin whereas less affine or no inhibition was observed with glycosylated forms of quercetin. Uptake of D-glucose or D-fructose in oocytes expressing human GLUT5 were inhibited neither by nonglycosylated quercetin nor by glycosylated quercetin and myricetin. Testing the acute effect of quercetin on an OGTT in diabetic Zucker $f a / f a$ rats, it was observed that quercetin blunted the increase of plasma D-glucose during the OGTT [363]. The data suggest an antidiabetic effect of quercetin after ingestion of high amounts of D-glucose or D-fructose when GLUT2/Glut2 is targeted to the BBM.

In Ussing chamber experiments with mouse jejunum, glucose-dependent transmucosal currents mediated by Sglt1 were decreased within few minutes after mucosal application of the anthocyanin flavonoid delphinidin [154]. Delphinidin also decreased 3-OMG absorption in mouse small intestine and in $\mathrm{Caco} 2$ cell that was correlated with oscillations of intracellular $\mathrm{Ca}^{2+}$ concentrations. In addition, data were reported suggesting that the delphinidin-mediated decrease of 3-OMG absorption in Caco-2 cells involves activation of fatty acid receptor GPR40. It was not resolved whether delphinidin inhibited SGLT1/Sglt1 or downregulated the abundance of SGLT1/Sglt1 in the BBM and whether effects on GLUT2/ Glut2 were involved.

1-Deoxynojirimycin (DNJ) is a glucose analogue occurring in mulberry leaves that inhibits $\alpha$-glucosidases and modulates hepatic metabolism [216, 237]. Effects of DNJ on OGTTs and on the amounts of Sglt1 in the BBM and of Glut2 in the BLM of IECs were investigated in healthy mice and in mice with STZ-induced T1DM [239]. DNJ was orally applicated for 3 days, twice a day, and 15 min before the OGTTs were started. In DNJ-treated mice, the increase of blood glucose during the OGTTs was blunted and the abundance of Sglt1 in the BBM and of Glut2 in the BLM after the OGTTs was decreased. It was not resolved whether the effects of DNJ on membrane abundance of Sglt1 and Glut2 were secondary to inhibition of Sglt1 or whether DNJ enters the enterocytes and exhibits intracellular effects on transporter regulation.

\section{Synthetic compounds}

\section{SGLT1 inhibitors}

In addition to selective SGLT2 inhibitors, dual inhibitors of SGLT1 and SGLT2 and selective SGLT1 inhibitors have been developed for oral treatment of T2DM. Whereas SGLT2/ Sglt2 inhibitors reduce the reabsorption of ultrafiltrated D-glucose in the kidney, inhibitors of SGLT1/Sglt1 decrease small intestinal D-glucose absorption. Sotagliflozin (LX4221) [227,
277, 436, 437] and licogliflozin [150] are effective dual inhibitors whereas mitagliflozin [175] and compounds GSK1614235 [88], LX2761 [131], and SGL5213 [176, 217] inhibit SGLT1/Sglt1 in the small intestine selectively. Mitagliflozin and GSK-1614235 are absorbed; however, they inhibit SGLT1/Sglt1 with a much higher efficacy compared to SGLT2/Sglt2. LX2761 and SLC5213 inhibit SGLT1/Sglt1 and SGLT2/Sglt2 with similar efficacies but enter the blood only slowly so that their systemic concentrations are not effective $[131,217]$. Selective inhibition of SGLT1/Sglt1 in the small intestine may induce three main effects. First, by inhibiting SGLT1/Sglt1 in IECs D-glucose absorption may be reduced. Second, a decreased absorption in the duodenum and proximal jejunum may lead to an increase of the D-glucose concentration in the distal jejunum and in the ileum where most L cells are located and may thereby increase Dglucose-dependent secretion of GLP-1 in L cells and promote pancreatic insulin secretion. Third, since glucose-dependent GLP-1 secretion in L cells is mediated by SGLT1/Sglt1, inhibition of SGLT1/Sglt1 in L cells may blunt GLP-1 secretion. Antidiabetic effects of selective SGLT1/Sglt1 inhibitors have been demonstrated in rodents. In normal rats, in rats with STZinduced T1DM, and in normal mice, it was observed that GSK-1614235, LX2761, and/or SGL5213 decreased postprandial elevation of blood glucose [88, 131, 176]. However, no consistent effects of the SGLT1/Sglt1 inhibitors on postprandial increase of GLP-1 in the blood were observed.

\section{Compounds that downregulate SGLT1}

A downregulation of SGLT1 abundance in the small intestine is considered an attractive alternative to inhibition of SGLT1 because longer lasting effects may be achieved. In addition, a selective downregulation of SGLT1 in IECs versus L cells and/or downregulation under defined physiologic or pathophysiologic conditions may be possible. Oral application of specific SGK1 inhibitors may be used to downregulate the increased expression SGLT1 in diabetic patients whereas modified peptides derived from the regulatory domain of RS1 may be employed to prevent the rapid upregulation of SGLT1 in the small intestinal BBM after ingestion of glucoserich food.

SGK1 is ubiquitously expressed and under genomic control of hormones including growth factors, corticosteroids, and insulin [224]. It participates in the regulation of various transporters, ion channels, and enzymes and is involved in pathophysiological changes during obesity, diabetes, hypertension, and tumor growth [223]. Under normal physiological conditions, the expression of SGK1 is low; however, it is increased under certain pathophysiological conditions such as hyperglycemia and ischemia. In obese and diabetic individuals, an increased SGK1 expression was observed in several tissues including small intestine [238]. In the small intestine of 
diabetic $d b / d b$ mice, higher mRNA and protein abundance of SGK1 and Sglt1 was observed compared to nondiabetic control mice [240]. After oral application of the selective SGK1 inhibitor EMD638683 for 8 weeks to $d b / d b$ mice, Sglt1 mRNA and Sglt1 protein in the small intestine were decreased and fasting blood glucose was reduced. Experiments performed with cultivated rat intestinal IEC- 6 cells revealed that dexamethasone treatment increased the expression of SGK1 and Sglt1 and that the expression and function of Sglt1 could be downregulated by incubation with EMD638683. The data suggest that oral application of selective SGK1 inhibitors that do not enter the systemic circulation may be employed for antidiabetic therapy (see effect of SGK1 on transcription of SGLT1 in Fig. 2).

Modified peptides derived from the regulatory domain of RS1 (RS1-Reg) may be used to prevent the glucose-dependent, short-term upregulation of SGLT1 in the small intestinal BBM [200]. The proposed mechanism is depicted in Fig. 4. In IECs, the release of SGLT1 containing vesicles from the Golgi is promoted by the enzymatic activity of ODC. At low intracellular D-glucose concentrations, the vesicle release is slowed down because RS1-Reg binds to ODC and blocks the enzymatic activity. After uptake of glucose-rich food when the Dglucose concentration in IECs increases, D-glucose binds to ODC. Thereby, a conformational change is induced that decreases the efficacy of RS1-Reg binding and prevents the inhibition of ODC. This promotes the release of SGLT1-containing vesicles from the Golgi and leads to the increase of SGLT1 in the BBM. Of note, it was observed that injection of a RS1-Reg variant in which serine in a QSP motif was replaced by glutamate (RS1-Reg(QEP)) into oocytes expressing human SGLT1 promoted highly efficient downregulation of SGLT1-mediated AMG uptake in the presence of high intracellular glucose concentrations [341, 408] (see Fig. 4(C)). After oral application of RS1-Reg(QEP) to mice and subsequent oral gavage with a high amount of D-glucose, a decrease of glucose absorption and of Sglt1 abundance in the small intestinal BBM was observed [408]. In these experiments, RS1-Reg(QEP) had been linked to nanohydrogels to promote uptake into IECs. Of note, it was also observed that QEP promoted downregulation of SGLT1-mediated uptake in oocytes expressing human SGLT1 at high intracellular glucose concentrations in contrast to QSP [341]. After oral application of QEP for 3-6 days to diabetic $d b / d b$ mice, antidiabetic effects were observed (, C. Otto, A. Friedrich, I. Vrhovac Madunić, C. Baumeier, R. W. Schwenk, A. Karaica, C.-T. Germer, A. Schürmann, I, Sabolić, H. Koepsell, unpublished data). Thus, fasting plasma glucose was decreased, insulin sensitivity was increased, the increase plasma glucose in OGTT was blunted, and the secretion of GLP-1 in the OGTT was increased. So far it has not been elucidated whether QEP also downregulates SGLT1/ Sglt1 in L cells. Future studies are necessary to improve drug formulation in order to accelerate uptake into IECs.

\section{Conclusions}

Extensive research has been performed concerning involvement of transporters and their regulation in monosaccharide absorption and impact of monosaccharide transporters on diseases and drug treatment. The data indicate a great complexity of these biomedically important issues and show that they demand further comprehensive in-depth investigation. For example, besides GLUT2, GLUT5, and SGLT1, several additional glucose transporters are expressed in the small intestine, the roles of which have not been investigated in appropriate detail. Regarding previous studies on GLUT2, GLUT5, and SGLT1, often short- and long-term post-translational regulations have not been distinguished unambiguously. Also, the functional mechanisms of most described regulatory processes of glucose transporters in ICEs have not been resolved in detail. In addition, most observations were made in rodents and have not been verified in humans. In view of overeating with carbohydrate-rich food and associated obesity with follow-up diseases in industrial societies, it is a challenge to develop drugs that downregulate small intestinal glucose transporters selectively in IECs. More detailed understanding on how all human glucose transporters expressed in small intestine function and are regulated in health and disease should be the basis for future dietary commendations.

Acknowledgements Open Access funding provided by Projekt DEAL.

Open Access This article is licensed under a Creative Commons Attribution 4.0 International License, which permits use, sharing, adaptation, distribution and reproduction in any medium or format, as long as you give appropriate credit to the original author(s) and the source, provide a link to the Creative Commons licence, and indicate if changes were made. The images or other third party material in this article are included in the article's Creative Commons licence, unless indicated otherwise in a credit line to the material. If material is not included in the article's Creative Commons licence and your intended use is not permitted by statutory regulation or exceeds the permitted use, you will need to obtain permission directly from the copyright holder. To view a copy of this licence, visit http://creativecommons.org/licenses/by/4.0/.

\section{References}

1. Abdullah AM, Abdullah MA, Abdurrahman MB, al Husain MA (1992) Glucose-galactose malabsorption with renal stones in a Saudi child. Ann Trop Paediatr 12:327-329. https://doi.org/10. 1080/02724936.1992.11747593

2. Abdullah AMA, el-Mouzan MI, Shiekh OKE, Mazyad AA (1996) Congenital glucose-galactose malabsorption in Arab children. J Pediatr Gastroenterol Nutr 23:561-564. https://doi.org/10.1097/ 00005176-199612000-00008

3. Abdul-Wahed A, Guilmeau S, Postic C (2017) Sweet sixteenth for ChREBP: established roles and future goals. Cell Metab 26:324 341. https://doi.org/10.1016/j.cmet.2017.07.004

4. Aerni-Flessner LB, Otu MC, Moley KH (2011) The amino acids upstream of $\mathrm{NH}(2)$-terminal dileucine motif play a role in 
regulating the intracellular sorting of the class III transporters GLUT8 and GLUT12. Mol Membr Biol 28:30-41. https://doi. org/10.3109/09687688.2010.508196

5. Affleck JA, Helliwell PA, Kellett GL (2003) Immunocytochemical detection of GLUT2 at the rat intestinal brush-border membrane. J Histochem Cytochem 51:1567-1574 http://www.ncbi.nlm.nih.gov/pubmed/14566028

6. Afshar N, Safaei S, Nickerson DP, Hunter PJ, Suresh V (2019) Computational modeling of glucose uptake in the enterocyte. Front Physiol 10:380. https://doi.org/10.3389/fphys.2019.00380

7. Ahn YH (2018) A journey to understand glucose homeostasis: starting from rat glucose transporter type 2 promoter cloning to hyperglycemia. Diabetes Metab J 42:465-471. https://doi.org/10. 4093/dmj.2018.0116

8. Akira S, Takeda K (2004) Toll-like receptor signalling. Nat Rev Immunol 4:499-511. https://doi.org/10.1038/nri1391

9. Ali M, Rellos P, Cox TM (1998) Hereditary fructose intolerance. J Med Genet 35:353-365. https://doi.org/10.1136/jmg.35.5.353

10. Aljure O, Diez-Sampedro A (2010) Functional characterization of mouse sodium/glucose transporter type 3b. Am J Physiol Cell Physiol 299, C58-69. https://doi.org/10.1152/ajpcell.00030.2010

11. Alzaid F, Cheung HM, Preedy VR, Sharp PA (2013) Regulation of glucose transporter expression in human intestinal Caco-2 cells following exposure to an anthocyanin-rich berry extract. PLoS One 8:e78932. https://doi.org/10.1371/journal.pone.0078932

12. Amsler K, Cook JS (1982) Development of Na+-dependent hexose transport in a cultured line of porcine kidney cells. Am J Phys 242:C94-C101. https://doi.org/10.1152/ajpcell.1982.242.1.C94

13. Andersson DE, Nygren A (1978) Four cases of long-standing diarrhoea and colic pains cured by fructose-free diet-a pathogenetic discussion. Acta Med Scand 203:87-92. https://doi.org/10. 1111/j.0954-6820.1978.tb14836.x

14. Andres SF, Simmons JG, Mah AT, Santoro MA, Van Landeghem L, Lund PK (2013) Insulin receptor isoform switching in intestinal stem cells, progenitors, differentiated lineages and tumors: evidence that IR-B limits proliferation. J Cell Sci 126:5645-5656. https://doi.org/10.1242/jcs.132985

15. Aranias T, Grosfeld A, Poitou C, Omar AA, Le Gall M, Miquel S, Garbin K, Ribeiro A, Bouillot JL, Bado A, Brot-Laroche E, Clement K, Leturque A, Guilmeau S, Serradas P (2015) Lipidrich diet enhances L-cell density in obese subjects and in mice through improved L-cell differentiation. J Nutr Sci 4:e22. https:// doi.org/10.1017/jns.2015.11

16. Artis D, Wang ML, Keilbaugh SA, He W, Brenes M, Swain GP, Knight PA, Donaldson DD, Lazar MA, Miller HR, Schad GA, Scott P, Wu GD (2004) RELMbeta/FIZZ2 is a goblet cell-specific immune-effector molecule in the gastrointestinal tract. Proc Natl Acad Sci U S A 101:13596-13600. https://doi.org/10.1073/pnas. 0404034101

17. Asano T, Katagiri H, Tsukuda K, Lin JL, Ishihara H, Yazaki Y, Oka Y (1992) Upregulation of GLUT2 mRNA by glucose, mannose, and fructose in isolated rat hepatocytes. Diabetes 41:22-25. https://doi.org/10.2337/diab.41.1.22

18. Au A, Gupta A, Schembri P, Cheeseman CI (2002) Rapid insertion of GLUT2 into the rat jejunal brush-border membrane promoted by glucagon-like peptide 2. Biochem J 367:247-254 https://doi.org/10.1042/BJ20020393

19. Augustin R, Riley J, Moley KH (2005) GLUT8 contains a [DE]XXXL[LI] sorting motif and localizes to a late endosomal/ lysosomal compartment. Traffic 6:1196-1212. https://doi.org/10. $1111 / \mathrm{j} .1600-0854.2005 .00354 . x$

20. Bado A, Levasseur S, Attoub S, Kermorgant S, Laigneau JP, Bortoluzzi MN, Moizo L, Lehy T, Guerre-Millo M, Le Marchand-Brustel Y, Lewin MJ (1998) The stomach is a source of leptin. Nature 394:790-793. https://doi.org/10.1038/29547
21. Baggio LL, Drucker DJ (2007) Biology of incretins: GLP-1 and GIP. Gastroenterology 132:2131-2157

22. Bailey CJ, Mynett KJ, Page T (1994) Importance of the intestine as a site of metformin-stimulated glucose utilization. Br J Pharmacol 112:671-675. https://doi.org/10.1111/j.1476-5381. 1994.tb13128.x

23. Balakrishnan A, Stearns AT, Ashley SW, Rhoads DB, Tavakkolizadeh A (2012) PER1 modulates SGLT1 transcription in vitro independent of E-box status. Dig Dis Sci 57:1525-1536. https://doi.org/10.1007/s10620-012-2166-8

24. Baldassano S, Liu S, Qu MH, Mule F, Wood JD (2009) Glucagon-like peptide-2 modulates neurally evoked mucosal chloride secretion in guinea pig small intestine in vitro. Am J Physiol Gastrointest Liver Physiol 297:G800-G805. https://doi. org/10.1152/ajpgi.00170.2009

25. Balen D, Ljubojevic M, Breljak D, Brzica H, Zlender V, Koepsell H, Sabolic I (2008) Revised immunolocalization of the Na+-Dglucose cotransporter SGLT1 in rat organs with an improved antibody. Am J Physiol Cell Physiol 295:C475-C489 https://doi. org/10.1152/ajpcell.00180.2008

26. Ban N, Yamada Y, Someya Y, Miyawaki K, Ihara Y, Hosokawa M, Toyokuni S, Tsuda K, Seino Y (2002) Hepatocyte nuclear factor-1alpha recruits the transcriptional co-activator p300 on the GLUT2 gene promoter. Diabetes 51:1409-1418. https://doi.org/ 10.2337/diabetes.51.5.1409

27. Barnes G, McKellar W, Lawrance S (1983) Detection of fructose malabsorption by breath hydrogen test in a child with diarrhea. $\mathrm{J}$ Pediatr 103:575-577. https://doi.org/10.1016/s0022-3476(83) 80588-5

28. Barone S, Fussell SL, Singh AK, Lucas F, Xu J, Kim C, Wu X, Yu Y, Amlal H, Seidler U, Zuo J, Soleimani M (2009) Slc2a5 (Glut5) is essential for the absorption of fructose in the intestine and generation of fructose-induced hypertension. J Biol Chem 284:50565066. https://doi.org/10.1074/jbc.M808128200

29. Barrenetxe J, Villaro AC, Guembe L, Pascual I, Munoz-Navas M, Barber A, Lostao MP (2002) Distribution of the long leptin receptor isoform in brush border, basolateral membrane, and cytoplasm of enterocytes. Gut 50:797-802. https://doi.org/10.1136/gut.50.6. 797

30. Batchelor DJ, Al-Rammahi M, Moran AW, Brand JG, Li X, Haskins M, German AJ, Shirazi-Beechey SP (2011) Sodium/ glucose cotransporter-1, sweet receptor, and disaccharidase expression in the intestine of the domestic dog and cat: two species of different dietary habit. Am J Physiol Regul Integr Comp Physiol 300:R67-R75. https://doi.org/10.1152/ajpregu.00262. 2010

31. Berger CN, Crepin VF, Roumeliotis TI, Wright JC, Carson D, Pevsner-Fischer M, Furniss RCD, Dougan G, Dori-Bachash M, $\mathrm{Yu}$ L, Clements A, Collins JW, Elinav E, Larrouy-Maumus GJ, Choudhary JS, Frankel G (2017) Citrobacter rodentium subverts ATP flux and cholesterol homeostasis in intestinal epithelial cells in vivo. Cell Metab 26(738-752):e736. https://doi.org/10.1016/j. cmet.2017.09.003

32. Bergeron JJ, Rachubinski R, Searle N, Borts D, Sikstrom R, Posner BI (1980) Polypeptide hormone receptors in vivo: demonstration of insulin binding to adrenal gland and gastrointestinal epithelium by quantitative radioautography. J Histochem Cytochem 28:824-835 http://https://doi.org/10.1177/28.8. 6255031

33. Binder HJ, Brown I, Ramakrishna BS, Young GP (2014) Oral rehydration therapy in the second decade of the twenty-first century. Curr Gastroenterol Rep 16:376. https://doi.org/10.1007/ s11894-014-0376-2

34. Bizot-Espiard JG, Double A, Guardiola-Lemaitre B, Delagrange P, Ktorza A, Penicaud L (1998) Diurnal rhythms in plasma glucose, insulin, growth hormone and melatonin levels in fasted and 
hyperglycaemic rats. Diabetes Metab 24:235-240 https://www. ncbi.nlm.nih.gov/pubmed/9690056

35. Bjerknes M, Cheng H (2001) Modulation of specific intestinal epithelial progenitors by enteric neurons. Proc Natl Acad Sci U S A 98:12497-12502. https://doi.org/10.1073/pnas.211278098

36. Blakemore SJ, Aledo JC, James J, Campbell FC, Lucocq JM, Hundal HS (1995) The GLUT5 hexose transporter is also localized to the basolateral membrane of the human jejunum. Biochem J 309:7-12 https://doi.org/10.1042/bj3090007

37. Bode C, Eisenhardt JM, Haberich FJ, Bode JC (1981) Influence of feeding fructose on fructose and glucose absorption in rat jejunum and ileum. Res Exp Med (Berl) 179:163-168. https://doi.org/10. 1007/bf01851984

38. Bonny C, Thompson N, Nicod P, Waeber G (1995) Pancreaticspecific expression of the glucose transporter type 2 gene: identification of cis-elements and islet-specific trans-acting factors. Mol Endocrinol 9:1413-1426. https://doi.org/10.1210/mend.9.10. 8544849

39. Boyer S, Sharp PA, Debnam ES, Baldwin SA, Srai SK (1996) Streptozotocin diabetes and the expression of GLUT1 at the brush border and basolateral membranes of intestinal enterocytes. FEBS Lett 396:218-222. https://doi.org/10.1016/0014-5793(96)011027

40. Bristol JB, Williamson RC (1988) Nutrition, operations, and intestinal adaptation. JPEN J Parenter Enteral Nutr 12:299-309. https://doi.org/10.1177/0148607188012003299

41. Buchman AL, Moukarzel AA, Bhuta S, Belle M, Ament ME, Eckhert CD, Hollander D, Gornbein J, Kopple JD, Vijayaroghavan SR (1995) Parenteral nutrition is associated with intestinal morphologic and functional changes in humans. JPEN J Parenter Enteral Nutr 19:453-460. https://doi.org/10.1177/ 0148607195019006453

42. Buchwald H, Estok R, Fahrbach K, Banel D, Jensen MD, Pories WJ, Bantle JP, Sledge I (2009) Weight and type 2 diabetes after bariatric surgery: systematic review and meta-analysis. Am J Med 122:248-256. https://doi.org/10.1016/j.amjmed.2008.09.041

43. Buddington RK, Chen JW, Diamond JM (1991) Dietary regulation of intestinal brush-border sugar and amino acid transport in carnivores. Am J Phys 261:R793-R801. https://doi.org/10.1152/ ajpregu.1991.261.4.R793

44. Bueter M, Lowenstein C, Olbers T, Wang M, Cluny NL, Bloom SR, Sharkey KA, Lutz TA, le Roux CW (2010) Gastric bypass increases energy expenditure in rats. Gastroenterology 138:18451853. https://doi.org/10.1053/j.gastro.2009.11.012

45. Burant CF, Saxena M (1994) Rapid reversible substrate regulation of fructose transporter expression in rat small intestine and kidney. Am J Phys 267:G71-G79. https://doi.org/10.1152/ajpgi.1994. 267.1.G71

46. Burant CF, Takeda J, Brot-Laroche E, Bell GI, Davidson NO (1992) Fructose transporter in human spermatozoa and small intestine is GLUT5. J Biol Chem 267:14523-14526. https://doi.org/ 10.1152/ajpgi.1994.267.1.G71

47. Burant CF, Flink S, DePaoli AM, Chen J, Lee W-S, Hediger MA, Buse JB, Chang EB (1994) Small intestine hexose transport in experimental diabetes. Increased transporter mRNA and protein expression in enterocytes. J Clin Invest 93:578-585 https://www. ncbi.nlm.nih.gov/pubmed/1634504

48. Burrin DG, Stoll B, Jiang R, Chang X, Hartmann B, Holst JJ, Greeley GH Jr, Reeds PJ (2000) Minimal enteral nutrient requirements for intestinal growth in neonatal piglets: how much is enough? Am J Clin Nutr 71:1603-1610. https://doi.org/10.1093/ ajen/71.6.1603

49. Cammisotto PG, Renaud C, Gingras D, Delvin E, Levy E, Bendayan M (2005) Endocrine and exocrine secretion of leptin by the gastric mucosa. J Histochem Cytochem 53:851-860. https://doi.org/10.1369/jhc.5A6620.2005
50. Cammisotto PG, Gingras D, Renaud C, Levy E, Bendayan M (2006) Secretion of soluble leptin receptors by exocrine and endocrine cells of the gastric mucosa. Am J Physiol Gastrointest Liver Physiol 290:G242-G249. https://doi.org/10.1152/ajpgi. 00334.2005

51. Cani PD, Holst JJ, Drucker DJ, Delzenne NM, Thorens B, Burcelin R, Knauf C (2007) GLUT2 and the incretin receptors are involved in glucose-induced incretin secretion. Mol Cell Endocrinol 276:18-23. https://doi.org/10.1016/j.mce.2007.06. 003

52. Cani PD, Hoste S, Guiot Y, Delzenne NM (2007) Dietary nondigestible carbohydrates promote L-cell differentiation in the proximal colon of rats. Br J Nutr 98:32-37. https://doi.org/10. 1017/S0007114507691648

53. Cardani D, Sardi C, La FB, D'Orazio G, Sommariva M, Marcucci F, Olivero D, Tagliabue E, Koepsell H, Nicotra F, Balsari A, Rumio C (2014) Sodium glucose cotransporter 1 ligand BLF501 as a novel tool for management of gastrointestinal mucositis. Mol Cancer 13:23. https://doi.org/10.1186/1476-4598-13-23

54. Cario E, Rosenberg IM, Brandwein SL, Beck PL, Reinecker HC, Podolsky DK (2000) Lipopolysaccharide activates distinct signaling pathways in intestinal epithelial cell lines expressing Toll-like receptors. J Immunol 164:966-972. https://doi.org/10.4049/ jimmunol.164.2.966

55. Carraway R, Leeman SE (1976) Characterization of radioimmunoassayable neurotensin in the rat. Its differential distribution in the central nervous system, small intestine, and stomach. J Biol Chem 251:7045-7052 https://www.ncbi.nlm.nih.gov/pubmed/ 993203

56. Carraway RE, Demers LM, Leeman SE (1976) Hyperglycemic effect of neurotensin, a hypothalamic peptide. Endocrinology 99: 1452-1462. https://doi.org/10.1210/endo-99-6-1452

57. Castaneda-Sceppa C, Subramanian S, Castaneda F (2010) Protein kinase $\mathrm{C}$ mediated intracellular signaling pathways are involved in the regulation of sodium-dependent glucose co-transporter SGLT1 activity. J Cell Biochem 109:1109-1117 http://www. ncbi.nlm.nih.gov/pubmed/20069550

58. Castello A, Guma A, Sevilla L, Furriols M, Testar X, Palacin M, Zorzano A (1995) Regulation of GLUT5 gene expression in rat intestinal mucosa: regional distribution, circadian rhythm, perinatal development and effect of diabetes. Biochem J 309(Pt 1):271277. https://doi.org/10.1042/bj3090271

59. Cavin JB, Couvelard A, Lebtahi R, Ducroc R, Arapis K, Voitellier E, Cluzeaud F, Gillard L, Hourseau M, Mikail N, Ribeiro-Parenti L, Kapel N, Marmuse JP, Bado A, Le Gall M (2016) Differences in alimentary glucose absorption and intestinal disposal of blood glucose after Roux-en-Y gastric bypass vs sleeve gastrectomy. Gastroenterology 150(454-464):e459. https://doi.org/10.1053/j. gastro.2015.10.009

60. Cha JY, Kim H, Kim KS, Hur MW, Ahn Y (2000) Identification of transacting factors responsible for the tissue-specific expression of human glucose transporter type 2 isoform gene. Cooperative role of hepatocyte nuclear factors $1 \mathrm{alpha}$ and 3 beta. J Biol Chem 275:18358-18365. https://doi.org/10.1074/jbc.M909536199

61. Chambers RA, Pratt RT (1956) Idiosyncrasy to fructose. Lancet 271:340. https://doi.org/10.1016/s0140-6736(56)92196-1

62. Chaudhri O, Small C, Bloom S (2006) Gastrointestinal hormones regulating appetite. Philos Trans R Soc Lond Ser B Biol Sci 361: 1187-1209. https://doi.org/10.1098/rstb.2006.1856

63. Cheeseman CI (1993) GLUT2 is the transporter for fructose across the rat intestinal basolateral membrane. Gastroenterology 105: $1050-1056$

64. Cheeseman CI (1997) Upregulation of SGLT-1 transport activity in rat jejunum induced by GLP-2 infusion in vivo. Am J Phys 273: R1965-R1971 https://doi.org/10.1152/ajpregu.1997.273.6.R1965 
65. Chen J, Williams S, Ho S, Loraine H, Hagan D, Whaley JM, Feder JN (2010) Quantitative PCR tissue expression profiling of the human SGLT2 gene and related family members. Diabetes Ther 1:57-92. https://doi.org/10.1007/s13300-010-0006-4

66. Chintalapati C, Keller T, Mueller TD, Gorboulev V, Schafer N, Zilkowski I, Veyhl-Wichmann M, Geiger D, Groll J, Koepsell H (2016) Protein RS1 (RSC1A1) downregulates the exocytotic pathway of glucose transporter SGLT1 at low intracellular glucose via inhibition of ornithine decarboxylase. Mol Pharmacol 90:508521. https://doi.org/10.1124/mol.116.104521

67. Chung BM, Wallace LE, Hardin JA, Gall DG (2002) The effect of epidermal growth factor on the distribution of SGLT-1 in rabbit jejunum. Can J Physiol Pharmacol 80:872-878 https://doi.org/10. $1139 / \mathrm{y} 02-115$

68. Clifford MN (2004) Diet-derived phenols in plasma and tissues and their implications for health. Planta Med 70:1103-1114. https://doi.org/10.1055/s-2004-835835

69. Corpe CP, Burant CF (1996) Hexose transporter expression in rat small intestine: effect of diet on diurnal variations. Am J Phys 271: G211-G216 http://www.ncbi.nlm.nih.gov/pubmed/8760125

70. Corpe CP, Basaleh MM, Affleck J, Gould G, Jess TJ, Kellett GL (1996) The regulation of GLUT5 and GLUT2 activity in the adaptation of intestinal brush-border fructose transport in diabetes. Pflugers Arch 432:192-201 https://doi.org/10.1007/ s004240050124

71. Corpe C, Sreenan S, Burant C (2001) Effects of type-2 diabetes and troglitazone on the expression patterns of small intestinal sugar transporters and PPAR-gamma in the Zucker diabetic fatty rat. Digestion 63:116-123. https://doi.org/10.1159/000051879

72. Cote CD, Zadeh-Tahmasebi M, Rasmussen BA, Duca FA, Lam TK (2014) Hormonal signaling in the gut. J Biol Chem 289: 11642-11649. https://doi.org/10.1074/jbc.O114.556068

73. Cottrell JJ, Stoll B, Buddington RK, Stephens JE, Cui L, Chang X, Burrin DG (2006) Glucagon-like peptide-2 protects against TPNinduced intestinal hexose malabsorption in enterally refed piglets. Am J Physiol Gastrointest Liver Physiol 290:G293-G300. https:// doi.org/10.1152/ajpgi.00275.2005

74. Cox TM, O'Donnell MW, Camilleri M, Burghes AH (1983) Isolation and characterization of a mutant liver aldolase in adult hereditary fructose intolerance. Identification of the enzyme variant by radioassay in tissue biopsy specimens. J Clin Invest 72 : 201-213. https://doi.org/10.1172/jci110958

75. Cross NC, Tolan DR, Cox TM (1988) Catalytic deficiency of human aldolase B in hereditary fructose intolerance caused by a common missense mutation. Cell 53:881-885. https://doi.org/10. 1016/s0092-8674(88)90349-2

76. Cui X-L, Soteropoulos P, Tolias P, Ferraris RP (2004) Fructoseresponsive genes in the small intestine of neonatal rats. Physiol Genomics 18:206-217 https://www.physiology.org/doi/pdf/10. 1152/ajpgi.00550.2004

77. Cui X-L, Schlesier AM, Fisher EL, Cerqueira C, Ferraris RP (2005) Fructose-induced increases in neonatal rat intestinal fructose transport involve the PI3-kinase/Akt signaling pathway. Am J Physiol Gastrointest Liver Physiol 288:G1310-G1320

78. D'Alessio DA, Kahn SE, Leusner CR, Ensinck JW (1994) Glucagon-like peptide 1 enhances glucose tolerance both by stimulation of insulin release and by increasing insulin-independent glucose disposal. J Clin Invest 93:2263-2266. https://doi.org/10. 1172/JCI117225

79. Dakka T, Cuber JC, Chayvialle JA (1993) Functional coupling between the active transport of glucose and the secretion of intestinal neurotensin in rats. J Physiol 469:753-765. https://doi.org/ 10.1113/jphysiol.1993.sp019841

80. Das S, Jayaratne R, Barrett KE (2018) The role of ion transporters in the pathophysiology of infectious diarrhea. Cell Mol
Gastroenterol Hepatol 6:33-45. https://doi.org/10.1016/j.jcmgh. 2018.02.009

81. Davidson NO, Hausman AML, Ifkovits CA, Buse JB, Gould GW, Burant CF, Bell GI (1992) Human intestinal glucose transporter expression and localization of GLUT5. Am J Phys 262:C795C800 https://www.physiology.org/doi/pdf/10.1152/ajpcell.1992. 262.3.C795

82. Dean P, Maresca M, Schuller S, Phillips AD, Kenny B (2006) Potent diarrheagenic mechanism mediated by the cooperative action of three enteropathogenic Escherichia coli-injected effector proteins. Proc Natl Acad Sci U S A 103:1876-1881. https://doi. org/10.1073/pnas.0509451103

83. Debnam ES, Smith MW, Sharp PA, Srai SK, Turvey A, Keable SJ (1995) The effects of streptozotocin diabetes on sodium-glucose transporter (SGLT1) expression and function in rat jejunal and ileal villus-attached enterocytes. Pflugers Arch 430:151-159. https://doi.org/10.1007/bf00374645

84. DeBosch BJ, Chi M, Moley KH (2012) Glucose transporter 8 (GLUT8) regulates enterocyte fructose transport and global mammalian fructose utilization. Endocrinology 153:4181-4191. https://doi.org/10.1210/en.2012-1541

85. Dey I, Lejeune M, Chadee K (2006) Prostaglandin E2 receptor distribution and function in the gastrointestinal tract. Br J Pharmacol 149:611-623. https://doi.org/10.1038/sj.bjp.0706923

86. Diamond JM, Karasov WH (1984) Effect of dietary carbohydrate on monosaccharide uptake by mouse small intestine in vitro. $\mathrm{J}$ Physiol 349:419-440 https://doi.org/10.1113/jphysiol.1984. sp015165

87. Dieter M, Palmada M, Rajamanickam J, Aydin A, Busjahn A, Boehmer C, Luft FC, Lang F (2004) Regulation of glucose transporter SGLT1 by ubiquitin ligase Nedd4-2 and kinases SGK1, SGK3, and PKB. Obes Res 12:862-870 https://onlinelibrary. wiley.com/doi/full/10.1038/oby.2004.104

88. Dobbins RL, Greenway FL, Chen L, Liu Y, Breed SL, Andrews SM, Wald JA, Walker A, Smith CD (2015) Selective sodiumdependent glucose transporter 1 inhibitors block glucose absorption and impair glucose-dependent insulinotropic peptide release. Am J Physiol Gastrointest Liver Physiol 308:G946-G954. https:// doi.org/10.1152/ajpgi.00286.2014

89. Doege H, Schurmann A, Bahrenberg G, Brauers A, Joost HG (2000) GLUT8, a novel member of the sugar transport facilitator family with glucose transport activity. J Biol Chem 275:1627516280. https://doi.org/10.1074/jbc.275.21.16275

90. Dominguez Rieg JA, Chirasani VR, Koepsell H, Senapati S, Mahata SK, Rieg T (2016) Regulation of intestinal SGLT1 by catestatin in hyperleptinemic type 2 diabetic mice. Lab Invest 96:98-111. https://doi.org/10.1038/labinvest.2015.129

91. Dotimas JR, Lee AW, Schmider AB, Carroll SH, Shah A, Bilen J, Elliott KR, Myers RB, Soberman RJ, Yoshioka J, Lee RT (2016) Diabetes regulates fructose absorption through thioredoxininteracting protein. Elife 5. https://doi.org/10.7554/eLife.18313

92. Douard V, Ferraris RP (2008) Regulation of the fructose transporter GLUT5 in health and disease. Am J Physiol Endocrinol Metab 295:E227-E237 https://www.physiology.org/doi/pdf/10. 1152/ajpendo.90245.2008

93. Douard V, Ferraris RP (2013) The role of fructose transporters in diseases linked to excessive fructose intake. J Physiol 591:401414. https://doi.org/10.1113/jphysiol.2011.215731

94. Drucker DJ (1999) Glucagon-like peptide 2. Trends Endocrinol Metab 10:153-156. https://doi.org/10.1016/s1043-2760(98) 00136-2

95. Ducroc R, Guilmeau S, Akasbi K, Devaud H, Buyse M, Bado A (2005) Luminal leptin induces rapid inhibition of active intestinal absorption of glucose mediated by sodium-glucose cotransporter 1. Diabetes 54:348-354 https://doi.org/10.2337/diabetes.54.2.348 
96. Duquette PP, Bissonnette P, Lapointe JY (2001) Local osmotic gradients drive the water flux associated with $\mathrm{Na}(+) /$ glucose cotransport. Proc Natl Acad Sci U S A 98:3796-3801. https://doi. org/10.1073/pnas.071245198

97. Dyer J, Garner A, Wood IS, Sharma AK, Chandranath I, ShiraziBeechey SP (1997) Changes in the levels of intestinal Na+/glucose co-transporter (SGLT1) in experimental diabetes. Biochem Soc Trans 25:479S. https://doi.org/10.1042/bst025479s

98. Dyer J, Wood IS, Palejwala A, Ellis A, Shirazi-Beechey SP (2002) Expression of monosaccharide transporters in intestine of diabetic humans. Am J Physiol Gastrointest Liver Physiol 282:G241G248 http://www.ncbi.nlm.nih.gov/pubmed/11804845

99. Dyer J, Vayro S, King TP, Shirazi-Beechey SP (2003) Glucose sensing in the intestinal epithelium. Eur J Biochem 270:33773388. https://doi.org/10.1046/j.1432-1033.2003.03721.x

100. Dyer J, Al-Rammahi M, Waterfall L, Salmon KS, Geor RJ, Boure L, Edwards GB, Proudman CJ, Shirazi-Beechey SP (2009) Adaptive response of equine intestinal $\mathrm{Na}+$ /glucose cotransporter (SGLT1) to an increase in dietary soluble carbohydrate. Pflugers Arch 458:419-430. https://doi.org/10.1007/ s00424-008-0620-4

101. Egerod KL, Engelstoft MS, Grunddal KV, Nohr MK, Secher A, Sakata I, Pedersen J, Windelov JA, Fuchtbauer EM, Olsen J, Sundler F, Christensen JP, Wierup N, Olsen JV, Holst JJ, Zigman JM, Poulsen SS, Schwartz TW (2012) A major lineage of enteroendocrine cells coexpress CCK, secretin, GIP, GLP-1, PYY, and neurotensin but not somatostatin. Endocrinology 153: 5782-5795. https://doi.org/10.1210/en.2012-1595

102. El-Naggar W, Balfe JW, Barbar M, Taha D (2005) Nephrocalcinosis in glucose-galactose malabsorption, association with renal tubular acidosis. Pediatr Nephrol 20:1336-1339. https://doi.org/10.1007/s00467-005-1885-x

103. Elsas LJ, Hillman RE, Patterson JH, Rosenberg LE (1970) Renal and intestinal hexose transport in familial glucose-galactose malabsorption. J Clin Invest 49:576-585. https://doi.org/10.1172/ JCI106268

104. Elvira B, Honisch S, Almilaji A, Pakladok T, Liu G, Shumilina E, Alesutan I, Yang W, Munoz C, Lang F (2013) Up-regulation of $\mathrm{Na}(+)$-coupled glucose transporter SGLT1 by caveolin-1. Biochim Biophys Acta 1828:2394-2398. https://doi.org/10. 1016/j.bbamem.2013.06.007

105. Erokhova L, Horner A, Ollinger N, Siligan C, Pohl P (2016) The sodium glucose cotransporter SGLT1 is an extremely efficient facilitator of passive water transport. J Biol Chem. https://doi. org/10.1074/jbc.M115.706986

106. Fanconi G, Bickel H (1949) Chronic aminoaciduria (amino acid diabetes or nephrotic-glucosuric dwarfism) in glycogen storage and cystine disease. Helv Paediatr Acta 4:359-396 https://www. ncbi.nlm.nih.gov/pubmed/15397919

107. Farrell TL, Ellam SL, Forrelli T, Williamson G (2013) Attenuation of glucose transport across Caco-2 cell monolayers by a polyphenol-rich herbal extract: interactions with SGLT1 and GLUT2 transporters. Biofactors 39:448-456. https://doi.org/10. 1002/biof.1090

108. Fatima J, Iqbal CW, Houghton SG, Kasparek MS, Duenes JA, Zheng Y, Sarr MG (2009) Hexose transporter expression and function in mouse small intestine: role of diurnal rhythm. J Gastrointest Surg 13:634-641 https://doi.org/10.1007/s11605008-0776-4

109. Fedorak RN, Cheeseman CI, Thomson ABR, Porter VM (1991) Altered glucose carrier expression: mechanism of intestinal adaptation during streptozocin-induced diabetes in rats. Am J Phys 261:G585-G591 https://doi.org/10.1152/ajpgi.1991.261.4.G585

110. Ferraris RP, Diamond J (1992) Crypt-villus site of glucose transporter induction by dietary carbohydrate in mouse intestine. Am J
Phys 262:G1069-G1073. https://doi.org/10.1152/ajpgi.1992.262. 6.G1069

111. Ferraris RP, Diamond JM (1993) Crypt/villus site of substratedependent regulation of mouse intestinal glucose transporters. Proc Natl Acad Sci U S A 90:5868-5872. https://doi.org/10. 1073/pnas.90.12.5868

112. Ferraris RP, Diamond J (1997) Regulation of intestinal sugar transport. Physiol Rev 77:257-302 https://doi.org/10.1073/pnas. 90.12.5868

113. Ferraris RP, Villenas SA, Hirayama BA, Diamond J (1992) Effect of diet on glucose transporter site density along the intestinal crypt-villus axis. Am J Phys 262:G1060-G1068 https://www. physiology.org/doi/abs/10.1152/ajpgi.1992.262.6.G1060

114. Field FJ, Born E, Murthy S, Mathur SN (2001) Regulation of sterol regulatory element-binding proteins in hamster intestine by changes in cholesterol flux. J Biol Chem 276:17576-17583. https://doi.org/10.1074/jbc.M010917200

115. Filatova A, Leyerer M, Gorboulev V, Chintalapati C, Reinders $\mathrm{Y}$, Muller TD, Srinivasan A, Hubner S, Koepsell H (2009) Novel shuttling domain in a regulator (RSC1A1) of transporter SGLT1 steers cell cycle-dependent nuclear location. Traffic 10:15991618 https://doi.org/10.1111/j.1600-0854.2009.00982.x

116. Fisher RB, Gardner ML (1976) A diurnal rhythm in the absorption of glucose and water by isolated rat small intestine. J Physiol 254: 821-825. https://doi.org/10.1113/jphysiol.1976.sp011262

117. Flessner LB, Moley KH (2009) Similar [DE]XXXL[LI] motifs differentially target GLUT8 and GLUT12 in Chinese hamster ovary cells. Traffic 10:324-333. https://doi.org/10.1111/j.16000854.2008.00866.x

118. Flynn CR, Albaugh VL, Cai S, Cheung-Flynn J, Williams PE, Brucker RM, Bordenstein SR, Guo Y, Wasserman DH, Abumrad NN (2015) Bile diversion to the distal small intestine has comparable metabolic benefits to bariatric surgery. Nat Commun 6:7715. https://doi.org/10.1038/ncomms8715

119. Folkers K, Chang D, Humphries J, Carraway R, Leeman SE, Bowers CY (1976) Synthesis and activities of neurotensin, and its acid and amide analogs: possible natural occurrence of [Gln4] neurotensin. Proc Natl Acad Sci U S A 73:3833-3837. https://doi. org/10.1073/pnas.73.11.3833

120. Fujio J, Kushiyama A, Sakoda H, Fujishiro M, Ogihara T, Fukushima Y, Anai M, Horike N, Kamata H, Uchijima Y, Kurihara H, Asano T (2008) Regulation of gut-derived resistinlike molecule beta expression by nutrients. Diabetes Res Clin Pract 79:2-10. https://doi.org/10.1016/j.diabres.2007.04.015

121. Fujita Y, Wideman RD, Speck M, Asadi A, King DS, Webber TD, Haneda M, Kieffer TJ (2009) Incretin release from gut is acutely enhanced by sugar but not by sweeteners in vivo. Am J Physiol Endocrinol Metab 296:E473-E479. https://doi.org/10.1152/ ajpendo.90636.2008

122. Fukumoto H, Seino S, Imura H, Seino Y, Bell GI (1988) Characterization and expression of human HepG2/erythrocyte glucose-transporter gene. Diabetes 37:657-661. https://doi.org/ 10.2337/diab.37.5.657

123. Fukumoto H, Seino S, Imura H, Seino Y, Eddy RL, Fukushima Y, Byers MG, Shows TB, Bell GI (1988) Sequence, tissue distribution, and chromosomal localization of mRNA encoding a human glucose transporter-like protein. Proc Natl Acad Sci U S A 85: 5434-5438. https://www.ncbi.nlm.nih.gov/pubmed/2834252

124. Furuya S, Takahashi S (1975) Absorption of L-histidine and glucose from the jejunum segment of the pig and its diurnal fluctuation. Br J Nutr 34:267-277. https://doi.org/10.1017/ s0007114575000311

125. Furuya S, Yugari Y (1974) Daily rhythmic change of L-histidine and glucose absorptions in rat small intestine in vivo. Biochim Biophys Acta 343:558-564. https://doi.org/10.1016/03044165(74)90274-8 
126. Gagnon MP, Bissonnette P, Deslandes LM, Wallendorff B, Lapointe JY (2004) Glucose accumulation can account for the initial water flux triggered by $\mathrm{Na}+$ /glucose cotransport. Biophys J 86:125-133. https://doi.org/10.1016/S0006-3495(04)74090-4

127. Galanos C, Freudenberg MA, Reutter W (1979) Galactosamineinduced sensitization to the lethal effects of endotoxin. Proc Natl Acad Sci U S A 76:5939-5943. https://doi.org/10.1073/pnas.76. 11.5939

128. Gerspach AC, Steinert RE, Schonenberger L, Graber-Maier A, Beglinger C (2011) The role of the gut sweet taste receptor in regulating GLP-1, PYY, and CCK release in humans. Am J Physiol Endocrinol Metab 301:E317-E325. https://doi.org/10. 1152/ajpendo.00077.2011

129. Gerstmayer B, Kusters D, Gebel S, Muller T, Van Miert E, Hofmann K, Bosio A (2003) Identification of RELMgamma, a novel resistin-like molecule with a distinct expression pattern. Genomics 81:588-595. https://doi.org/10.1016/s0888-7543(03) 00070-3

130. Gibson PR, Newnham E, Barrett JS, Shepherd SJ, Muir JG (2007) Review article: fructose malabsorption and the bigger picture. Aliment Pharmacol Ther 25:349-363. https://doi.org/10.1111/j. 1365-2036.2006.03186.x

131. Goodwin NC, Ding ZM, Harrison BA, Strobel ED, Harris AL, Smith M, Thompson AY, Xiong W, Mseeh F, Bruce DJ, Diaz D, Gopinathan S, Li L, O'Neill E, Thiel M, Wilson AG, Carson KG, Powell DR, Rawlins DB (2017) Discovery of LX2761, a sodiumdependent glucose cotransporter 1 (SGLT1) inhibitor restricted to the intestinal lumen, for the treatment of diabetes. J Med Chem 60: 710-721. https://doi.org/10.1021/acs.jmedchem.6b01541

132. Gorboulev V, Schürmann A, Vallon V, Kipp H, Jaschke A, Klessen D, Friedrich A, Scherneck S, Rieg T, Cunard R, VeyhlWichmann M, Srinivasan A, Balen D, Breljak D, Rexhepaj R, Parker HE, Gribble FM, Reimann F, Lang F, Wiese S, Sabolic I, Sendtner M, Koepsell H (2012) Na+-D-glucose cotransporter SGLT1 is pivotal for intestinal glucose absorption and glucosedependent incretin secretion. Diabetes 61:187-196. https://oi. org/10.2337/db11-1029

133. Gould GW, Thomas HM, Jess TJ, Bell GI (1991) Expression of human glucose transporters in Xenopus oocytes: kinetic characterization and substrate specificities of the erythrocyte, liver, and brain isoforms. Biochemistry 30:5139-5145. https://doi.org/10. 1021/bi00235a004

134. Gouyon F, Caillaud L, Carriere V, Klein C, Dalet V, Citadelle D, Kellett GL, Thorens B, Leturque A, Brot-Laroche E (2003) Simple-sugar meals target GLUT2 at enterocyte apical membranes to improve sugar absorption: a study in GLUT2-null mice. J Physiol 552:823-832. https://doi.org/10.1113/jphysiol.2003. 049247

135. Gouyon F, Onesto C, Dalet V, Pages G, Leturque A, Brot-Laroche E (2003) Fructose modulates GLUT5 mRNA stability in differentiated Caco-2 cells: role of cAMP-signalling pathway and PABP (polyadenylated-binding protein)-interacting protein (Paip) 2 . Biochem J 375:167-174. https://doi.org/10.1042/BJ20030661

136. Grey VL, Morin CL (1990) A growth-stimulating activity derived from the proximal small intestine is associated with an adaptive response. Can J Physiol Pharmacol 68:646-649. https://doi.org/ $10.1139 / \mathrm{y} 90-095$

137. Gribble FM (2012) The gut endocrine system as a coordinator of postprandial nutrient homoeostasis. Proc Nutr Soc 71:456-462. https://doi.org/10.1017/S0029665112000705

138. Groos S, Hunefeld G, Luciano L (1996) Parenteral versus enteral nutrition: morphological changes in human adult intestinal mucosa. J Submicrosc Cytol Pathol 28:61-74. https://www.ncbi.nlm. nih.gov/pubmed/8929627

139. Gröschl M, Rauh M, Wagner R, Neuhuber W, Metzler M, Tamgüney G, Zenk J, Schoof E, Dörr HG, Blum WF, Rascher
W, Dötsch J (2001) Identification of leptin in human saliva. J Clin Endocrinol Metab 86:5234-5239

140. Guan X, Karpen HE, Stephens J, Bukowski JT, Niu S, Zhang G, Stoll B, Finegold MJ, Holst JJ, Hadsell D, Nichols BL, Burrin DG (2006) GLP-2 receptor localizes to enteric neurons and endocrine cells expressing vasoactive peptides and mediates increased blood flow. Gastroenterology 130:150-164. https://doi.org/10.1053/j. gastro.2005.11.005

141. Guo X, Yang B, Tan J, Jiang J, Li D (2016) Associations of dietary intakes of anthocyanins and berry fruits with risk of type 2 diabetes mellitus: a systematic review and meta-analysis of prospective cohort studies. Eur J Clin Nutr 70:1360-1367. https://doi. org/10.1038/ejen.2016.142

142. Haase W, Heitmann K, Friese W, Ollig D, Koepsell H (1990) Characterization and histochemical localization of the rat intestinal $\mathrm{Na}^{+}$-D-glucose cotransporter by monoclonal antibodies. Eur J Cell Biol 52:297-309. https://www.ncbi.nlm.nih.gov/pubmed/ 2081531

143. Habib AM, Richards P, Cairns LS, Rogers GJ, Bannon CA, Parker HE, Morley TC, Yeo GS, Reimann F, Gribble FM (2012) Overlap of endocrine hormone expression in the mouse intestine revealed by transcriptional profiling and flow cytometry. Endocrinology 153:3054-3065. https://doi.org/10.1210/en.20112170

144. Halaihel N, Lievin V, Ball JM, Estes MK, Alvarado F, Vasseur M (2000) Direct inhibitory effect of rotavirus NSP4(114-135) peptide on the $\mathrm{Na}(+)$-D-glucose symporter of rabbit intestinal brush border membrane. J Virol 74:9464-9470. https://doi.org/10.1128/ jvi.74.20.9464-9470.2000

145. Hansen CF, Bueter M, Theis N, Lutz T, Paulsen S, Dalboge LS, Vrang N, Jelsing J (2013) Hypertrophy dependent doubling of Lcells in Roux-en-Y gastric bypass operated rats. PLoS One 8: e65696. https://doi.org/10.1371/journal.pone.0065696

146. Hanson PJ, Morton AP (1983) Metabolism of glucose in the small intestine of lean and obese (ob/ob) mice. Ann Nutr Metab 27:396403. https://doi.org/10.1159/000176711

147. Hara E, Saito M (1980) Diurnal changes in plasma glucose and insulin responses to oral glucose load in rats. Am J Phys 238: E463-E466. https://doi.org/10.1152/ajpendo.1980.238.5.E463

148. Hara E, Saito M (1989) Diurnal change in digestion and absorption of sucrose in vivo in rats. J Nutr Sci Vitaminol (Tokyo) 35: 667-671. https://doi.org/10.3177/jnsv.35.667

149. Hardin JA, Wong JK, Cheeseman CI, Gall DG (1996) Effect of luminal epidermal growth factor on enterocyte glucose and proline transport. Am J Physiol Gastrointest Liver Physiol 271:G509G515. https://doi.org/10.1152/ajpgi.1996.271.3.G509

150. He YL, Haynes W, Meyers CD, Amer A, Zhang Y, Mahling P, Mendonza AE, Ma S, Chutkow W, Bachman E (2019) The effects of licogliflozin, a dual SGLT1/2 inhibitor, on body weight in obese patients with or without diabetes. Diabetes Obes Metab. https://doi.org/10.1111/dom.13654

151. Helliwell PA, Richardson M, Affleck J, Kellett GL (2000) Regulation of GLUT5, GLUT2 and intestinal brush-border fructose absorption by the extracellular signal-regulated kinase, p38 mitogen- activated kinase and phosphatidylinositol 3-kinase intracellular signalling pathways: implications for adaptation to diabetes. Biochem J 350:163-169. http://www.ncbi.nlm.nih.gov/ pubmed/0010926840

152. Helliwell PA, Richardson M, Affleck J, Kellett GL (2000) Stimulation of fructose transport across the intestinal brushborder membrane by PMA is mediated by GLUT2 and dynamically regulated by protein kinase C. Biochem J 350:149-154. https://www.ncbi.nlm.nih.gov/pubmed/10926838

153. Hers HG, Joassin G (1961) Anomaly of hepatic aldolase in intolerance to fructose. Enzymol Biol Clin (Basel) 1:4-14. https:// www.ncbi.nlm.nih.gov/pubmed/13906876 
154. Hidalgo J, Teuber S, Morera FJ, Ojeda C, Flores CA, Hidalgo MA, Nunez L, Villalobos C, Burgos RA (2017) Delphinidin reduces glucose uptake in mice jejunal tissue and human intestinal cell lines through FFA1/GPR40. Int J Mol Sci 18. https://doi.org/ 10.3390/ijms 18040750

155. Hirayama BA, Wong HC, Smith CD, Hagenbuch BA, Hediger MA, Wright EM (1991) Intestinal and renal $\mathrm{Na}^{+} /$glucose cotransporters share common structures. Am J Phys 261:C296C304. https://doi.org/10.1152/ajpcell.1991.261.2.C296

156. Hirsch JR, Loo DDF, Wright EM (1996) Regulation of $\mathrm{Na}^{+} /$glucose cotransporter expression by protein kinases in Xenopus laevis oocytes. J Biol Chem 271:14740-14746 http://www.jbc.org/ content/271/25/14740.full.pdf

157. Hirschhorn N, Kinzie JL, Sachar DB, Northrup RS, Taylor JO, Ahmad SZ, Phillips RA (1968) Decrease in net stool output in cholera during intestinal perfusion with glucose-containing solutions. N Engl J Med 279:176-181. https://doi.org/10.1056/ NEJM196807252790402

158. Hirsh AJ, Cheeseman CI (1998) Cholecystokinin decreases intestinal hexose absorption by a parallel reduction in SGLT1 abundance in the brush-border membrane. J Biol Chem 273:1454514549

159. Hoekstra JH, van den Aker JH (1996) Facilitating effect of amino acids on fructose and sorbitol absorption in children. J Pediatr Gastroenterol Nutr 23:118-124. https://doi.org/10.1097/ 00005176-199608000-00004

160. Holst JJ, Madsbad S (2016) Mechanisms of surgical control of type 2 diabetes: GLP-1 is key factor. Surg Obes Relat Dis 12: 1236-1242. https://doi.org/10.1016/j.soard.2016.02.033

161. Holzer P, Michl T, Danzer M, Jocic M, Schicho R, Lippe IT (2001) Surveillance of the gastrointestinal mucosa by sensory neurons. J Physiol Pharmacol 52:505-521. https://www.ncbi. nlm.nih.gov/pubmed/11787755

162. Honma K, Masuda Y, Mochizuki K, Goda T (2014) Re-feeding rats a high-sucrose diet after 3 days of starvation enhances histone $\mathrm{H} 3$ acetylation in transcribed region and expression of jejunal GLUT5 gene. Biosci Biotechnol Biochem 78:1071-1073. https://doi.org/10.1080/09168451.2014.912121

163. Hopfer U (1975) Diabetes mellitus: changes in the transport properties of isolated intestinal microvillous membranes. Proc Natl Acad Sci U S A 72:2027-2031. https://doi.org/10.1073/pnas.72. 6.2027

164. Hoque KM, Sarker R, Guggino SE, Tse C-M (2009) A new insight into pathophysiological mechanisms of zinc in diarrhea. Ann N Y Acad Sci 1165:279-284

165. Horakova O, Kroupova P, Bardova K, Buresova J, Janovska P, Kopecky J, Rossmeisl M (2019) Metformin acutely lowers blood glucose levels by inhibition of intestinal glucose transport. Sci Rep 9:6156. https://doi.org/10.1038/s41598-019-42531-0

166. Hosseinzadeh Z, Bhavsar SK, Shojaiefard M, Saxena A, Merches K, Sopjani M, Alesutan I, Lang F (2011) Stimulation of the glucose carrier SGLT1 by JAK2. Biochem Biophys Res Commun 408:208-213. https://doi.org/10.1016/j.bbrc.2011.03.036

167. Hu Z, Wang Y, Graham WV, Su L, Musch MW, Turner JR (2006) MAPKAPK-2 is a critical signaling intermediate in NHE3 activation following Na+-glucose cotransport. J Biol Chem 281:2424724253. https://doi.org/10.1074/jbc.M602898200

168. Hwang ES, Hirayama BA, Wright EM (1991) Distribution of the SGLT1 Na+/glucose cotransporter and mRNA along the cryptvillus axis of rabbit small intestine. Biochem Biophys Res Commun 181:1208-1217. https://doi.org/10.1016/0006$291 \mathrm{x}(91) 92067-\mathrm{t}$

169. Ibberson M, Uldry M, Thorens B (2000) GLUTX1, a novel mammalian glucose transporter expressed in the central nervous system and insulin-sensitive tissues. J Biol Chem 275:4607-4612. https:// doi.org/10.1074/jbc.275.7.4607
170. Iizuka K, Bruick RK, Liang G, Horton JD, Uyeda K (2004) Deficiency of carbohydrate response element-binding protein (ChREBP) reduces lipogenesis as well as glycolysis. Proc Natl Acad Sci U S A 101:7281-7286. https://doi.org/10.1073/pnas. 0401516101

171. Ikari A, Nakano M, Kawano K, Suketa Y (2002) Up-regulation of sodium-dependent glucose transporter by interaction with heat shock protein 70. J Biol Chem 277:33338-33343. https://doi. org/10.1016/j.bbamem.2005.10.003

172. Ikari A, Nagatani Y, Tsukimoto M, Harada H, Miwa M, Takagi K (2005) Sodium-dependent glucose transporter reduces peroxynitrite and cell injury caused by cisplatin in renal tubular epithelial cells. Biochim Biophys Acta 1717:109-117. https://doi. org/10.1074/jbc.M200310200

173. Im SS, Kang SY, Kim SY, Kim HI, Kim JW, Kim KS, Ahn YH (2005) Glucose-stimulated upregulation of GLUT2 gene is mediated by sterol response element-binding protein- $1 \mathrm{c}$ in the hepatocytes. Diabetes 54:1684-1691. https://doi.org/10.2337/diabetes. 54.6.1684

174. Inoue Y, Espat NJ, Frohnapple DJ, Epstein H, Copeland EM, Souba WW (1993) Effect of total parenteral nutrition on amino acid and glucose transport by the human small intestine. Ann Surg 217:604-612; discussion 612-604. https://doi.org/10.1097/ 00000658-199306000-00002

175. Inoue $\mathrm{T}$, Takemura $\mathrm{M}$, Fushimi $\mathrm{N}$, Fujimori $\mathrm{Y}$, Onozato $\mathrm{T}$, Kurooka T, Asari T, Takeda H, Kobayashi M, Nishibe H, Isaji M (2017) Mizagliflozin, a novel selective SGLT1 inhibitor, exhibits potential in the amelioration of chronic constipation. Eur J Pharmacol 806:25-31. https://doi.org/10.1016/j.ejphar.2017.04. 010

176. Io F, Gunji E, Koretsune H, Kato K, Sugisaki-Kitano M, Okumura-Kitajima L, Kimura K, Uchida S, Yamamoto K (2019) SGL5213, a novel and potent intestinal SGLT1 inhibitor, suppresses intestinal glucose absorption and enhances plasma GLP-1 and GLP-2 secretion in rats. Eur J Pharmacol 853:136144. https://doi.org/10.1016/j.ejphar.2019.03.023

177. Iwashina I, Mochizuki K, Inamochi Y, Goda T (2011) Clock genes regulate the feeding schedule-dependent diurnal rhythm changes in hexose transporter gene expressions through the binding of BMAL1 to the promoter/enhancer and transcribed regions. J Nutr Biochem 22:334-343. https://doi.org/10.1016/j.jnutbio. 2010.02.012

178. Jang HJ, Kokrashvili Z, Theodorakis MJ, Carlson OD, Kim BJ, Zhou J, Kim HH, Xu X, Chan SL, Juhaszova M, Bernier M, Mosinger B, Margolskee RF, Egan JM (2007) Gut-expressed gustducin and taste receptors regulate secretion of glucagon-like peptide-1. Proc Natl Acad Sci U S A 104:15069-15074. https:// doi.org/10.1073/pnas.0706890104

179. Jang C, Hui S, Lu W, Cowan AJ, Morscher RJ, Lee G, Liu W, Tesz GJ, Birnbaum MJ, Rabinowitz JD (2018) The small intestine converts dietary fructose into glucose and organic acids. Cell Metab 27(351-361):e353. https://doi.org/10.1016/j.cmet.2017.12. 016

180. Jeppesen PB, Hartmann B, Thulesen J, Graff J, Lohmann J, Hansen BS, Tofteng F, Poulsen SS, Madsen JL, Holst JJ, Mortensen PB (2001) Glucagon-like peptide 2 improves nutrient absorption and nutritional status in short-bowel patients with no colon. Gastroenterology 120:806-815. https://doi.org/10.1053/ gast.2001.22555

181. Johnson LR, Copeland EM, Dudrick SJ, Lichtenberger LM, Castro GA (1975) Structural and hormonal alterations in the gastrointestinal tract of parenterally fed rats. Gastroenterology 68: 1177-1183. https://www.ncbi.nlm.nih.gov/pubmed/2182619

182. Johnson JH, Newgard CB, Milburn JL, Lodish HF, Thorens B (1990) The high km glucose transporter of islets of Langerhans is functionally similar to the low affinity transporter of liver and 
has an identical primary sequence. J Biol Chem 265:6548-6551. https://www.ncbi.nlm.nih.gov/pubmed/805078

183. Jurowich CF, Rikkala PR, Thalheimer A, Wichelmann C, Seyfried F, Sander V, Kreissl M, Germer CT, Koepsell H, Otto C (2013) Duodenal-jejunal bypass improves glycemia and decreases SGLT1-mediated glucose absorption in rats with streptozotocin-induced Type 2 diabetes. Ann Surg. https://doi. org/10.1097/SLA.0b013e3182890311

184. Jurowich CF, Otto C, Rikkala PR, Wagner N, Vrhovac I, Sabolic I, Germer CT, Koepsell H (2015) Ileal interposition in rats with experimental type 2 like diabetes improves glycemic control independently of glucose absorption. J Diabetes Res 2015:490365. https://doi.org/10.1155/2015/490365

185. Kanerva K, Makitie LT, Back N, Andersson LC (2010) Ornithine decarboxylase antizyme inhibitor 2 regulates intracellular vesicle trafficking. Exp Cell Res 316:1896-1906. https://doi.org/10.1016/ j.yexcr.2010.02.021

186. Kang HW, Lim WC, Lee JK, Ho JN, Lim EJ, Cho HY (2017) Germinated waxy black rice ameliorates hyperglycemia and dyslipidemia in streptozotocin-induced diabetic rats. Biol Pharm Bull 40:1846-1855. https://doi.org/10.1248/bpb.b17-00239

187. Kasahara M, Maeda M, Hayashi S, Mori Y, Abe T (2001) A missense mutation in the $\mathrm{Na}(+) /$ glucose cotransporter gene SGLT1 in a patient with congenital glucose-galactose malabsorption: normal trafficking but inactivation of the mutant protein. Biochim Biophys Acta 1536:141-147. https://doi.org/10.1016/ s0925-4439(01)00043-6

188. Kayano T, Burant CF, Fukomoto H, Gould GW, Fan Y, Eddy RL, Byers MG, Shows TB, Seino S, Bell GI (1990) Human facilitative glucose transporters isolation, functional characterization, and gene localization of cDNAs encoding an isoform (GLUT5) expressed in small intestine, kidney, muscle and adipose tissue and an unususl glucose transporter pseudogene-like sequence (GLUT6). J Biol Chem 265:13276-13282. https://www.ncbi. nlm.nih.gov/pubmed/1695905

189. Kellett GL (2001) The facilitated component of intestinal glucose absorption. J Physiol 531:585-595. https://doi.org/10.1111/j. 1469-7793.2001.0585h.x

190. Kellett GL, Brot-Laroche E (2005) Apical GLUT2: a major pathway of intestinal sugar absorption. Diabetes 54:3056-3062. https://doi.org/10.2337/diabetes.54.10.3056

191. Kellett GL, Helliwell PA (2000) The diffusive component of intestinal glucose absorption is mediated by the glucose-induced recruitment of GLUT2 to the brush-border membrane. Biochem J 350:155-162. https://doi.org/10.1146/annurev.nutr.28.061807. 155518

192. Kellett GL, Brot-Laroche E, Mace OJ, Leturque A (2008) Sugar absorption in the intestine: the role of GLUT2. Annu Rev Nutr 28: 35-54. https://www.ncbi.nlm.nih.gov/pubmed/10926839

193. Kieffer TJ, Buchan AM, Barker H, Brown JC, Pederson RA (1994) Release of gastric inhibitory polypeptide from cultured canine endocrine cells. Am J Phys 267:E489-E496. https://doi. org/10.1152/ajpendo.1994.267.4.E489

194. Kim JW, Ahn YH (1998) CCAAT/enhancer binding protein regulates the promoter activity of the rat GLUT2 glucose transporter gene in liver cells. Biochem J 336(Pt 1):83-90. https://doi.org/10. 1042/bj3360083

195. Kim H-R, Park S-W, Cho H-J, Chae K-A, Sung J-M, Kim J-S, Landowski CP, Sun D, Abd El-Aty AM, Amidon GL, Shin H-C (2007) Comparative gene expression profiles of intestinal transporters in mice, rats and humans. Pharmacol Res 56:224-236. https://doi.org/10.1042/bj3360083

196. Kim MS, Krawczyk SA, Doridot L, Fowler AJ, Wang JX, Trauger SA, Noh HL, Kang HJ, Meissen JK, Blatnik M, Kim JK, Lai M, Herman MA (2016) ChREBP regulates fructose-induced glucose production independently of insulin signaling. J Clin Invest 126: 4372-4386. https://doi.org/10.1172/JCI81993

197. Kim M, Astapova II, Flier SN, Hannou SA, Doridot L, Sargsyan A, Kou HH, Fowler AJ, Liang G, Herman MA (2017) Intestinal, but not hepatic, ChREBP is required for fructose tolerance. JCI Insight 2. https://doi.org/10.1172/jci.insight.96703

198. Kipp H, Khoursandi S, Scharlau D, Kinne RKH (2003) More than apical: distribution of SGLT1 in Caco-2 cells. Am J Physiol Cell Physiol 285:C737-C749. https://doi.org/10.1152/ajpcell.00041. 2003

199. Kishi K, Tanaka T, Igawa M, Takase S, Goda T (1999) Sucraseisomaltase and hexose transporter gene expressions are coordinately enhanced by dietary fructose in rat jejunum. J Nutr 129: 953-956. https://doi.org/10.1093/jn/129.5.953

200. Koepsell H (2017) The Na(+)-D-glucose cotransporters SGLT1 and SGLT2 are targets for the treatment of diabetes and cancer. Pharmacol Ther 170:148-165. https://doi.org/10.1016/j. pharmthera.2016.10.017

201. Koffert JP, Mikkola K, Virtanen KA, Andersson AD, Faxius L, Hallsten K, Heglind M, Guiducci L, Pham T, Silvola JMU, Virta J, Eriksson O, Kauhanen SP, Saraste A, Enerback S, Iozzo P, Parkkola R, Gomez MF, Nuutila P (2017) Metformin treatment significantly enhances intestinal glucose uptake in patients with type 2 diabetes: results from a randomized clinical trial. Diabetes Res Clin Pract 131:208-216. https://doi.org/10.1016/j.diabres. 2017.07.015

202. Kohli R, Kirby M, Setchell KD, Jha P, Klustaitis K, Woollett LA, Pfluger PT, Balistreri WF, Tso P, Jandacek RJ, Woods SC, Heubi JE, Tschoep MH, D'Alessio DA, Shroyer NF, Seeley RJ (2010) Intestinal adaptation after ileal interposition surgery increases bile acid recycling and protects against obesity-related comorbidities. Am J Physiol Gastrointest Liver Physiol 299:G652-G660. https:// doi.org/10.1152/ajpgi.00221.2010

203. Kojima T, Nishimura M, Yajima T, Kuwata T, Suzuki Y, Goda T, Takase S, Harada E (1999) Developmental changes in the regional $\mathrm{Na}+$ /glucose transporter mRNA along the small intestine of suckling rats. Comp Biochem Physiol B Biochem Mol Biol 122:89 95. https://doi.org/10.1016/s0305-0491(98)10159-1

204. Koopmans HS, Sclafani A, Fichtner C, Aravich PF (1982) The effects of ileal transposition on food intake and body weight loss in VMH-obese rats. Am J Clin Nutr 35:284-293. https://doi.org/10. 1093/ajen/35.2.284

205. Korn T, Kuhlkamp T, Track C, Schatz I, Baumgarten K, Gorboulev V, Koepsell H (2001) The plasma membraneassociated protein RS1 decreases transcription of the transporter SGLT1 in confluent LLC-PK1 cells. J Biol Chem 276:45330 45340. https://doi.org/10.1074/jbc.M105975200

206. Korner J, Bessler M, Cirilo LJ, Conwell IM, Daud A, Restuccia NL, Wardlaw SL (2005) Effects of Roux-en-Y gastric bypass surgery on fasting and postprandial concentrations of plasma ghrelin, peptide YY, and insulin. J Clin Endocrinol Metab 90: 359-365. https://doi.org/10.1210/jc.2004-1076

207. Kotler DP, Levine GM, Shiau YF (1981) Effects of luminal nutrition and metabolic status on in vivo glucose absorption. Am J Phys 240:G432-G436. https://doi.org/10.1152/ajpgi.1981.240.6. G432

208. Kottra G, Daniel H (2007) Flavonoid glycosides are not transported by the human $\mathrm{Na}+$ /glucose transporter when expressed in Xenopus laevis oocytes, but effectively inhibit electrogenic glucose uptake. J Pharmacol Exp Ther 322:829-835. https://doi.org/10.1124/jpet.107.124040

209. Kovalenko PL, Basson MD (2012) Changes in morphology and function in small intestinal mucosa after Roux-en-Y surgery in a rat model. J Surg Res 177:63-69. https://doi.org/10.1016/j.jss. 2012.03.011 
210. Krieger JP, Arnold M, Pettersen KG, Lossel P, Langhans W, Lee SJ (2016) Knockdown of GLP-1 receptors in vagal afferents affects normal food intake and glycemia. Diabetes 65:34-43. https:// doi.org/10.2337/db15-0973

211. Krimi RB, Letteron P, Chedid P, Nazaret C, Ducroc R, Marie JC (2009) Resistin-like molecule-beta inhibits SGLT-1 activity and enhances GLUT2-dependent jejunal glucose transport. Diabetes 58:2032-2038. https://doi.org/10.2337/db08-1786

212. Kroiss M, Leyerer M, Gorboulev V, Kühlkamp T, Kipp H, Koepsell H (2006) Transporter regulator RS1 (RSC1A1) coats the trans-Golgi network and migrates into the nucleus. Am J Physiol Renal Physiol 291:F1201-F1212. https://doi.org/10. 1152/ajprenal.00067.2006

213. Kuhre RE, Gribble FM, Hartmann B, Reimann F, Windelov JA, Rehfeld JF, Holst JJ (2014) Fructose stimulates GLP-1 but not GIP secretion in mice, rats, and humans. Am J Physiol Gastrointest Liver Physiol 306:G622-G630. https://doi.org/10. 1152/ajpgi.00372.2013

214. Kuhre RE, Bechmann LE, Wewer Albrechtsen NJ, Hartmann B, Holst JJ (2015) Glucose stimulates neurotensin secretion from the rat small intestine by mechanisms involving SGLT1 and GLUT2, leading to cell depolarization and calcium influx. Am J Physiol Endocrinol Metab 308:E1123-E1130. https://doi.org/10.1152/ ajpendo.00012.2015

215. Kuhre RE, Frost CR, Svendsen B, Holst JJ (2015) Molecular mechanisms of glucose-stimulated GLP-1 secretion from perfused rat small intestine. Diabetes 64:370-382. https://doi.org/10.2337/ db14-0807

216. Kuriyama C, Kamiyama O, Ikeda K, Sanae F, Kato A, Adachi I, Imahori T, Takahata H, Okamoto T, Asano N (2008) In vitro inhibition of glycogen-degrading enzymes and glycosidases by six-membered sugar mimics and their evaluation in cell cultures. Bioorg Med Chem 16:7330-7336. https://doi.org/10.1016/j.bmc. 2008.06.026

217. Kuroda S, Kobashi Y, Oi T, Kawabe K, Shiozawa F, OkumuraKitajima L, Sugisaki-Kitano M, Io F, Yamamoto K, Kakinuma H (2019) Discovery of potent, low-absorbable sodium-dependent glucose cotransporter 1 (SGLT1) inhibitor SGL5213 for type 2 diabetes treatment. Bioorg Med Chem 27:394-409. https://doi. org/10.1016/j.bmc.2018.12.015

218. Kurokawa T, Hashida F, Kawabata S, Ishibashi S (1995) Evidence for the regulation of small intestinal $\mathrm{Na}+$ /glucose cotransporter by insulin. Biochem Mol Biol Int 37:33-38. https://www.ncbi.nlm. nih.gov/pubmed/8653085

219. Kwon O, Eck P, Chen S, Corpe CP, Lee JH, Kruhlak M, Levine M (2007) Inhibition of the intestinal glucose transporter GLUT2 by flavonoids. FASEB J 21:366-377. https://doi.org/10.1096/fj.06$6620 \mathrm{com}$

220. La FB, Spinosa V, D’Orazio G, Palazzo M, Balsari A, Foppoli AA, Rumio C, Nicotra F (2010) Dansyl C-glucoside as a novel agent against endotoxic shock. ChemMedChem 5:1677-1680. https://doi.org/10.1002/cmdc.201000282

221. Laferrere B, Pattou F (2018) Weight-independent mechanisms of glucose control after Roux-en-Y gastric bypass. Front Endocrinol (Lausanne) 9:530. https://doi.org/10.3389/fendo.2018.00530

222. Lambotte S, Veyhl M, Köhler M, Morrison-Shetlar AI, Kinne RKH, Schmid M, Koepsell H (1996) The human gene of a protein that modifies $\mathrm{Na}^{+}$-D-glucose co-transport. DNA Cell Biol 15: 769-777. https://doi.org/10.1089/dna.1996.15.769

223. Lang F, Voelkl J (2013) Therapeutic potential of serum and glucocorticoid inducible kinase inhibition. Expert Opin Investig Drugs 22:701-714. https://doi.org/10.1517/13543784.2013. 778971

224. Lang F, Bohmer C, Palmada M, Seebohm G, Strutz-Seebohm N, Vallon V (2006) (Patho)physiological significance of the serum- and glucocorticoid-inducible kinase isoforms. Physiol Rev 86: 1151-1178. https://doi.org/10.1152/physrev.00050.2005

225. Laplane R, Polonovski C, Lods JC, Debray P, Etienne M, Pissarro B (1962) L'intolerance aux sucres a transfert intestinal actif - ses rapports a vec l'intolerance au lactose et le syndrome coeliaque. Arch Fr Pediatr 19:895-898< < Go to ISI>://WOS: A19625393A00022

226. Lapointe JY, Gagnon M, Poirier S, Bissonnette P (2002) The presence of local osmotic gradients can account for the water flux driven by the Na+-glucose cotransporter. J Physiol 542:61-62. https://doi.org/10.1113/jphysiol.2002.013328

227. Lapuerta P, Zambrowicz B, Strumph P, Sands A (2015) Development of sotagliflozin, a dual sodium-dependent glucose transporter 1/2 inhibitor. Diab Vasc Dis Res 12:101-110. https:// doi.org/10.1177/1479164114563304

228. Larsen EH, Sorensen JB, Sorensen JN (2000) A mathematical model of solute coupled water transport in toad intestine incorporating recirculation of the actively transported solute. J Gen Physiol 116:101-124. https://doi.org/10.1085/jgp.116.2.101

229. Le KA, Ith M, Kreis R, Faeh D, Bortolotti M, Tran C, Boesch C, Tappy L (2009) Fructose overconsumption causes dyslipidemia and ectopic lipid deposition in healthy subjects with and without a family history of type 2 diabetes. Am J Clin Nutr 89:1760-1765. https://doi.org/10.3945/ajen.2008.27336

230. Lee HJ, Cha JY (2018) Recent insights into the role of ChREBP in intestinal fructose absorption and metabolism. BMB Rep 51:429 436. https://www.ncbi.nlm.nih.gov/pubmed/30158026

231. Lee W-S, Kanai Y, Wells RG, Hediger MA (1994) The high affinity $\mathrm{Na}^{+}$/glucose cotransporter. Re-evaluation of function and distribution of expression. J Biol Chem 269:12032-12039. http:// www.ncbi.nlm.nih.gov/pubmed $/ 8163506$

232. Lee WY, Loflin P, Clancey CJ, Peng H, Lever JE (2000) Cyclic nucleotide regulation of $\mathrm{Na}+$ /glucose cotransporter (SGLT1) mRNA stability. Interaction of a nucleocytoplasmic protein with a regulatory domain in the 3 -untranslated region critical for stabilization. J Biol Chem 275:33998-34008. https://doi.org/10. 1074/jbc.M005040200

233. Lescale-Matys L, Dyer J, Scott D, Freeman TC, Wright EM, Shirazi-Beechey SP (1993) Regulation of the ovine intestinal $\mathrm{Na}^{+} /$glucose co-transporter (SGLT1) is dissociated from mRNA abundance. Biochem J 291:435-440. https://www.ncbi.nlm.nih. gov/pmc/articles/PMC1132544/pdf/biochemj00113-0108.pdf

234. Levine GM, Deren JJ, Steiger E, Zinno R (1974) Role of oral intake in maintenance of gut mass and disaccharide activity. Gastroenterology 67:975-982 https://www.ncbi.nlm.nih.gov/ pubmed/4214726

235. Li M, Carpio DF, Zheng Y, Bruzzo P, Singh V, Ouaaz F, Medzhitov RM, Beg AA (2001) An essential role of the NFkappa B/Toll-like receptor pathway in induction of inflammatory and tissue-repair gene expression by necrotic cells. J Immunol 166:7128-7135. https://doi.org/10.4049/jimmunol.166.12.7128

236. Li Q, Manolescu A, Ritzel M, Yao S, Slugoski M, Young JD, Chen XZ, Cheeseman CI (2004) Cloning and functional characterization of the human GLUT7 isoform SLC2A7 from the small intestine. Am J Physiol Gastrointest Liver Physiol 287:G236G242. https://doi.org/10.1152/ajpgi.00396.2003

237. Li YG, Ji DF, Zhong S, Lv ZQ, Lin TB, Chen S, Hu GY (2011) Hybrid of 1-deoxynojirimycin and polysaccharide from mulberry leaves treat diabetes mellitus by activating PDX-1/insulin-1 signaling pathway and regulating the expression of glucokinase, phosphoenolpyruvate carboxykinase and glucose-6-phosphatase in alloxan-induced diabetic mice. J Ethnopharmacol 134:961970. https://doi.org/10.1016/j.jep.2011.02.009

238. Li P, Pan F, Hao Y, Feng W, Song H, Zhu D (2013) SGK1 is regulated by metabolic-related factors in 3T3-L1 adipocytes and overexpressed in the adipose tissue of subjects with obesity and 
diabetes. Diabetes Res Clin Pract 102:35-42. https://doi.org/10. 1016/j.diabres.2013.08.009

239. Li YG, Ji DF, Zhong S, Lin TB, Lv ZQ, Hu GY, Wang X (2013) 1-deoxynojirimycin inhibits glucose absorption and accelerates glucose metabolism in streptozotocin-induced diabetic mice. Sci Rep 3:1377. https://doi.org/10.1038/srep01377

240. Li P, Hao Y, Pan FH, Zhang M, Ma JQ, Zhu DL (2016) SGK1 inhibitor reverses hyperglycemia partly through decreasing glucose absorption. J Mol Endocrinol 56:301-309. https://doi.org/ 10.1530/JME-15-0285

241. Lim JS, Mietus-Snyder M, Valente A, Schwarz JM, Lustig RH (2010) The role of fructose in the pathogenesis of NAFLD and the metabolic syndrome. Nat Rev Gastroenterol Hepatol 7:251-264. https://doi.org/10.1038/nrgastro.2010.41

242. Lindquist B, Meeuwisse GW (1962) Chronic diarrhoea caused by monosaccharide malabsorption. Acta Paediatr 51:674-685. https://doi.org/10.1111/j.1651-2227.1962.tb06600.x

243. Lisinski I, Schurmann A, Joost HG, Cushman SW, Al-Hasani H (2001) Targeting of GLUT6 (formerly GLUT9) and GLUT8 in rat adipose cells. Biochem J 358:517-522. https://doi.org/10.1042/ 0264-6021:3580517

244. Loflin P, Lever JE (2001) HuR binds a cyclic nucleotide-dependent, stabilizing domain in the 3' untranslated region of $\mathrm{Na}^{+} / \mathrm{glu}-$ cose cotransporter (SGLT1) mRNA. FEBS Lett 509:267-271

245. Loo DD, Zeuthen T, Chandy G, Wright EM (1996) Cotransport of water by the $\mathrm{Na}+$ /glucose cotransporter. Proc Natl Acad Sci U S A 93:13367-13370. https://doi.org/10.1073/pnas.93.23.13367

246. Lorenz-Meyer H, Thiel F, Menge H, Gottesburen H, Riecken EO (1977) Structural and functional studies on the transformation of the intestinal mucosa in rats with experimental diabetes. Res Exp Med (Berl) 170:89-99. https://doi.org/10.1007/bf01851379

247. Lostao MP, Urdaneta E, Martinez-Anso E, Barber A, Martinez JA (1998) Presence of leptin receptors in rat small intestine and leptin effect on sugar absorption. FEBS Lett 423:302-306. https://doi. org/10.1016/s0014-5793(98)00110-0

248. Louis-Sylvestre J (1978) Feeding and metabolic patterns in rats with truncular vagotomy or with transplanted beta-cells. Am J Phys 235:E119-E125. https://doi.org/10.1152/ajpendo.1978.235. 2.E119

249. Ma J, Bellon M, Wishart JM, Young R, Blackshaw LA, Jones KL, Horowitz M, Rayner CK (2009) Effect of the artificial sweetener, sucralose, on gastric emptying and incretin hormone release in healthy subjects. Am J Physiol Gastrointest Liver Physiol 296: G735-G739. https://doi.org/10.1152/ajpgi.90708.2008

250. Mace OJ, Morgan EL, Affleck JA, Lister N, Kellett GL (2007) Calcium absorption by Cav1.3 induces terminal web myosin II phosphorylation and apical GLUT2 insertion in rat intestine. J Physiol 580:605-616. https://doi.org/10.1113/jphysiol.2006. 124784

251. Mace OJ, Schindler M, Patel S (2012) The regulation of K- and Lcell activity by GLUT2 and the calcium-sensing receptor CasR in rat small intestine. J Physiol 590:2917-2936. https://doi.org/10. 1113/jphysiol.2011.223800

252. Madsen KL, Ariano D, Fedorak RN (1996) Insulin downregulates diabetic-enhanced intestinal glucose transport rapidly in ileum and slowly in jejunum. Can J Physiol Pharmacol 74:1294-1301. https://doi.org/10.1139/cjpp-74-12-1294

253. Madunic IV, Breljak D, Karaica D, Koepsell H, Sabolic I (2017) Expression profiling and immunolocalization of Na+-D-glucosecotransporter 1 in mice employing knockout mice as specificity control indicate novel locations and differences between mice and rats. Pflugers Arch. https://doi.org/10.1007/s00424-017-2056-1

254. Mahraoui L, Rousset M, Dussaulx E, Darmoul D, Zweibaum A, Brot-Laroche E (1992) Expression and localization of GLUT-5 in Caco-2 cells, human small intestine, and colon. Am J Phys 263: G312-G318. https://doi.org/10.1152/ajpgi.1992.263.3.G312
255. Mahraoui L, Takeda J, Mesonero J, Chantret I, Dussaulx E, Bell GI, Brot-Laroche E (1994) Regulation of expression of the human fructose transporter (GLUT5) by cyclic AMP. Biochem J 301: 169-175

256. Manzano S, Williamson G (2010) Polyphenols and phenolic acids from strawberry and apple decrease glucose uptake and transport by human intestinal Caco-2 cells. Mol Nutr Food Res 54:17731780. https://doi.org/10.1002/mnfr.201000019

257. Margolskee RF, Dyer J, Kokrashvili Z, Salmon KS, Ilegems E, Daly K, Maillet EL, Ninomiya Y, Mosinger B, Shirazi-Beechey SP (2007) T1R3 and gustducin in gut sense sugars to regulate expression of Na+-glucose cotransporter 1. Proc Natl Acad Sci U S A 104:15075-15080. https://doi.org/10.1073/pnas. 0706678104

258. Martin MG, Turk E, Lostao MP, Kerner C, Wright EM (1996) Defects in $\mathrm{Na}^{+}$/glucose cotransporter (SGLT1) trafficking and function cause glucose-galactose malabsorption. Nat Genet 12: 216-220. https://doi.org/10.1038/ng0296-216

259. Martin MG, Wang J, Solorzano-Vargas RS, Lam JT, Turk E, Wright EM (2000) Regulation of the human $\mathrm{Na}^{+}$-glucose cotransporter gene, SGLT1, by HNF-1 and Sp1. Am J Physiol Gastrointest Liver Physiol 278:G591-G603. https://doi.org/10. 1152/ajpgi.2000.278.4.G591

260. Matosin-Matekalo M, Mesonero JE, Laroche TJ, Lacasa M, BrotLaroche E (1999) Glucose and thyroid hormone co-regulate the expression of the intestinal fructose transporter GLUT5. Biochem J 339(Pt 2):233-239. https://www.ncbi.nlm.nih.gov/pubmed/ 10191252

261. Mehta DI, Horvath K, Chanasongcram S, Hill ID, Panigrahi P (1997) Epidermal growth factor up-regulates sodium-glucose cotransport in enterocyte models in the presence of cholera toxin. JPEN J Parenter Enteral Nutr 21:185-191. https://doi.org/10. 1177/0148607197021004185

262. Melin K, Meeuwisse GW (1969) Glucose-galactose malabsorption. A genetic study. Acta Paediatr Scand Suppl 188:119+. https://www.ncbi.nlm.nih.gov/pubmed/5371329

263. Mingrone G, Panunzi S, De Gaetano A, Guidone C, Iaconelli A, Leccesi L, Nanni G, Pomp A, Castagneto M, Ghirlanda G, Rubino F (2012) Bariatric surgery versus conventional medical therapy for type 2 diabetes. N Engl J Med 366:1577-1585. https://doi.org/10. 1056/NEJMoa1200111

264. Miyamoto K, Hase K, Taketani Y, Minami H, Oka T, Nakabou Y, Hagihira H (1991) Diabetes and glucose transporter gene expression in rat small intestine. Biochem Biophys Res Commun 181: 1110-1117. https://doi.org/10.1016/0006-291x(91)92053-m

265. Miyamoto K, Hase K, Takagi T, Fujii T, Taketani Y, Minami H, Oka T, Nakabou Y (1993) Differential responses of intestinal glucose transporter mRNA transcripts to levels of dietary sugars. Biochem J 295(Pt 1):211-215. https://doi.org/10.1042/bj2950211

266. Miyamoto K, Tatsumi S, Morimoto A, Minami H, Yamamoto H, Sone K, Taketani Y, Nakabou Y, Oka T, Takeda E (1994) Characterization of the rabbit intestinal fructose transporter (GLUT5). Biochem J 303(Pt 3):877-883. https://doi.org/10. 1042/bj3030877

267. Moran A, Turner RJ, Handler JS (1983) Regulation of sodiumcoupled glucose transport by glucose in a cultured epithelium. J Biol Chem 258:15087-15090. https://www.ncbi.nlm.nih.gov/ pubmed/6654906

268. Moran AW, Al-Rammahi MA, Batchelor DJ, Bravo DM, ShiraziBeechey SP (2018) Glucagon-like peptide-2 and the enteric nervous system are components of cell-cell communication pathway regulating intestinal $\mathrm{Na}(+) /$ glucose co-transport. Front Nutr 5:101. https://doi.org/10.3389/fnut.2018.00101

269. Morgan EL, Mace OJ, Helliwell PA, Affleck J, Kellett GL (2003) A role for $\mathrm{Ca}_{\mathrm{v} 1.3}$ in rat intestinal calcium absorption. Biochem 
Biophys Res Commun 312:487-493. https://doi.org/10.1113/ jphysiol.2006.124768

270. Morgan EL, Mace OJ, Affleck J, Kellett GL (2007) Apical GLUT2 and Cav1.3: regulation of rat intestinal glucose and calcium absorption. J Physiol 580:593-604. https://doi.org/10.1113/ jphysiol.2006.124768

271. Moriya R, Shirakura T, Ito J, Mashiko S, Seo T (2009) Activation of sodium-glucose cotransporter 1 ameliorates hyperglycemia by mediating incretin secretion in mice. Am J Physiol Endocrinol Metab 297:E1358-E1365. https://doi.org/10.1152/ajpendo. 00412.2009

272. Morton AP, Hanson PJ (1984) Monosaccharide transport by the small intestine of lean and genetically obese (ob/ob) mice. Q J Exp Physiol 69:117-126. https://doi.org/10.1113/expphysiol.1984. sp002772

273. Mueller T, Terada T, Rosenberg IM, Shibolet O, Podolsky DK (2006) Th2 cytokines down-regulate TLR expression and function in human intestinal epithelial cells. J Immunol 176:5805-5814. https://doi.org/10.4049/jimmunol.176.10.5805

274. Mumphrey MB, Patterson LM, Zheng H, Berthoud HR (2013) Roux-en-Y gastric bypass surgery increases number but not density of CCK-, GLP-1-, 5-HT-, and neurotensin-expressing enteroendocrine cells in rats. Neurogastroenterol Motil 25:e70 e79. https://doi.org/10.1111/nmo.12034

275. Mumy KL, McCormick BA (2005) Events at the host-microbial interface of the gastrointestinal tract. II. Role of the intestinal epithelium in pathogen-induced inflammation. Am J Physiol Gastrointest Liver Physiol 288:G854-G859. https://doi.org/10. 1152/ajpgi.00565.2004

276. Munnich A, Besmond C, Darquy S, Reach G, Vaulont S, Dreyfus JC, Kahn A (1985) Dietary and hormonal regulation of aldolase B gene expression. J Clin Invest 75:1045-1052. https://doi.org/10. 1172/JCI111766

277. Musso G, Gambino R, Cassader M, Paschetta E (2019) Efficacy and safety of dual SGLT $1 / 2$ inhibitor sotagliflozin in type 1 diabetes: meta-analysis of randomised controlled trials. BMJ 365: 11328. https://doi.org/10.1136/bmj.11328

278. Nair MG, Guild KJ, Du Y, Zaph C, Yancopoulos GD, Valenzuela DM, Murphy A, Stevens S, Karow M, Artis D (2008) Goblet cellderived resistin-like molecule $\mathrm{b}$ augments $\mathrm{CD} 4^{+} \mathrm{T}$ cell production of IFN-g and infection-induced intestinal inflammation. J Immunol 181:4709-4715. https://www.ncbi.nlm.nih.gov/ pubmed/18802073

279. Nielsen LB, Ploug KB, Swift P, Ørskov C, Jansen-Olesen I, Chiarelli F, Holst JJ, Hougaard P, Pörksen S, Holl R, dB C, Gammeltoft S, Rorsman P, Mortensen HB, Hansen L (2007) Co-localisation of the Kir6.2/SUR1 channel complex with glucagon-like peptide-1 and glucose-dependent insulinotrophic polypeptide expression in human ileal cells and implications for glycaemic control in new onset type 1 diabetes. Eur J Endocrinol 156:663-671 https://doi.org/10.1530/EJE-06-0756

280. Nishida T, Saito M, Suda M (1978) Parallel between circadian rhythms of intestinal disaccharidases and foot intake of rats under constant lighting conditions. Gastroenterology 74:224-227. https://www.ncbi.nlm.nih.gov/pubmed/340321

281. Nolan JJ, Ludvik B, Beerdsen P, Joyce M, Olefsky J (1994) Improvement in glucose tolerance and insulin resistance in obese subjects treated with troglitazone. N Engl J Med 331:1188-1193. https://doi.org/10.1056/NEJM199411033311803

282. Ogata H, Seino Y, Harada N, Iida A, Suzuki K, Izumoto T, Ishikawa K, Uenishi E, Ozaki N, Hayashi Y, Miki T, Inagaki N, Tsunekawa S, Hamada Y, Seino S, Oiso Y (2014) KATP channel as well as SGLT1 participates in GIP secretion in the diabetic state. J Endocrinol 222:191-200. https://doi.org/10.1530/JOE$14-0161$
283. Oh AR, Sohn S, Lee J, Park JM, Nam KT, Hahm KB, Kim YB, Lee HJ, Cha JY (2018) ChREBP deficiency leads to diarrheapredominant irritable bowel syndrome. Metabolism 85:286-297. https://doi.org/10.1016/j.metabol.2018.04.006

284. Ohta T, Isselbacher KJ, Rhoads DB (1990) Regulation of glucose transporters in $\mathrm{LLC}^{-\mathrm{PK}_{1}}$ cells: effects of D-glucose and monosaccharides. Mol Cell Biol 10:6491-6499. https://doi.org/10.1128/ mcb.10.12.6491

285. Oliveira DM, Freitas HS, Souza MF, Arcari DP, Ribeiro ML, Carvalho PO, Bastos DH (2008) Yerba Mate (Ilex paraguariensis) aqueous extract decreases intestinal SGLT1 gene expression but does not affect other biochemical parameters in alloxan-diabetic Wistar rats. J Agric Food Chem 56:10527-10532. https://doi.org/ 10.1021/jf8021404

286. Osswald C, Baumgarten K, Stümpel F, Gorboulev V, Akimjanova M, Knobeloch K-P, Horak I, Kluge R, Joost H-G, Koepsell H (2005) Mice without the regulator gene RsclAl exhibit increased $\mathrm{Na}^{+}$-D-glucose cotransport in small intestine and develop obesity. Mol Cell Biol 25:78-87. https://doi.org/10.1128/MCB.25.1.7887.2005

287. Ozulker T, Ozulker F, Mert M, Ozpacaci T (2010) Clearance of the high intestinal (18)F-FDG uptake associated with metformin after stopping the drug. Eur J Nucl Med Mol Imaging 37:10111017. https://doi.org/10.1007/s00259-009-1330-7

288. Pahari A, Milla PJ, van't Hoff WG (2003) Neonatal nephrocalcinosis in association with glucose-galactose malabsorption. Pediatr Nephrol 18:700-702. https://doi.org/10.1007/ s00467-003-1155-8

289. Pais R, Gribble FM, Reimann F (2016) Stimulation of incretin secreting cells. Ther Adv Endocrinol Metab 7:24-42. https://doi. org/10.1177/2042018815618177

290. Pal A, Rhoads DB, Tavakkoli A (2015) Foregut exclusion disrupts intestinal glucose sensing and alters portal nutrient and hormonal milieu. Diabetes 64:1941-1950. https://doi.org/10.2337/db141578

291. Palazzo M, Balsari A, Rossini A, Selleri S, Calcaterra C, Gariboldi S, Zanobbio L, Arnaboldi F, Shirai YF, Serrao G, Rumio C (2007) Activation of enteroendocrine cells via TLRs induces hormone, chemokine, and defensin secretion. J Immunol 178:4296-4303. https://doi.org/10.4049/jimmunol.178.7.4296

292. Palazzo M, Gariboldi S, Zanobbio L, Selleri S, Dusio GF, Mauro V, Rossini A, Balsari A, Rumio C (2008) Sodium-dependent glucose transporter-1 as a novel immunological player in the intestinal mucosa. J Immunol 181:3126-3136. https://doi.org/10.4049/ jimmunol.181.5.3126

293. Panaro MA, Cianciulli A, Mitolo V, Mitolo CI, Acquafredda A, Brandonisio O, Cavallo P (2007) Caspase-dependent apoptosis of the HCT-8 epithelial cell line induced by the parasite Giardia intestinalis. FEMS Immunol Med Microbiol 51:302-309. https:// doi.org/10.1111/j.1574-695X.2007.00304.X

294. Parker HE, Habib AM, Rogers GJ, Gribble FM, Reimann F (2009) Nutrient-dependent secretion of glucose-dependent insulinotropic polypeptide from primary murine $\mathrm{K}$ cells. Diabetologia 52:289-298. https://doi.org/10.1007/s00125-0081202-x

295. Parker HE, Adriaenssens A, Rogers G, Richards P, Koepsell H, Reimann F, Gribble FM (2012) Predominant role of active versus facilitative glucose transport for glucagon-like peptide-1 secretion. Diabetologia 55:2445-2455. https://doi.org/10.1007/s00125-0122585-2

296. Patel C, Sugimoto K, Douard V, Shah A, Inui H, Yamanouchi T, Ferraris RP (2015) Effect of dietary fructose on portal and systemic serum fructose levels in rats and in KHK-/- and GLUT5-/- mice. Am J Physiol Gastrointest Liver Physiol 309:G779-G790. https:// doi.org/10.1152/ajpgi.00188.2015 
297. Patriti A, Facchiano E, Annetti C, Aisa MC, Galli F, Fanelli C, Donini A (2005) Early improvement of glucose tolerance after ileal transposition in a non-obese type 2 diabetes rat model. Obes Surg 15:1258-1264. https://doi.org/10.1381/ 096089205774512573

298. Patriti A, Aisa MC, Annetti C, Sidoni A, Galli F, Ferri I, Gulla N, Donini A (2007) How the hindgut can cure type 2 diabetes. Ileal transposition improves glucose metabolism and beta-cell function in Goto-kakizaki rats through an enhanced Proglucagon gene expression and L-cell number. Surgery 142:74-85. https://doi.org/ 10.1381/096089205774512573

299. Patti ME, Houten SM, Bianco AC, Bernier R, Larsen PR, Holst JJ, Badman MK, Maratos-Flier E, Mun EC, Pihlajamaki J, Auwerx J, Goldfine AB (2009) Serum bile acids are higher in humans with prior gastric bypass: potential contribution to improved glucose and lipid metabolism. Obesity (Silver Spring) 17:1671-1677. https://doi.org/10.1038/oby.2009.102

300. Patwari P, Lee RT (2012) An expanded family of arrestins regulate metabolism. Trends Endocrinol Metab 23:216-222. https:// doi.org/10.1016/j.tem.2012.03.003

301. Pedersen J, Pedersen NB, Brix SW, Grunddal KV, Rosenkilde MM, Hartmann B, Orskov C, Poulsen SS, Holst JJ (2015) The glucagon-like peptide 2 receptor is expressed in enteric neurons and not in the epithelium of the intestine. Peptides 67:20-28. https://doi.org/10.1016/j.peptides.2015.02.007

302. Peng H, Lever JE (1993) Polyamine regulation of $\mathrm{Na}^{+} /$glucose symporter expression in LLC-PK1 cells. J Cell Physiol 154:238$247 \mathrm{https} / / /$ onlinelibrary.wiley.com/doi/abs/10.1002/jcp. 1041540205

303. Peng H, Lever JE (1995) Post-transcriptional regulation of $\mathrm{Na}^{+} /$ glucose cotransporter (SGLT1) gene expression in LLC-PK 1 cells - increased message stability after cyclic AMP elevation or differentation inducer treatment. J Biol Chem 270:20536-20542. https://doi.org/10.1074/jbc.270.35.20536

304. Penicaud L, Hitier Y, Ferre P, Girard J (1989) Hypoglycaemic effect of metformin in genetically obese (fa/fa) rats results from an increased utilization of blood glucose by intestine. Biochem $\mathrm{J}$ 262:881-885. https://doi.org/10.1042/bj2620881

305. Pennington AM, Corpe CP, Kellett GL (1994) Rapid regulation of rat jejunal glucose transport by insulin in a luminally and vascularly perfused preparation. J Physiol 478(Pt 2):187-193. https://doi.org/10.1113/jphysiol.1994.sp020241

306. Pierce NF, Banwell JG, Rupak DM, Mitra RC, Caranasos GJ, Keimowitz RI, Mondal A, Manji PM (1968) Effect of intragastric glucose-electrolyte infusion upon water and electrolyte balance in Asiatic cholera. Gastroenterology 55:333-343. https://www.ncbi. nlm.nih.gov/pubmed/5675364

307. Pinto AB, Carayannopoulos MO, Hoehn A, Dowd L, Moley KH (2002) Glucose transporter 8 expression and translocation are critical for murine blastocyst survival. Biol Reprod 66:1729-1733. https://doi.org/10.1095/biolreprod66.6.1729

308. Playford RJ, Hanby AM, Gschmeissner S, Peiffer LP, Wright NA, McGarrity T (1996) The epidermal growth factor receptor (EGF$\mathrm{R})$ is present on the basolateral, but not the apical, surface of enterocytes in the human gastrointestinal tract. Gut 39:262-266. https://doi.org/10.1136/gut.39.2.262

309. Rajas F, Bruni N, Montano S, Zitoun C, Mithieux G (1999) The glucose- 6 phosphatase gene is expressed in human and rat small intestine: regulation of expression in fasted and diabetic rats. Gastroenterology 117:132-139

310. Ramzy AR, Nausheen S, Chelikani PK (2014) Ileal transposition surgery produces ileal length-dependent changes in food intake, body weight, gut hormones and glucose metabolism in rats. Int $\mathrm{J}$ Obes (Lond) 38:379-387. https://doi.org/10.1038/ijo.2013.201

311. Rand EB, Depaoli AM, Davidson NO, Bell GI, Burant CF (1993) Sequence, tissue distribution, and functional characterization of the rat fructose transporter GLUT5. Am J Phys 264:G1169G1176. https://doi.org/10.1152/ajpgi.1993.264.6.G1169

312. Rao MC (2004) Oral rehydration therapy: new explanations for an old remedy. Annu Rev Physiol 66:385-417. https://doi.org/10. 1146/annurev.physiol.66.032902.134726

313. Ravich WJ, Bayless TM, Thomas M (1983) Fructose: incomplete intestinal absorption in humans. Gastroenterology 84:26-29. https:/www.ncbi.nlm.nih.gov/pubmed/6847852

314. Raybould HE (2002) Visceral perception: sensory transduction in visceral afferents and nutrients. Gut 51(Suppl 1):i11-i14. https:// doi.org/10.1136/gut.51.suppl 1.i11

315. Reimann F, Gribble FM (2002) Glucose-sensing in glucagon-like peptide-1-secreting cells. Diabetes 51:2757-2763. https://doi.org/ 10.2337/diabetes.51.9.2757

316. Reimann F, Habib AM, Tolhurst G, Parker HE, Rogers GJ, Gribble FM (2008) Glucose sensing in L cells: a primary cell study. Cell Metab 8:532-539. https://doi.org/10.1016/j.cmet. 2008.11.002

317. Reimann F, Tolhurst G, Gribble FM (2012) G-protein-coupled receptors in intestinal chemosensation. Cell Metab 15:421-431. https://doi.org/10.1016/j.cmet.2011.12.019

318. Rencurel F, Waeber G, Antoine B, Rocchiccioli F, Maulard P, Girard J, Leturque A (1996) Requirement of glucose metabolism for regulation of glucose transporter type 2 (GLUT2) gene expression in liver. Biochem J 314(Pt 3):903-909. https://doi.org/10. 1042/bj3140903

319. Rhoads DB, Rosenbaum DH, Unsal H, Isselbacher KJ, Levitsky LL (1998) Circadian periodicity of intestinal $\mathrm{Na}^{+} /$glucose cotransporter $1 \mathrm{mRNA}$ levels is transcriptionally regulated. $\mathrm{J}$ Biol Chem 273:9510-9516 https://doi.org/10.1074/jbc.273.16. 9510

320. Rindi G, Leiter AB, Kopin AS, Bordi C, Solcia E (2004) The "normal" endocrine cell of the gut: changing concepts and new evidences. Ann N Y Acad Sci 1014:1-12 https://doi.org/10.1196/ annals. 1294.001

321. Ritzel U, Fromme A, Ottleben M, Leonhardt U, Ramadori G (1997) Release of glucagon-like peptide-1 (GLP-1) by carbohydrates in the perfused rat ileum. Acta Diabetol 34:18-21 https:// doi.org/10.1007/s005920050059

322. Roder PV, Geillinger KE, Zietek TS, Thorens B, Koepsell H, Daniel H (2014) The role of SGLT1 and GLUT2 in intestinal glucose transport and sensing. PLoS One 9:e89977. https://doi. org/10.1371/journal.pone.0089977

323. Rogers S, Macheda ML, Docherty SE, Carty MD, Henderson MA, Soeller WC, Gibbs EM, James DE, Best JD (2002) Identification of a novel glucose transporter-like protein-GLUT12. Am J Physiol Endocrinol Metab 282:E733-E738. https://doi. org/10.1152/ajpendo.2002.282.3.E733

324. Rogers S, Chandler JD, Clarke AL, Petrou S, Best JD (2003) Glucose transporter GLUT12-functional characterization in Xenopus laevis oocytes. Biochem Biophys Res Commun 308: 422-426. https://doi.org/10.1016/s0006-291x(03)01417-7

325. Rogers GJ, Tolhurst G, Ramzan A, Habib AM, Parker HE, Gribble FM, Reimann F (2011) Electrical activity-triggered glucagon-like peptide-1 secretion from primary murine L-cells. J Physiol 589:1081-1093. https://doi.org/10.1113/jphysiol.2010. 198069

326. Romero A, Terrado J, Brot-Laroche E, Mesonero JE (2007) Glucose transporter GLUT8 mRNA expression in intestinal Caco-2 cells is regulated by growth and metabolism. Horm Metab Res 39:62-64. https://doi.org/10.1055/s-2007-957351

327. Romero A, Gomez O, Terrado J, Mesonero JE (2009) Expression of GLUT8 in mouse intestine: identification of alternative spliced variants. J Cell Biochem 106:1068-1078. https://doi.org/10.1002/ jcb. 22090 
328. Ross JA, Kasum CM (2002) Dietary flavonoids: bioavailability, metabolic effects, and safety. Annu Rev Nutr 22:19-34. https:// doi.org/10.1146/annurev.nutr.22.111401.144957

329. Rubino F, Marescaux J (2004) Effect of duodenal-jejunal exclusion in a non-obese animal model of type 2 diabetes: a new perspective for an old disease. Ann Surg 239:1-11. https://doi.org/10. 1097/01.sla.0000102989.54824.fc

330. Rumessen JJ, Gudmand-Hoyer E (1986) Absorption capacity of fructose in healthy adults. Comparison with sucrose and its constituent monosaccharides. Gut 27:1161-1168. https://doi.org/10. 1136/gut.27.10.1161

331. Rumessen JJ, Gudmand-Hoyer E (1987) Malabsorption of fructose-sorbitol mixtures. Interactions causing abdominal distress. Scand J Gastroenterol 22:431-436. https://doi.org/10. 3109/00365528708991486

332. Rumessen JJ, Gudmand-Hoyer E (1988) Functional bowel disease: malabsorption and abdominal distress after ingestion of fructose, sorbitol, and fructose-sorbitol mixtures. Gastroenterology 95: 694-700. https://doi.org/10.1016/s0016-5085(88)80016-7

333. Ryan KK, Tremaroli V, Clemmensen C, Kovatcheva-Datchary P, Myronovych A, Karns R, Wilson-Perez HE, Sandoval DA, Kohli R, Backhed F, Seeley RJ (2014) FXR is a molecular target for the effects of vertical sleeve gastrectomy. Nature 509:183-188. https://doi.org/10.1038/nature13135

334. Saeidi N, Meoli L, Nestoridi E, Gupta NK, Kvas S, Kucharczyk J, Bonab AA, Fischman AJ, Yarmush ML, Stylopoulos N (2013) Reprogramming of intestinal glucose metabolism and glycemic control in rats after gastric bypass. Science 341:406-410. https:// doi.org/10.1126/science. 1235103

335. Sakar Y, Meddah B, Faouzi MA, Cherrah Y, Bado A, Ducroc R (2010) Metformin-induced regulation of the intestinal D-glucose transporters. J Physiol Pharmacol 61:301-307. https://www.ncbi. nlm.nih.gov/pubmed/20610860

336. Santer R, Schneppenheim R, Dombrowski A, Gotze H, Steinmann B, Schaub J (1997) Mutations in GLUT2, the gene for the livertype glucose transporter, in patients with Fanconi-Bickel syndrome. Nat Genet 17:324-326. https://doi.org/10.1038/ng1197324

337. Santer R, Schneppenheim R, Suter D, Schaub J, Steinmann B (1998) Fanconi-Bickel syndrome-the original patient and his natural history, historical steps leading to the primary defect, and a review of the literature. Eur J Pediatr 157:783-797. https://doi.org/ $10.1007 / \mathrm{s} 004310050937$

338. Santer R, Groth S, Kinner M, Dombrowski A, Berry GT, Brodehl J, Leonard JV, Moses S, Norgren S, Skovby F, Schneppenheim R, Steinmann B, Schaub J (2002) The mutation spectrum of the facilitative glucose transporter gene SLC2A2 (GLUT2) in patients with Fanconi-Bickel syndrome. Hum Genet 110:21-29. https:// doi.org/10.1007/s00439-001-0638-6

339. Santer R, Steinmann B, Schaub J (2002) Fanconi-Bickel syndrome - a congenital defect of facilitative glucose transport. Curr Mol Med 2:213-227. https://doi.org/10.2174/1566524024605743

340. Savioli L, Smith H, Thompson A (2006) Giardia and cryptosporidium join the 'Neglected Diseases Initiative'. Trends Parasitol 22:203-208. https://doi.org/10.1016/j.pt.2006.02.015

341. Schafer N, Rikkala PR, Veyhl-Wichmann M, Keller T, Jurowich CF, Geiger D, Koepsell H (2019) A modified tripeptide motif of RS1 (RSC1A1) down-regulates exocytotic pathways of human $\mathrm{Na}(+)$-D-glucose cotransporters SGLT1, SGLT2, and glucose sensor sGLT3 in the presence of glucose. Mol Pharmacol 95:8296. https://doi.org/10.1124/mol.118.113514

342. Schauer PR, Kashyap SR, Wolski K, Brethauer SA, Kirwan JP, Pothier CE, Thomas S, Abood B, Nissen SE, Bhatt DL (2012) Bariatric surgery versus intensive medical therapy in obese patients with diabetes. N Engl J Med 366:1567-1576. https://doi. org/10.1056/NEJMoa1200225
343. Schedl HP, Wilson HD (1971) Effects of diabetes on intestinal growth and hexose transport in the rat. Am J Phys 220:17391745. https://doi.org/10.1152/ajplegacy.1971.220.6.1739

344. Schmidt U, Briese S, Leicht K, Schurmann A, Joost HG, AlHasani H (2006) Endocytosis of the glucose transporter GLUT8 is mediated by interaction of a dileucine motif with the beta2adaptin subunit of the AP-2 adaptor complex. J Cell Sci 119: 2321-2331. https://doi.org/10.1242/jcs.02943

345. Schmitt CC, Aranias T, Viel T, Chateau D, Le Gall M, WaligoraDupriet AJ, Melchior C, Rouxel O, Kapel N, Gourcerol G, Tavitian B, Lehuen A, Brot-Laroche E, Leturque A, Serradas P, Grosfeld A (2017) Intestinal invalidation of the glucose transporter GLUT2 delays tissue distribution of glucose and reveals an unexpected role in gut homeostasis. Mol Metab 6:61-72. https://doi. org/10.1016/j.molmet.2016.10.008

346. Schoeler M, Klag T, Wendler J, Bernhard S, Adolph M, Kirschniak A, Goetz M, Malek N, Wehkamp J (2018) GLP-2 analog teduglutide significantly reduces need for parenteral nutrition and stool frequency in a real-life setting. Ther Adv Gastroenterol 11:1756284818793343. https://doi.org/10.1177/ 1756284818793343

347. Scholtka B, Stümpel F, Jungermann K (1999) Acute increase, stimulated by prostaglandin $\mathrm{E}_{2}$, in glucose absorption via the sodium dependent glucose transporter-1 in rat intestine. Gut 44:490 496. https://doi.org/10.1136/gut.44.4.490

348. Scott KG, Meddings JB, Kirk DR, Lees-Miller SP, Buret AG (2002) Intestinal infection with Giardia spp. reduces epithelial barrier function in a myosin light chain kinase-dependent fashion. Gastroenterology 123:1179-1190. https://doi.org/10.1053/gast. 2002.36002

349. Seeley RJ, Chambers AP, Sandoval DA (2015) The role of gut adaptation in the potent effects of multiple bariatric surgeries on obesity and diabetes. Cell Metab 21:369-378. https://doi.org/10. 1016/j.cmet.2015.01.001

350. Sharp PA, Debnam ES (1994) The role of cyclic AMP in the control of sugar transport across the brush-border and basolateral membranes of rat jejunal enterocytes. Exp Physiol 79:203-214. https:/www.ncbi.nlm.nih.gov/pubmed/8003304

351. Sharp PA, Debnam ES, Srai SKS (1996) Rapid enhancement of brush border glucose uptake after exposure of rat jejunal mucosa to glucose. Gut 39:545-550. https://doi.org/10.1136/gut.39.4.545

352. Shaw D, Gohil K, Basson MD (2012) Intestinal mucosal atrophy and adaptation. World J Gastroenterol 18:6357-6375. https://doi. org/10.3748/wjg.v18.i44.6357

353. Shioda T, Ohta T, Isselbacher KJ, Rhoads DB (1994) Differentiation-dependent expression of the $\mathrm{Na}+$ glucose cotransporter (SGLT1) in LLC-PK1 cells: role of protein kinase $\mathrm{C}$ activation and ongoing transcription. Proc Natl Acad Sci U S A 91:11919-11923. https://doi.org/10.1073/pnas.91.25.11919

354. Shirazi-Beechey SP (1996) Intestinal sodium-dependent D-glucose co-transporter: dietary regulation. Proc Nutrit Soc 55:167178.354, https://www.ncbi.nlm.nih.gov/pubmed/8832789

355. Shirazi-Beechey SP, Hirayama BA, Wang Y, Scott D, Smith MW, Wright EM (1991) Ontogenic development of lamb intestinal sodium-glucose co-transporter is regulated by diet. J Physiol 437:699-708. https://doi.org/10.1113/jphysiol.1991.sp018620

356. Shiue H, Musch MW, Wang Y, Chang EB, Turner JR (2005) Akt2 phosphorylates ezrin to trigger NHE3 translocation and activation. J Biol Chem 280:1688-1695. https://doi.org/10.1074/jbc. M409471200

357. Shojima N, Ogihara T, Inukai K, Fujishiro M, Sakoda H, Kushiyama A, Katagiri H, Anai M, Ono H, Fukushima Y, Horike N, Viana AY, Uchijima Y, Kurihara H, Asano T (2005) Serum concentrations of resistin-like molecules beta and gamma are elevated in high-fat-fed and obese $\mathrm{db} / \mathrm{db}$ mice, with increased 
production in the intestinal tract and bone marrow. Diabetologia 48:984-992. https://doi.org/10.1007/s00125-005-1735-1

358. Singh AK, Amlal H, Haas PJ, Dringenberg U, Fussell S, Barone SL, Engelhardt R, Zuo J, Seidler U, Soleimani M (2008) Fructoseinduced hypertension: essential role of chloride and fructose absorbing transporters PAT1 and Glut5. Kidney Int 74:438-447. https://doi.org/10.1038/ki.2008.184

359. Singh V, Yang J, Chen TE, Zachos NC, Kovbasnjuk O, Verkman AS, Donowitz M (2014) Translating molecular physiology of intestinal transport into pharmacologic treatment of diarrhea: stimulation of $\mathrm{Na}+$ absorption. Clin Gastroenterol Hepatol 12:27-31. https://doi.org/10.1016/j.cgh.2013.10.020

360. Skoog SM, Bharucha AE (2004) Dietary fructose and gastrointestinal symptoms: a review. Am J Gastroenterol 99:2046-2050. https://doi.org/10.1111/j.1572-0241.2004.40266.x

361. Smith MW, Peacock MA, James PS (1991) Galactose increases microvillus development in mouse jejunal enterocytes. Comp Biochem Physiol A Comp Physiol 100:489-493. https://doi.org/ 10.1016/0300-9629(91)90505-7

362. Solberg DH, Diamond JM (1987) Comparison of different dietary sugars as inducers of intestinal sugar transporters. Am J Phys 252: G574-G584. https://doi.org/10.1152/ajpgi.1987.252.4.G574

363. Song J, Kwon O, Chen S, Daruwala R, Eck P, Park JB, Levine M (2002) Flavonoid inhibition of sodium-dependent vitamin C transporter 1 (SVCT1) and glucose transporter isoform 2 (GLUT2), intestinal transporters for vitamin $\mathrm{C}$ and glucose. J Biol Chem 277:15252-15260. https://doi.org/10.1074/jbc.M110496200

364. Sonis ST (2004) The pathobiology of mucositis. Nat Rev Cancer 4:277-284. https://doi.org/10.1038/nrc1318

365. Soylu OB, Ecevit C, Altinoz S, Ozturk AA, Temizkan AK, Maeda M, Kasahara M (2008) Nephrocalcinosis in glucose-galactose malabsorption: nephrocalcinosis and proximal tubular dysfunction in a young infant with a novel mutation of SGLT1. Eur J Pediatr 167:1395-1398. https://doi.org/10.1007/s00431-008-0681-6

366. Spiegel HU, Skawran S (2011) From longitudinal gastric resection to sleeve gastrectomy-revival of a previously established surgical procedure. J Gastrointest Surg 15:219-228. https://doi.org/10. 1007/s11605-010-1293-9

367. Spring KR (1998) Routes and mechanism of fluid transport by epithelia. Annu Rev Physiol 60:105-119. https://doi.org/10. 1146/annurev.physiol.60.1.105

368. Stearns AT, Balakrishnan A, Tavakkolizadeh A (2010) Impact of Roux-en-Y gastric bypass surgery on rat intestinal glucose transport. Am J Physiol Gastrointest Liver Physiol 297:G950-G957. https://doi.org/10.1152/ajpgi.00253.2009

369. Steinert RE, Beglinger C (2011) Nutrient sensing in the gut: interactions between chemosensory cells, visceral afferents and the secretion of satiation peptides. Physiol Behav 105:62-70. https:// doi.org/10.1016/j.physbeh.2011.02.039

370. Steinert RE, Frey F, Topfer A, Drewe J, Beglinger C (2011) Effects of carbohydrate sugars and artificial sweeteners on appetite and the secretion of gastrointestinal satiety peptides. Br J Nutr 105:1320-1328. https://doi.org/10.1017/S000711451000512X

371. Stephens JW, Bodvarsdottir TB, Wareham K, Prior SL, Bracken RM, Lowe GD, Rumley A, Dunseath G, Luzio S, Deacon CF, Holst JJ, Bain SC (2011) Effects of short-term therapy with glibenclamide and repaglinide on incretin hormones and oxidative damage associated with postprandial hyperglycaemia in people with type 2 diabetes mellitus. Diabetes Res Clin Pract 94:199 206. https://doi.org/10.1016/j.diabres.2011.07.014

372. Steppan CM, Brown EJ, Wright CM, Bhat S, Banerjee RR, Dai CY, Enders GH, Silberg DG, Wen X, Wu GD, Lazar MA (2001) A family of tissue-specific resistin-like molecules. Proc Natl Acad Sci U S A 98:502-506
373. Stevenson NR, Fierstein JS (1976) Circadian rhythms of intestinal sucrase and glucose transport: cued by time of feeding. Am J Phys 230:731-735. https://doi.org/10.1152/ajplegacy.1976.230.3.731

374. Stevenson NR, Ferrigni F, Parnicky K, Day S, Fierstein JS (1975) Effect of changes in feeding schedule on the diurnal rhythms and daily activity levels of intestinal brush border enzymes and transport systems. Biochim Biophys Acta 406:131-145. https://doi. org/10.1016/0005-2736(75)90048-6

375. Stevenson NR, Sitren HS, Furuya S (1980) Circadian rhythmicity in several small intestinal functions is independent of use of the intestine. Am J Phys 238:G203-G207. https://doi.org/10.1152/ ajpgi.1980.238.3.G203

376. Stirling CE, Schneider AJ, Wong MD, Kinter WB (1972) Quantitative radioautography of sugar transport in intestinal biopsies from normal humans and a patient with glucose-galactose malabsorption. J Clin Invest 51:438-451. https://doi.org/10. 1172/JCI106830

377. Stuart CA, Howell ME, Zhang Y, Yin D (2009) Insulin-stimulated translocation of glucose transporter (GLUT) 12 parallels that of GLUT4 in normal muscle. J Clin Endocrinol Metab 94:35353542. https://doi.org/10.1210/jc.2009-0162

378. Stümpel F, Scholtka B, Jungermann K (1997) A new role for enteric glucagon-37: acute stimulation of glucose absorption in rat small intestine. FEBS Lett 410:515-519. https://doi.org/10. 1073/pnas.211357698

379. Stumpel F, Scholtka B, Hunger A, Jungermann K (1998) Enteric glucagon 37 rather than pancreatic glucagon 29 stimulates glucose absorption in rat intestine. Gastroenterology 115:1163-1171

380. Stumpel F, Scholtka B, Jungermann K (2000) Stimulation by portal insulin of intestinal glucose absorption via hepatoenteral nerves and prostaglandin E2 in the isolated, jointly perfused small intestine and liver of the rat. Ann N Y Acad Sci 915:111-116. https:// doi.org/10.1111/j.1749-6632.2000.tb05232.x

381. Stümpel F, Burcelin R, Jungermann K, Thorens B (2001) Normal kinetics of intestinal glucose absorption in the absence of GLUT2: evidence for a transport pathway requiring glucose phosphorylation and transfer into the endoplasmic reticulum. Proc Natl Acad Sci U S A 98:11330-11335. https://doi.org/10.1016/s00145793(97)00628-5

382. Sun EW, de Fontgalland D, Rabbitt P, Hollington P, Sposato L, Due SL, Wattchow DA, Rayner CK, Deane AM, Young RL, Keating DJ (2017) Mechanisms controlling glucose-induced GLP-1 secretion in human smalliIntestine. Diabetes 66:2144 2149. https://doi.org/10.2337/db17-0058

383. Sussman CR, Renfro JL (1997) Heat shock-induced protection and enhancement of $\mathrm{Na}+-$ glucose cotransport by LLC-PK1 monolayers. Am J Phys 273:F530-F537. https://doi.org/10. 1152/ajprenal.1997.273.4.F530

384. Sutherland K, Young RL, Cooper NJ, Horowitz M, Blackshaw LA (2007) Phenotypic characterization of taste cells of the mouse small intestine. Am J Physiol Gastrointest Liver Physiol 292: G1420-G1428. https://doi.org/10.1152/ajpcell.1990.259.2.C279

385. Suzuki T, Douard V, Mochizuki K, Goda T, Ferraris RP (2011) Diet-induced epigenetic regulation in vivo of the intestinal fructose transporter GLUT5 during development of rat small intestine. Biochem J 535:43-53. https://doi.org/10.1042/BJ20101987

386. Sykaras AG, Demenis C, Cheng L, Pisitkun T, McLaughlin JT, Fenton RA, Smith CP (2014) Duodenal CCK cells from male mice express multiple hormones including ghrelin. Endocrinology 155:3339-3351. https://doi.org/10.1210/en.20132165

387. Takata K, Kasahara T, Kasahara M, Ezaki O, Hirano H (1992) Immunohistochemical localization of $\mathrm{Na}^{+}$-dependent glucose transporter in rat jejunum. Cell Tissue Res 267:3-9. https://doi. org/10.1007/BF00318685 
388. Tasic V, Slaveska N, Blau N, Santer R (2004) Nephrolithiasis in a child with glucose-galactose malabsorption. Pediatr Nephrol 19: 244-246. https://doi.org/10.1007/s00467-003-1327-6

389. Tavakkolizadeh A, Berger UV, Shen KR, Levitsky LL, Zinner MJ, Hediger MA, Ashley SW, Whang EE, Rhoads DB (2001) Diurnal rhythmicity in intestinal SGLT-1 function, $\mathrm{V}_{\max }$, and mRNA expression topography. Am J Physiol Gastrointest Liver Physiol 280:G209-G215. https://doi.org/10.1152/ajpgi.2001.280. 2.G209

390. Tavakkolizadeh A, Ramsanahie A, Levitsky LL, Zinner MJ, Whang EE, Ashley SW, Rhoads DB (2005) Differential role of vagus nerve in maintaining diurnal gene expression rhythms in the proximal small intestine. J Surg Res 129:73-78. https://doi.org/ 10.1016/j.jss.2005.05.023

391. Tazawa S, Yamato T, Fujikura H, Hiratochi M, Itoh F, Tomae M, Takemura Y, Maruyama H, Sugiyama T, Wakamatsu A, Isogai T, Isaji M (2005) SLC5A9/SGLT4, a new $\mathrm{Na}^{+}$-dependent glucose transporter, is an essential transporter for mannose, 1,5-anhydroD-glucitol, and fructose. Life Sci 76:1039-1050. http://www.ncbi. nlm.nih.gov/pubmed/15607332

392. Teoh DA, Kamieniecki D, Pang G, Buret AG (2000) Giardia lamblia rearranges $\mathrm{F}$-actin and alpha-actinin in human colonic and duodenal monolayers and reduces transepithelial electrical resistance. J Parasitol 86:800-806. https://doi.org/10.1645/00223395(2000)086[0800:GLRFAA]2.0.CO;2

393. Theodorakis MJ, Carlson O, Michopoulos S, Doyle ME, Juhaszova M, Petraki K, Egan JM (2006) Human duodenal enteroendocrine cells: source of both incretin peptides, GLP-1 and GIP. Am J Physiol Endocrinol Metab 290:E550-E559. https://doi.org/10.1152/ajpendo.00326.2004

394. Thorens B, Sarkar HK, Kaback HR, Lodish HF (1988) Cloning and functional expression in bacteria of a novel glucose transporter present in liver, intestine, kidney, and b-pancreatic islet cells. Cell 55:281-290. https://doi.org/10.1016/0092-8674(88)90051-7. https://www.ncbi.nlm.nih.gov/pubmed/3048704

395. Thorens B, Cheng ZQ, Brown D, Lodish HF (1990) Liver glucose transporter: a basolateral protein in hepatocytes and intestine and kidney cells. Am J Phys 259:C279-C285. https://doi.org/10.1016/ 0092-8674(88)90051-7

396. Tobin V, Le Gall M, Fioramonti X, Stolarczyk E, Blazquez AG, Klein C, Prigent M, Serradas P, Cuif MH, Magnan C, Leturque A, Brot-Laroche E (2008) Insulin internalizes GLUT2 in the enterocytes of healthy but not insulin-resistant mice. Diabetes 57:555-562. https://doi.org/10.2337/db07-0928

397. Towle HC (2005) Glucose as a regulator of eukaryotic gene transcription. Trends Endocrinol Metab 16:489-494. https://doi.org/ 10.1016/j.tem.2005.10.003

398. Troeger H, Epple HJ, Schneider T, Wahnschaffe U, Ullrich R, Burchard GD, Jelinek T, Zeitz M, Fromm M, Schulzke JD (2007) Effect of chronic Giardia lamblia infection on epithelial transport and barrier function in human duodenum. Gut 56:328 335. https://doi.org/10.1136/gut.2006.100198

399. Truswell AS, Seach JM, Thorburn AW (1988) Incomplete absorption of pure fructose in healthy subjects and the facilitating effect of glucose. Am J Clin Nutr 48:1424-1430. https://doi.org/10. 1093/ajcn/48.6.1424

400. Turk E, Zabel B, Mundlos S, Dyer J, Wright EM (1991) Glucose/ galactose malabsorption caused by a defect in the $\mathrm{Na}^{+} /$glucose cotransporter. Nature 350:354-356. https://doi.org/10.1038/ $350354 \mathrm{a} 0$

401. Turner JR, Rill BK, Carlson SL, Carnes D, Kerner R, Mrsny RJ, Madara JL (1997) Physiological regulation of epithelial tight junctions is associated with myosin light-chain phosphorylation. Am J Phys 273:C1378-C1385. https://doi.org/10.1152/ajpcell.1997. 273.4.C1378
402. Uldry M, Thorens B (2004) The SLC2 family of facilitated hexose and polyol transporters. Pflugers Arch 447:480-489. https://doi. org/10.1007/s00424-003-1085-0

403. Uldry M, Ibberson M, Hosokawa M, Thorens B (2002) GLUT2 is a high affinity glucosamine transporter. FEBS Lett 524:199-203. http://www.ncbi.nlm.nih.gov/pubmed/12135767

404. Vayro S, Wood IS, Dyer J, Shirazi-Beechey SP (2001) Transcriptional regulation of the ovine intestinal $\mathrm{Na}^{+} /$glucose cotransporter $S G L T 1$ gene. Role of HNF-1 in glucose activation of promoter function. Eur J Biochem 268:5460-5470

405. Vernaleken A, Veyhl M, Gorboulev V, Kottra G, Palm D, Burckhardt B-C, Burckhardt G, Pipkorn R, Beier N, van Amsterdam C, Koepsell H (2007) Tripeptides of RS1 (RSC1A1) inhibit a monosaccharide-dependent exocytotic pathway of $\mathrm{Na}^{+}-$ D-glucose cotransporter SGLT1 with high affinity. J Biol Chem 282:28501-28513. https://doi.org/10.1074/jbc.M705416200

406. Veyhl M, Spangenberg J, Püschel B, Poppe R, Dekel C, Fritzsch G, Haase W, Koepsell H (1993) Cloning of a membraneassociated protein which modifies activity and properties of the $\mathrm{Na}^{+}$-D-glucose cotransporter. J Biol Chem 268:25041-25053. https://doi.org/10.1124/mol.115.101162

407. Veyhl M, Keller T, Gorboulev V, Vernaleken A, Koepsell H (2006) RS1(RSC1A1) regulates the exocytotic pathway of $\mathrm{Na}^{+}-$ D-glucose cotransporter SGLT1. Am J Physiol Renal Physiol 291: F1213-F1223. https://doi.org/10.1152/ajprenal.00068.2006

408. Veyhl-Wichmann M, Friedrich A, Vernaleken A, Singh S, Kipp H, Gorboulev V, Keller T, Chintalapati C, Pipkorn R, PastorAnglada M, Groll J, Koepsell H (2016) Phosphorylation of RS1 (RSC1A1) steers inhibition of different exocytotic pathways for glucose transporter SGLT1 and nucleoside transporter CNT1, and an RS1-derived peptide inhibits glucose absorption. Mol Pharmacol 89:118-132. https://doi.org/10.1124/mol.115.101162

409. Victora CG, Bryce J, Fontaine O, Monasch R (2000) Reducing deaths from diarrhoea through oral rehydration therapy. Bull World Health Organ 78:1246-1255. https://www.ncbi.nlm.nih. gov/pubmed/11100619

410. Vrhovac I, Balen ED, Klessen D, Burger C, Breljak D, Kraus O, Radovic N, Jadrijevic S, Aleksic I, Walles T, Sauvant C, Sabolic I, Koepsell H (2015) Localizations of $\mathrm{Na}(+)$-D-glucose cotransporters SGLT1 and SGLT2 in human kidney and of SGLT1 in human small intestine, liver, lung, and heart. Pflugers Arch 467:1881-1898. https://doi.org/10.1007/s00424-014-1619-7

411. Wales JK, Primhak RA, Rattenbury J, Taylor CJ (1990) Isolated fructose malabsorption. Arch Dis Child 65:227-229. https://doi. org/10.1136/adc.65.2.227

412. Walker J, Jijon HB, Diaz H, Salehi P, Churchill T, Madsen KL (2005) 5-aminoimidazole-4-carboxamide riboside (AICAR) enhances GLUT2-dependent jejunal glucose transport: a possible role for AMPK. Biochem J 385:485-491. https://doi.org/10. 1042/BJ20040694

413. Wang W, Fan J, Yang X, Furer-Galban S, Lopez de Silanes I, von Kobbe C, Guo J, Georas SN, Foufelle F, Hardie DG, Carling D, Gorospe M (2002) AMP-activated kinase regulates cytoplasmic HuR. Mol Cell Biol 22:3425-3436. https://doi.org/10.1128/mcb. 22.10.3425-3436.2002

414. Wang J, Cortina G, Wu SV, Tran R, Cho JH, Tsai MJ, Bailey TJ, Jamrich M, Ament ME, Treem WR, Hill ID, Vargas JH, Gershman G, Farmer DG, Reyen L, Martin MG (2006) Mutant neurogenin-3 in congenital malabsorptive diarrhea. N Engl J Med 355:270-280. https://doi.org/10.1056/NEJMoa054288

415. Wang TT, Hu SY, Gao HD, Zhang GY, Liu CZ, Feng JB, Frezza EE (2008) Ileal transposition controls diabetes as well as modified duodenal jejunal bypass with better lipid lowering in a nonobese rat model of type II diabetes by increasing GLP-1. Ann Surg 247: 968-975. https://doi.org/10.1097/SLA.0b013e318172504d 
416. Wang B, Chandrasekera PC, Pippin JJ (2014) Leptin- and leptin receptor-deficient rodent models: relevance for human type 2 diabetes. Curr Diabetes Rev 10:131-145

417. Wang CW, Su SC, Huang SF, Huang YC, Chan FN, Kuo YH, Hung MW, Lin HC, Chang WL, Chang TC (2015) An essential role of cAMP response element binding protein in ginsenoside Rg1-mediated inhibition of Na+/glucose cotransporter 1 gene expression. Mol Pharmacol 88:1072-1083. https://doi.org/10.1124/ mol.114.097352

418. Wasserman D, Hoekstra JH, Tolia V, Taylor CJ, Kirschner BS, Takeda J, Bell GI, Taub R, Rand EB (1996) Molecular analysis of the fructose transporter gene (GLUT5) in isolated fructose malabsorption. J Clin Invest 98:2398-2402. https://doi.org/10.1172/ JCI1 19053

419. Wedick NM, Pan A, Cassidy A, Rimm EB, Sampson L, Rosner B, Willett W, Hu FB, Sun Q, van Dam RM (2012) Dietary flavonoid intakes and risk of type 2 diabetes in US men and women. Am J Clin Nutr 95:925-933. https://doi.org/10.3945/ajen.111.028894

420. Wilder-Smith CH, Li X, Ho SS, Leong SM, Wong RK, Koay ES, Ferraris RP (2014) Fructose transporters GLUT5 and GLUT2 expression in adult patients with fructose intolerance. United European Gastroenterol J 2:14-21. https://doi.org/10.1177/ 2050640613505279

421. Williams M, Sharp P (2002) Regulation of jejunal glucose transporter expression by forskolin. Biochim Biophys Acta 1559:179185. https://doi.org/10.1016/s0005-2736(01)00449-7

422. Wisniewski JR, Friedrich A, Keller T, Mann M, Koepsell H (2015) The impact of high-fat diet on metabolism and immune defense in small intestine mucosa. J Proteome Res 14:353-365. https://doi.org/10.1021/pr500833v

423. Wright EM (2013) Glucose transport families SLC5 and SLC50. Mol Aspects Med 34:183-196. https://doi.org/10.1016/j.mam. 2012.11.002

424. Wright EM, Loo DDF, Hirayama BA (2011) Biology of human sodium glucose transporters. Physiol Rev 91:733-794 http:// www.ncbi.nlm.nih.gov/pubmed/21527736

425. Wu T, Zhao BR, Bound MJ, Checklin HL, Bellon M, Little TJ, Young RL, Jones KL, Horowitz M, Rayner CK (2012) Effects of different sweet preloads on incretin hormone secretion, gastric emptying, and postprandial glycemia in healthy humans. Am J Clin Nutr 95:78-83. https://doi.org/10.3945/ajcn.111.021543

426. Xia J, He Q, He M, Xu G, Tang Y, Ren Y (2019) Residual gastric dilatation interferes with metabolic improvements following sleeve gastrectomy by upregulating the expression of sodiumglucose cotransporter-1. Obes Surg 29:3324-3333. https://doi. org/10.1007/s11695-019-03997-z

427. Xiao W (2004) Advances in NF-kappaB signaling transduction and transcription. Cell Mol Immunol 1:425-435 https://www. ncbi.nlm.nih.gov/pubmed/16293211

428. Yamauchi H, Honma K, Mochizuki K, Goda T (2018) Regulation of the circadian rhythmic expression of Sglt1 in the mouse small intestine through histone acetylation and the mRNA elongation factor, BRD4-P-TEFb. Biosci Biotechnol Biochem 82:11761179. https://doi.org/10.1080/09168451.2018.1451743

429. Yan S, Sun F, Li Z, Xiang J, Ding Y, Lu Z, Tian Y, Chen H, Zhang J, Wang Y, Song P, Zhou L, Zheng S (2013) Reduction of intestinal electrogenic glucose absorption after duodenojejunal bypass in a mouse model. Obes Surg. https://doi.org/10.1007/ s11695-013-0954-7

430. Yasutake H, Goda T, Takase S (1995) Dietary regulation of sucrase-isomaltase gene expression in rat jejunum. Biochim Biophys Acta 1243:270-276. https://doi.org/10.1016/03044165(94)00143-1
431. Yoshikawa T, Inoue R, Matsumoto M, Yajima T, Ushida K, Iwanaga T (2011) Comparative expression of hexose transporters (SGLT1, GLUT1, GLUT2 and GLUT5) throughout the mouse gastrointestinal tract. Histochem Cell Biol 135:183-194. https:// doi.org/10.1007/s00418-011-0779-1

432. Yu LC, Flynn AN, Turner JR, Buret AG (2005) SGLT-1mediated glucose uptake protects intestinal epithelial cells against LPS-induced apoptosis and barrier defects: a novel cellular rescue mechanism? FASEB J 19:1822-1835. https://doi.org/10.1096/fj. $05-4226 \mathrm{com}$

433. Yu LC, Turner JR, Buret AG (2006) LPS/CD14 activation triggers SGLT-1-mediated glucose uptake and cell rescue in intestinal epithelial cells via early apoptotic signals upstream of caspase-3. Exp Cell Res 312:3276-3286. https://doi.org/10.1016/j.yexcr.2006.06. 023

434. Yu LC, Huang CY, Kuo WT, Sayer H, Turner JR, Buret AG (2008) SGLT-1-mediated glucose uptake protects human intestinal epithelial cells against Giardia duodenalis-induced apoptosis. Int J Parasitol 38:923-934. https://doi.org/10.1016/j.ijpara.2007. 12.004

435. Yusta B, Huang L, Munroe D, Wolff G, Fantaske R, Sharma S, Demchyshyn L, Asa SL, Drucker DJ (2000) Enteroendocrine localization of GLP-2 receptor expression in humans and rodents. Gastroenterology 119:744-755. https://doi.org/10.1053/gast. 2000.16489

436. Zambrowicz B, Freiman J, Brown PM, Frazier KS, Turnage A, Bronner J, Ruff D, Shadoan M, Banks P, Mseeh F, Rawlins DB, Goodwin NC, Mabon R, Harrison BA, Wilson A, Sands A, Powell DR (2012) LX4211, a dual SGLT1/SGLT2 inhibitor, improved glycemic control in patients with type 2 diabetes in a randomized, placebo-controlled trial. Clin Pharmacol Ther 92:158169. https://doi.org/10.1038/clpt.2012.58

437. Zambrowicz B, Lapuerta P, Strumph P, Banks P, Wilson A, Ogbaa I, Sands A, Powell D (2015) LX4211 therapy reduces postprandial glucose levels in patients with type 2 diabetes mellitus and renal impairment despite low urinary glucose excretion. Clin Ther 37(71-82):e12. https://doi.org/10.1016/j.clinthera. 2014.10.026

438. Zhang X, Yu B, Yang D, Qiao Z, Cao T, Zhang P (2016) Gastric volume reduction is essential for the remission of type 2 diabetes mellitus after bariatric surgery in nonobese rats. Surg Obes Relat Dis 12:1569-1576. https://doi.org/10.1016/j.soard.2016.04.018

439. Zhao H, Shiue H, Palkon S, Wang Y, Cullinan P, Burkhardt JK, Musch MW, Chang EB, Turner JR (2004) Ezrin regulates NHE3 translocation and activation after $\mathrm{Na}^{+}$-glucose cotransport. Proc Natl Acad Sci U S A 101:9485-9490. https://doi.org/10.1073/ pnas.0308400101

440. Zhou G, Myers R, Li Y, Chen Y, Shen X, Fenyk-Melody J, Wu M, Ventre J, Doebber T, Fujii N, Musi N, Hirshman MF, Goodyear LJ, Moller DE (2001) Role of AMP-activated protein kinase in mechanism of metformin action. J Clin Invest 108:11671174. https://doi.org/10.1172/JCI13505

441. Zwarts I, van Zutphen T, Kruit JK, Liu W, Oosterveer MH, Verkade HJ, Uhlenhaut NH, Jonker JW (2019) Identification of the fructose transporter GLUT5 (SLC2A5) as a novel target of nuclear receptor LXR. Sci Rep 9:9299. https://doi.org/10.1038/ s41598-019-45803-X

Publisher's note Springer Nature remains neutral with regard to jurisdictional claims in published maps and institutional affiliations. 